\title{
A Dual-Process Motivational Model of Cross-Cultural Adaptation
}

\author{
By
}

Claudia Recker

Thesis submitted in fulfilment of the requirements for the degree of Masters of Science in Cross-Cultural Psychology

December 2012

Victoria University of Wellington

Te Whare Wānanga o te Ūpoko o te Ika a Māui

Aotearoa / New Zealand 
A Dual-Process Motivational Model of Cross-Cultural Adaptation

The Kiwi way - the New Zealand way of life

New Zealand is a beautiful and easy place to live. There's lots to do here, our standard of living is high and the country is internationally regarded as being very safe.

For newcomers however, it can be very different to what you're used to.

Immigration New Zealand, Settlement Services (2012) 


\begin{abstract}
Past research suggests that immigrants are relatively inclined to maintain their cultural heritage and identity and at the same time engage with host nationals and the host society. However, to my best knowledge, no study has examined whether these 'inclinations' are in fact distinct motivational drives. I argue that the motivational drives of Cultural Maintenance Motivation (MCM) and Cultural Exploration Motivation (MCE) influence acculturation behaviours when individuals immigrate to another country and that these acculturation behaviours in turn impact psychological and sociocultural adaptation. The present research first examines the psychometric properties of scales designed to measure these two motivations in a preliminary study with international students $(N=50)$, and then investigates a dual-process model based on the relationships between the novel motivations, acculturation behaviours and psychological and sociocultural adaptation in a larger New Zealand migrant sample $(N=280)$. Results from structural equation modeling largely supported the proposed dual-process model. The findings suggest that MCM predicted psychological adaptation through ethnic peer connections, whereas MCE predicted sociocultural adaptation, which in turn predicted psychological adaptation. Thus the proposed novel motivations have predictive power and contribute to the extant acculturation literature. Implications of the findings for acculturation research, policy makers and migrants are discussed.
\end{abstract}

Keywords:

Adaptation, Motivation, Migrants, Cultural Maintenance, Cultural Exploration 


\section{Acknowledgements}

I would like to thank my primary supervisor Dr Taciano Milfont for his guidance and patience over the last two years, and my secondary supervisor Prof Colleen Ward for her invaluable input. Both provided many helpful suggestions for improving this thesis.

Thanks also to the members of the cross-cultural lab of the Centre for Applied CrossCultural Research for their encouragement and feedback. In particular many thanks to Agnes Szabo for sharing her statistical knowledge with me. Moreover, I would like to acknowledge the support of the many organisations and community groups that helped spread the word about my research and without whom this project would not have been feasible. Thanks to all the participants who donated their time and filled in my surveys. Last but not least, I would like to give special thanks to my husband Thomas for supporting me in so many ways throughout my research-journey and for going on this New Zealand adventure with me. 


\section{Table of Contents}

\section{Introduction}

The Scope of Immigration

Cultural Maintenance or Participation in the Host Culture -

The Acculturation Framework ........................................ 1

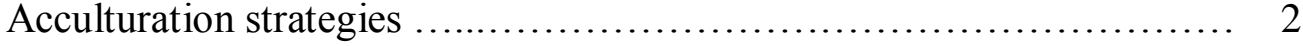

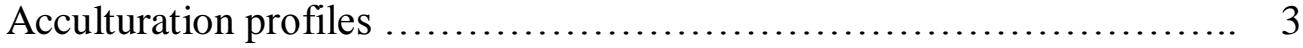

Adaptation in the acculturation context .............................. 4

Migrants' Behaviours Predicting Adaptation Outcomes ................... 6

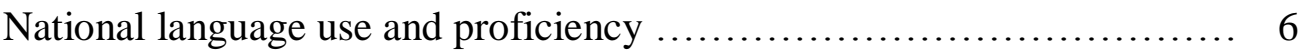

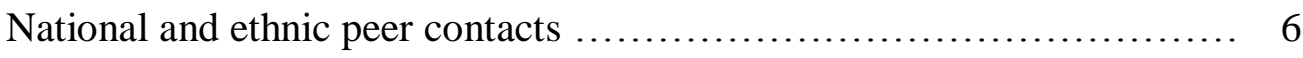

Motivations Underpinning Behaviours during the Acculturation Process: A

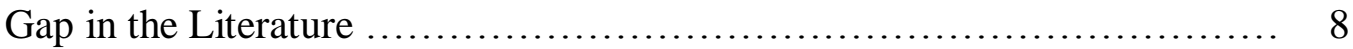

Grounding the two Drives in the Motivational Literature ................. 10

Basic motives in motivational research ............................ 10

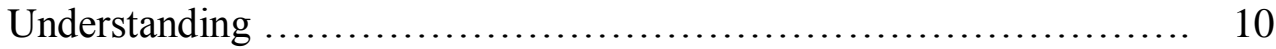

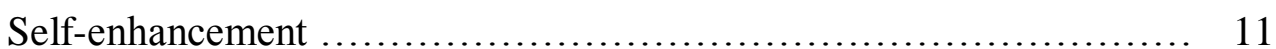

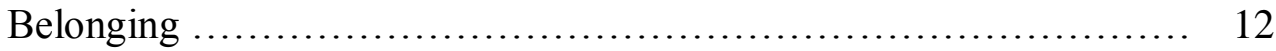

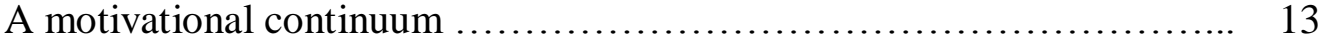

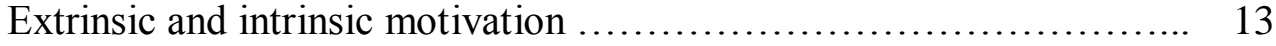

Cognitive theories of motivation $\ldots \ldots \ldots \ldots \ldots \ldots \ldots \ldots \ldots \ldots \ldots \ldots \ldots \ldots, 14$

Desire for novelty .............................................. 14

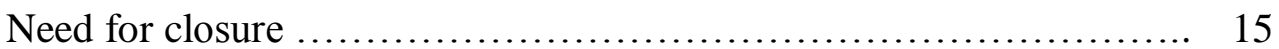

Maintenance versus Exploration in the Psychological Literature ........... 16

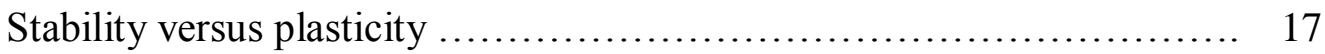

Conservation versus openness to change $\ldots \ldots \ldots \ldots \ldots \ldots \ldots \ldots \ldots \ldots \ldots . \ldots \ldots \ldots$

Safe haven versus exploration of environment f...................... 17

Prevention versus promotion focus ................................ 17

Monumentalism versus flexumility ................................ 18

Links between Motivational Drives, Acculturation Behaviours and

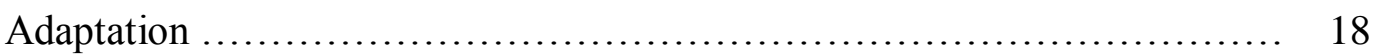

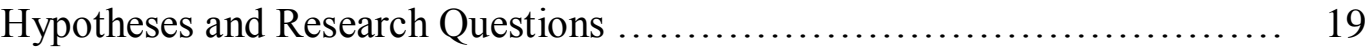

Additional Research Question .................................... 20 


\section{Study 1}

Objective and Hypotheses ......................................... 21

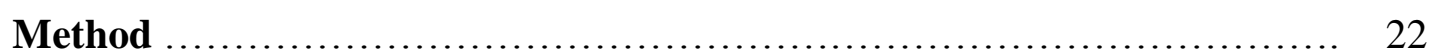

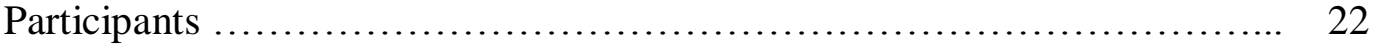

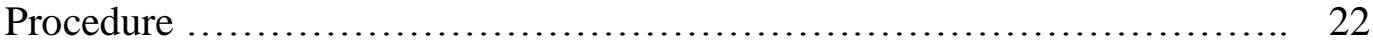

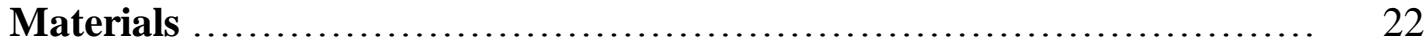

Development of the initial MCM and MCE scales ........................ 22

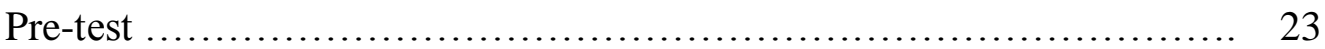

Measures .............................................................. 23

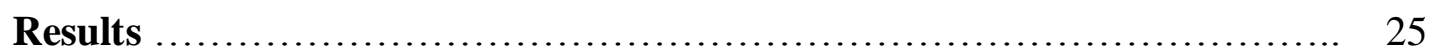

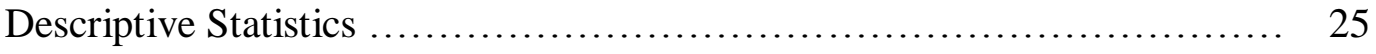

Reliability of the MCM and MCE Scales .............................. 26

MCM Scale .................................................... 26

MCE Scale ....................................................... 26

Convergent Validity of the MCM and MCE Scales ..................... 26

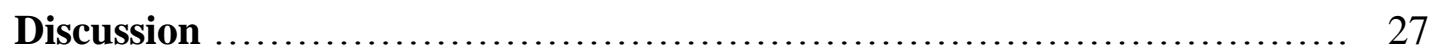

\section{Study 2}

Objective and Hypotheses ............................................ 29

Further validation of MCM and MCE scales............................. 29

Method ................................................................ 30

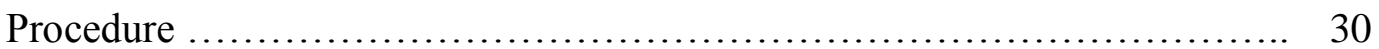

Participants ................................................... 31

Recruitment .................................................. 31

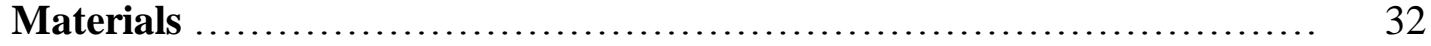

Cultural Maintenance and Cultural Exploration $\ldots \ldots \ldots \ldots \ldots \ldots \ldots \ldots \ldots \ldots . \quad 32$

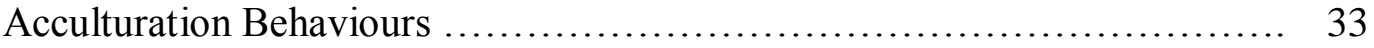

Psychological and Sociocultural Adaptation ............................. 35

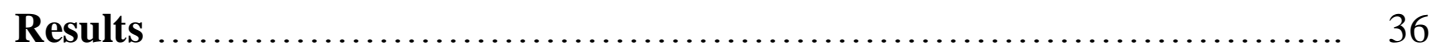

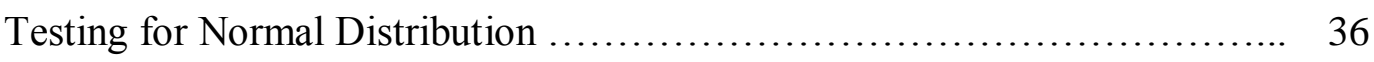

Descriptive Statistics of Scales ................................... 37

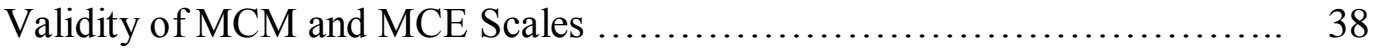


Correlations between MCM and MCE ........................... 38

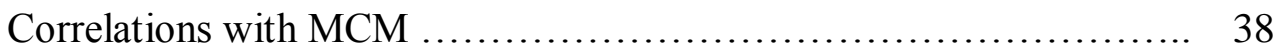

Correlations with MCE ............................................ 39

Confirmatory Factor Analysis (CFA) for MCM and MCE Scales ........... 39

Model Testing with Structural Equation Modeling (SEM) ............... 41

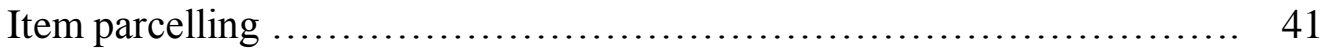

Testing the model components .................................. 42

Testing the full model ........................................... 42

Mediating effects ................................................ 44

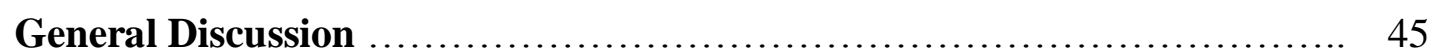

MCM and MCE Scales .............................................. 46

The Relationship between MCM/MCE, Acculturation Behaviour and

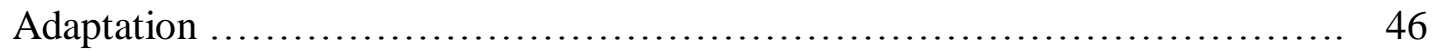

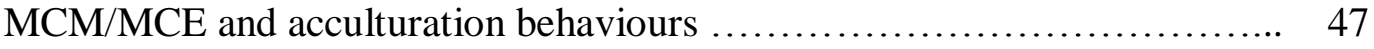

The predictors of psychological and sociocultural adaptation ............... 48

Mediating effects ...................................................... 52

The Value of the Proposed Model ...................................... 53

Implications of the Current Study .................................. 54

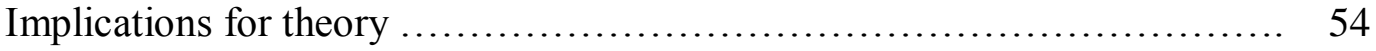

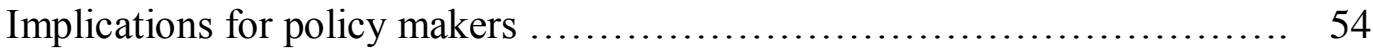

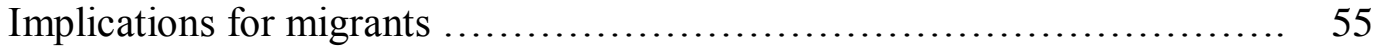

Limitations and Directions for future Research ........................... 56

Conclusion ............................................................. 57

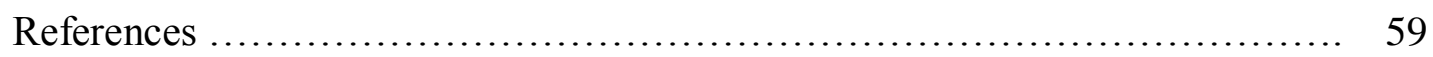

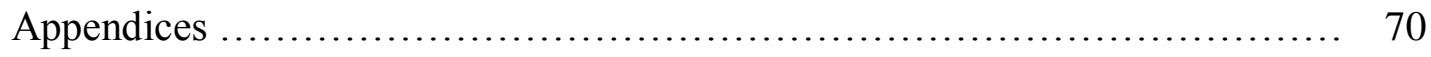


A Dual-Process Motivational Model of Cross-Cultural Adaptation

\section{List of Tables}

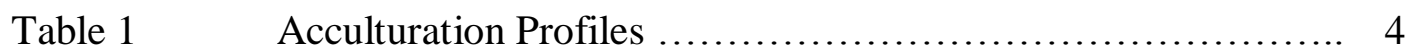

Table 2 Constructs of Maintenance versus Exploration ................. 16

Table 3 Items of the Motivation for Cultural Maintenance (MCM) and Motivation for Cultural Exploration (MCE) Scales ............ 24

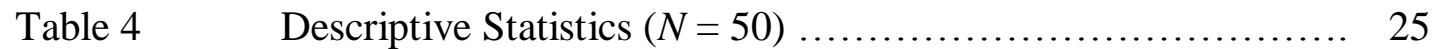

Table 5 Correlations between MCM, MCE Scales, R-NFC, DFN ........ 27

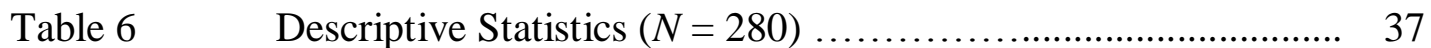

Table 7 Correlations between the MCM and MCE Scales and Criterion

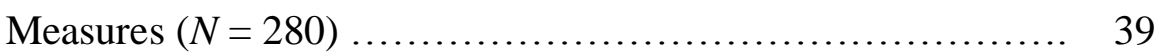

Table $8 \quad$ Fit Indices for Models ................................... 44

Table 9 Mediation Effects in the Final Model ........................ 45 
A Dual-Process Motivational Model of Cross-Cultural Adaptation

\section{List of Figures}

Figure $1 \quad$ Berry's model of acculturation ............................ 3

Figure 2 A mediation model of the relationship between two

motivational drives and adaptation outcomes as mediated by

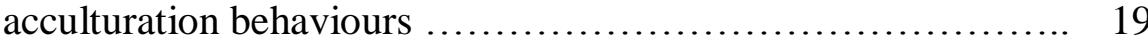

Figure $3 \quad$ Two-factor model of MCM and MCE scales .................. 41

Figure 4 Final structural equation model testing the strength of the relationships between maintenance/exploration motivation, peer connectedness and adaptation 


\section{Appendices}

Appendix A Study 1: Information Sheet, Questionnaire and Debriefing Sheet

Appendix B Study 2: Information Sheet, Questionnaire and Debriefing Sheet

Appendix C Participants' Countries of Birth 89

Appendix D Participants' Ethnicity and Religious Affiliation .............. 90

Appendix E Descriptive Statistics (Non-English Language Sub-Sample) . ... 91

Appendix F Correlations .......................................... 92

Appendix G Skewness and Kurtosis .................................. 93

Appendix H Inter-item Total Correlations for Scales with Cronbach's Alpha

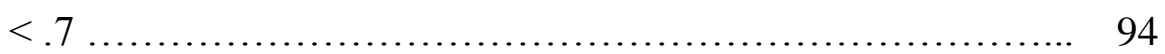

Appendix I Structural Equation Model testing the Strength of the Relationships between Motivation for Cultural Maintenance, Ethnic Peer Connections and Psychological Adaptation

Appendix J Structural Equation Model testing the Strength of the Relationships between Motivation for Cultural Exploration, National Peer Connections and Sociocultural Adaptation ........ 96

Appendix K Model 1: Structural Equation Model testing the Strength of the Relationships between Maintenance/Exploration Motivation, Ethnic/National Peer Connections and Psychological and Sociocultural Adaptation

Appendix L Effect Sizes for the Impact of Ethnic Peer Support on Adaptation 


\section{Introduction}

\section{The Scope of Immigration}

Approximately 190 million people worldwide live outside their countries of origin (International Organization for Migration, 2011). These people cross national and cultural borders, and many of them make the decision to settle in the country of their choice. As a consequence of migration, the contact between people from different cultural backgrounds increases. For example, in New Zealand almost a quarter of the population (22.9\%) have been born overseas, and therefore, the ethnic composition of the people living in New Zealand is culturally diverse (Statistics New Zealand, 2007).

Taking these numbers into account it is not surprising that a large body of research has investigated the psychological processes that underlie the migration phenomenon and the effects of migration on individuals (e.g.,Ward, 2001; Tabor \& Milfont, 2011; Berry, Phinney, Sam, \& Vedder, 2006). In the psychological literature, the processes and the cultural and psychological outcomes that result from intercultural contact are referred to as 'acculturation' (Berry, 1997), and it seems that migrants deal with the challenge of migration differently, according to Berry's acculturation framework.

\section{Cultural Maintenance or Participation in the Host Culture? - The}

\section{Acculturation Framework}

It has been proposed that during the acculturation process individuals are relatively inclined to maintain their cultural heritage and identity and at the same time to engage with their host nationals and to take part in the host society (Berry, 2005). Following this rationale two main questions arise for individuals and groups who have migrated to another country (Berry, 1997). The first question refers to cultural maintenance, or the extent to which the maintenance of the culture of origin is important to individuals migrating to another country. This refers to the importance of cultural identity and how critical it is for individuals and groups to maintain this identity, as well as their values, norms and traditions. The second question is about contact/participation, or the extent to which individuals seek contact with host nationals and participate in the host culture. Should they become involved in other 
cultural groups or should they remain mostly amongst their ethnic peers? The interplay between these two core questions leads to specific acculturation strategies.

Acculturation strategies. With cultural maintenance on the one hand and contact and participation on the other hand, four different acculturation strategies emerge (Berry, 1997; as depicted in Figure 1). Berry (2003) suggested that acculturation strategies do not only refer to the attitudes of migrants, but also to the behaviours they exhibit in their everyday lives in their new country of residence.

First, individuals may follow an assimilation strategy if they decide not to maintain their original cultural identity but seek daily interaction with their host culture (low maintenance/high contact). They shed their cultural heritage and are absorbed into the dominant society. In a second strategy, individuals may want to hold on to their original culture, and avoid contact with host nationals and remain amongst their ethnic peers as much as possible (high maintenance/low contact). Separation from the larger host society will be the consequence. A third strategy occurs if individuals are interested in maintaining their heritage culture as well as interested in interacting with their host culture (high maintenance/high contact). With this integration strategy, a level of cultural integrity is maintained and at the same time, people partake in the larger host society. Lastly, a marginalisation strategy occurs if individuals are not interested in maintaining their cultural heritage (or do not have the opportunity to do so) and are also not interested in interacting with the host nationals (low maintenance/low contact). Consequently, the acculturation strategies are a reflection of how immigrants are trying to deal with the challenges of living in a new culture (Berry, 2006). 


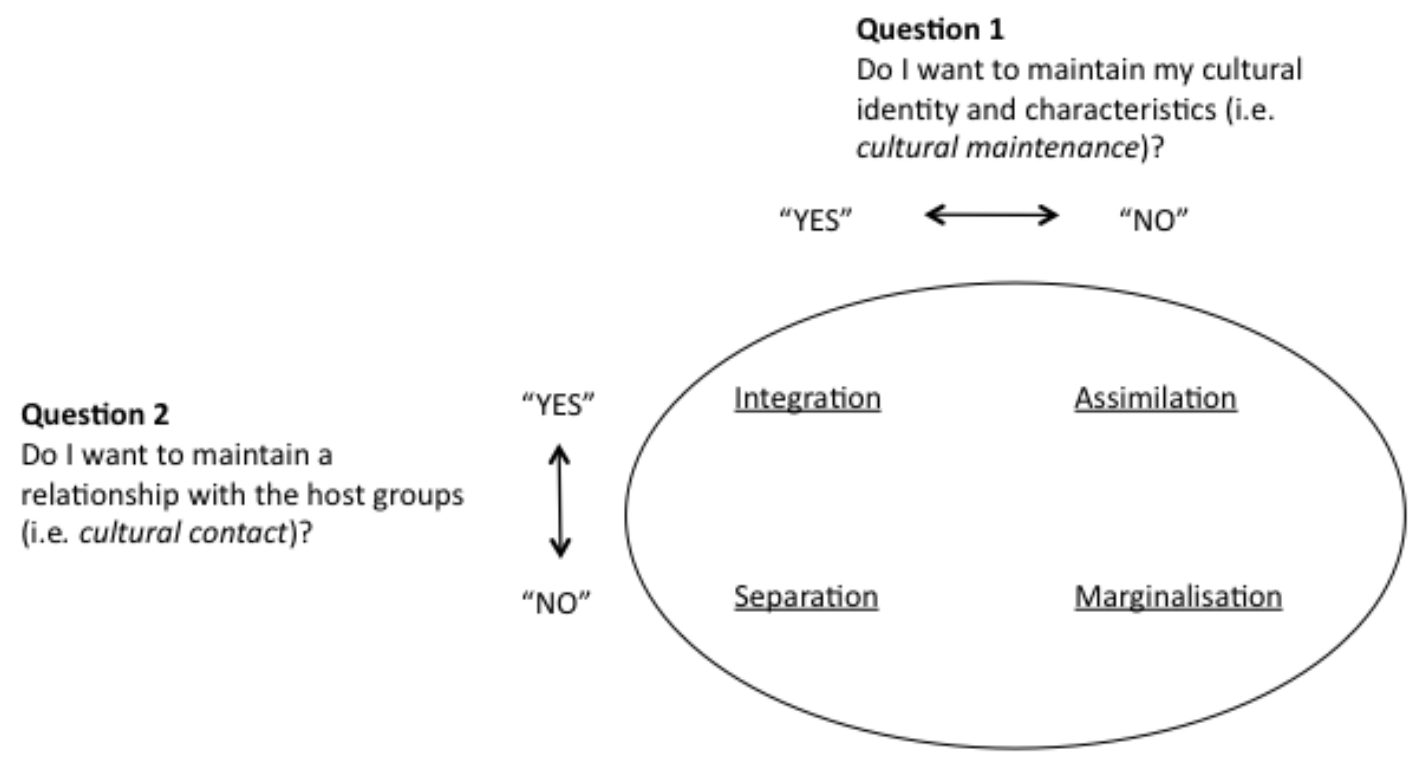

Figure 1. Berry's model of acculturation (adapted from Berry,1997)

Berry's acculturation model (Figure 1) suggests that the dimensions of seeking contact with the host group on the one hand and maintaining one's cultural heritage on the other hand are orthogonal (i.e., independent of each other). This means that individuals can be high on both dimensions, low on both dimensions or high on one and low on the other dimension. These dimensions that, in the broadest sense, reflect cultural orientations have been operationalised in a number of different ways (Berry \& Sabatier, 2011). For example, Phinney, Berry, Vedder and Liebkind (2006) operationalised them respectively as national and ethnic identity. Supporting the independence of the dimensions, they found that ethnic and national identity were negatively correlated in Germany, positively correlated in Australia and unrelated in Canada. The authors argued that positive relationships between ethnic and national identity have been found in countries with a history of immigration (i.e., settler societies). This means that the dimensions of contact and maintenance may correlate differently depending on the context of the country from which the sample is taken.

Acculturation profiles. Whereas the acculturation strategies discussed above are a reflection of how migrants acculturate, Berry and colleagues (2006) argued that acculturation profiles are an indication of how well migrants adapt. The profiles reflect the orientation of migrants towards the host society and a behavioural component is again obvious. Do they seek involvement with the host culture or do 
they prefer to interact with their ethnic peers? Table 1 presents an overview of the main acculturation profiles based on the 'Immigrant Youth in Cultural Transition (ICSEY)' study. This study surveyed almost 8,000 adolescents from 13 countries and found that $22.5 \%$ of participants had an ethnic profile, $18.7 \%$ a national profile, $36.4 \%$ an integration profile and $22.4 \%$ a diffuse profile (Berry et al., 2006). These findings are based on cluster analysis with variables, such as acculturation attitudes, ethnic and national identity, as well as behavioural indicators such as ethnic and national language use and ethnic and national peer contact. The researchers found that depending on the acculturation profile, migrants fared differently during the acculturation process; in other words they had different adaptation outcomes. Overall, migrants with an integration profile had the best adaptation outcomes (e.g., higher life satisfaction, fewer psychological problems), whereas migrants with a diffuse profile fared worst (Sam, Vedder, Ward, \& Horenczyk, 2006).

Table 1

Acculturation Profiles (based on: Berry, Phinney, Sam \& Vedder, 2006)

\begin{tabular}{llll}
\hline & $\begin{array}{l}\text { Acculturation } \\
\text { Attitude }\end{array}$ & $\begin{array}{l}\text { Involvement in } \\
\text { Heritage Culture }\end{array}$ & $\begin{array}{l}\text { Involvement in Host } \\
\text { Culture }\end{array}$ \\
\hline Ethnic Profile & Separation & high & low \\
National Profile & Assimilation & low & high \\
Integration Profile & Integration & high & high \\
Diffuse Profile & $\begin{array}{l}\text { Assimilation } \\
\text { Marginalisation } \\
\end{array}$ & inconsistent & inconsistent \\
& Separation & & \\
\hline
\end{tabular}

Adaptation in the acculturation context. Broadly speaking, adaptation is referred to as the long-term outcomes of acculturation (Sam, 2006). Adaptation refers to two different domains distinguished by Searle and Ward (1990): psychological and sociocultural adaptation. Psychological adaptation refers to the individuals' affective domain, and concerns the level of wellbeing or satisfaction that individuals experience when they settle into the host culture. Sociocultural adaptation, on the other hand, is 
linked to the behavioural domain and refers to the ability to negotiate life in the host culture and to 'fit in' (Ward, 2001).

Ward and Kennedy (1994) outlined that even though sociocultural and psychological adaptation are conceptually related, they are empirically distinct. This is because they do not show the same patterns of change across time and because they are largely predicted by different variables. The greatest problems with psychological adaptation manifest themselves in the early stages of the cultural transition, and variability is experienced over time. In contrast, there is a steep learning curve in the sociocultural domain in the first months of the transition with the curve levelling off in the following months. Whereas psychological adaptation is predicted by factors such as life changes, personality and social support variables, sociocultural adaptation, on the other hand, is predicted by factors such as cultural distance, identification with host nationals and length of stay in the new country. Overall, psychological adaptation can be understood in a stress and coping framework, whereas sociocultural adaptation can be seen in a social learning framework (Ward, 2001). Within the stress and coping framework, cultural transitions are seen as being inherently stressful. The transitioning individual needs to adjust and actively cope with the stressful life changes. This approach takes the characteristics of the individual, as well as the characteristics of the situation into account that may support or hinder the adjustment of the individual to the new cultural environment. The social learning framework on the other hand, emphasises the importance of learning culturally appropriate behaviours and skills, for example, through contact with host nationals. Within the social learning framework, it has been suggested that migrants experience cross-cultural difficulties because they do not know how to handle daily social interactions effectively (Searle \& Ward, 1990).

As outlined above both psychological and sociocultural adaptation are components of the overall cultural adaptation of migrating individuals, and it has been found that both are linked with each other. Past research consistently suggests positive relationships between sociocultural and psychological adaptation (median .31) across various cultural settings and diverse samples (Ward, Okura, Kennedy, \& Kojima, 1998). More specifically, the magnitude of the positive relationship between sociocultural and psychological adaptation increases as a function of the length of residence in the host country and increasing involvement in the host countries culture. Furthermore, Vedder, Van de Vijver and Liebkind (2006) found in the 
aforementioned ICSEY study that sociocultural adaptation was a predictor of psychological adaptation. This finding does make intuitive sense because migrants who know how to interact in social situations with their host national peers, might feel better about themselves than those migrants who struggle during social encounters.

\section{Migrants' behaviours Predicting Adaptation Outcomes}

A number of studies have shown that there is a link between the behaviours that migrants engage in and their sociocultural and psychological adaptation outcomes. Particularly, language use, language proficiency and whether migrants have national or ethnic peer contacts have been subject of research.

National language use and proficiency. In their study with 178 New Zealand students in 23 different countries, Ward and Kennedy (1993a) found that the ability to speak the host language was a predictor of sociocultural adaptation. Thus, learning the language of the host country facilitates interactions with host nationals and this in turn may lead to sociocultural learning and adaptation.

Similarly, Vedder and Virta (2005) found in a study with 158 Turkish adolescent immigrants in the Netherlands and 237 Turkish adolescents in Sweden that proficiency in the host language predicted psychological adaptation in both samples. The finding makes sense in the stress and coping framework: emotional wellbeing is increased when migrants are able to communicate with their host national peers and when they are in a position of making themselves understood in the local language.

National and ethnic peer contacts. There appears to be a link between whether migrants choose to establish contact with ethnic peers or with their national peers, and psychological and sociocultural adaptation outcomes.

First, establishing contact with ethnic peers seems to predict psychological adaptation outcomes. For example, Vedder et al. (2006) used a structural equation modeling approach to analyse the ICESY data set. They found that ethnic peer contacts predicted psychological adaptation but not sociocultural adaptation. Thus, the results indicate that having contact with ethnic peers positively affects psychological wellbeing but not the learning of the new skills necessary to adapt successfully to the new cultural context (unless maybe ethnic peers know the 'rules' of the host country and provide informational support). Sam et al. (2006) drew similar conclusions from the ICSEY study. They suggested that adolescents who are orientated towards their ethnic group, who have a lot of ethnic peer contact and who use their ethnic language 
(i.e., ethnic profile) on average had good psychological adaptation but poor sociocultural adaptation.

Similar findings were obtained by Ward and Kennedy (1993b). The results of a study with 145 Malaysian and Singaporean university students in New Zealand suggested that, among other factors, satisfying relationships with ethnic peers were predictive of psychological adjustment. Along the same lines, strong identification with ethnic peers predicted less depressive symptoms (i.e., better psychological adaptation) in a sample of 98 sojourners in New Zealand (Ward \& Kennedy, 1994).

Second, having contact with national peers appears to predict sociocultural adaptation outcomes. For example, Ward and Kennedy (1993b) found in their previously mentioned study that the quantity of interactions with host nationals was predictive of sociocultural adaptation. These findings were supported by the results of the second part of their research with 156 Malaysian university students in Singapore.

In another example, Li and Gasser (2005) conducted a study with 117 Asian international students in the US and found that contact with host nationals was a predictor for sociocultural adaptation. Host national contact may have led to an increased understanding of 'how things work' in the host country and may have equipped migrants with the skills necessary to adjust effectively. Similarly, Ward and Kennedy (1994) investigated the sociocultural and psychological adaptation outcomes in a sample of 98 sojourners in New Zealand. The researchers found that a strong identification with national peers lead to better sociocultural adaptation.

Overall, past research suggests that ethnic and national peer contacts are predictors of psychological and sociocultural adaptation. More specifically, ethnic peer contacts seem predict psychological adaptation, whereas national peer contacts seem to predict sociocultural adaptation. However, it needs to be acknowledged that some studies are not consistent with this pattern. For example, Furnham and Li (1993) found that contacts with host nationals predicted psychological adaptation in a sample of first-generation Chinese migrants in Great Britain. Whether peer contact predicts psychological or sociocultural adaptation may depend on how the peer networks are utilised. For example, one the one hand, host nationals provide a source of information about the rules of the host culture and thus facilitate sociocultural adaptation. On the other hand, they can also be a source of emotional support and thus facilitate psychological adaptation. 
Whatever type of adaptation language use, language proficiency and peer contact predict, there appears to be a clear link between what migrants do during the acculturation process (e.g., Do they learn the local language? Who do they socialise with?), and their sociocultural and psychological adaptation. Consequently, the motivations that drive these behaviours deserve closer investigation.

\section{Motivations Underpinning Behaviours during the Acculturation Process: A Gap in the Literature}

The review above indicates that the acculturation literature acknowledges that the behaviours of migrants during the acculturation process are important for understanding and predicting acculturation outcomes. Generally speaking, however, there appears to be a lack of acculturation research that focuses on the motivations underpinning these behaviours and also acculturation research that takes motivational theories into account more generally.

For example, in the acculturation framework Berry does not explicitly refer to the motivational underpinnings that, on the one hand, drive individuals to maintain their culture and, on the other hand, drive them to seek contact with the host nationals and to participate in the host culture. Berry $(1997$, p. 9) refers to the extent to which "cultural identity and characteristics [are] considered to be important" and the extent to which people "strive" for cultural maintenance. He outlines that some people "do not wish" to keep their cultural heritage, but "seek daily interaction" with the host culture. Some may "wish to avoid" contact with other cultures and "place a value" on their heritage culture. However, there is no explicit linkage with motivational underpinnings.

To my best knowledge, studies in the acculturation literature that focus on motivations investigate very specific motivational issues. A recent search in the PsycInfo database (December 2012) yielded 127 hits when looking for 'motivation' and 'acculturation' as keywords. These studies investigate, for example, achievement motivation (Castigan \& Dokis, 2006; Buddington, 2002; Ibañez, Kuperminc, Jurkovic, \& Perilla, 2004), television viewing motivation (Reece \& Palmgreen, 2000; Stilling, 1996), the motivation to engage in outdoor recreation activities (Walker, Deng, \& Dieser, 2001) or sports (Ryska, 2001), to learn the language of the host country (Clément, 1986), academic motivation (Plunkett \& Bámaca-Gómez, 2003), career motivation (Bhagat \& London, 1999), motivation for immigration as a 
predictor for cross-cultural adaptation (Takeda, 2000), power motivation (Boneva \& Frieze, 2001), motivation to self-enhance and self-criticise (Zusho, 2008) or the motivation for alcohol use (Kail, Zayas, \& Malgady, 2000).

At the same time, some other acculturation researchers have started to point out the importance of motivation theory in the literature. For instance, Gezentsvey and Ward (2008) suggested that a motivational point of view may offer a new outlook on acculturation. They considered agency, i.e., the "active, positive engagement of individuals in the acculturation process" (p. 217), to be at the centre of the acculturation process because it influences for example, culture learning and identity. Along the same lines, Ward, Wilson and Fischer (2011) acknowledged that a further investigation of motivation and cross-cultural adaptation could enrich the acculturation literature.

It appears that the motivation to keep the cultural heritage on the one hand and the motivation to be open and participate in the host culture on the other hand do not seem to have been investigated so far. The motivations that drive the behaviours through which people engage in cultural maintenance or cultural contact deserve closer investigation. I posit that two distinct motives underlie acculturation behaviours: the motivational drive of cultural maintenance and the motivational drive of cultural exploration.

Motivation for cultural maintenance (MCM) refers to the need to keep an enduring link with one's own cultural heritage to facilitate the maintenance of a stable psychosocial organisation (in terms of a sense of self and identity concerns). Motivation for cultural exploration (MCE) refers to the need to explore the host culture and to be open to new experiences. It fulfils the need to integrate novel cultural knowledge into the psychosocial organisation (in terms of broadening one's own self and identity). My argument is that these motivational drives will influence acculturation behaviours when individuals immigrate to a new country because the proposed motivations suggest a distinction between two types of personal concerns.

On the one hand, acculturation behaviour may be governed primarily by selfmaintenance and self-integrity concerns, such as managing one's public image and confirming one's self-concept regarding the specific cultural heritage. Here the underlying drive is motivation for cultural maintenance (MCM). On the other hand, acculturation behaviour may be governed primarily by self-broadening and selfimprovement concerns, such as assuring one's attainment to new ways of doing 
things, engaging with people from other cultural heritages, and living up to the expectations of a host culture. Here the underlying drive is motivation for cultural exploration (MCE). These two basic drives have been neglected in the acculturation literature, and it is the aim of this research to fill this gap. The next section will discuss how the proposed motivations link with motivational theory.

\section{Grounding the two Drives in the Motivational Literature}

This section focuses on three main areas of motivational research and how the proposed motivations 'fit' into those theories and approaches. First, three of the five core motives that drive behaviour will be discussed. Second, the approach to view motivation as a continuum will be explored. Third, the cognitive view on motivation will be illustrated. Furthermore, the relevance of these theories and approaches to the present research will be highlighted.

Basic motives in motivational research. One strand of contemporary motivational literature mainly revolves around the five core motives of trust, control, understanding, self-enhancement and belonging (Fiske, 2008). Only the last three will be discussed in the following section because of their relevance to the current research.

Understanding. Fiske (2008) proposed that people strive to understand their social environment in such a way that their understanding is the same as the understanding of others in the same environment; in other words people want to obtain a "coherent, socially shared understanding" (p. 12) of what is going on around them. A shared understanding helps them to predict other people's actions, to assess situations quickly and to create a common view of the world (Fiske, 2004). If people are in the environment that they are accustomed to, the shared understanding is often automatic. However, in some instances it is not possible to have an automatic shared understanding, for example, when people move to a different culture. In such new social contexts people need to get exact perceptions of the host culture (Guinote, 2001). These new accurate perceptions will give migrants the information necessary to develop new shared understandings that may become automatic over time (Fiske \& Taylor, 2008).

Understanding and the proposed motivations. MCM appears to be related to the motive of understanding because maintaining the heritage culture in a new cultural environment preserves the shared understanding of migrants with their ethnic peers. 
This means they have a familiar base to operate from and they can access and function well in one network of social support in the host country. Conversely, through behaviours that are related to MCE migrants may get an accurate perception of the host culture. MCE may drive migrants to gather enough information about the host culture to create new shared understandings with national peers. This in turn potentially enables them to function well in a new cultural environment.

Self-enhancement. The self-enhancement motive refers to preserving self-esteem or to continuing self-improvement (Fiske, 2008). Ultimately, the motivation to selfenhance may well be adaptive. For example, Taylor and Sherman (2008) proposed that self-enhancement and self-affirmation are resources for dealing with life challenges (e.g., illness) because they motivate people to pursue a goal even if the odds are against them. Without the tendency to self-enhance in order to preserve a positive self-image, individuals would be more likely to give up in the face of difficulty. In that sense self-enhancement "holds the power to inspire and motivate" (Taylor \& Sherman, 2008, p. 59). Similarly, in their Self-Affirmation Theory, Sherman and Cohen (2006) pointed to the motivational power of self-enhancement. They proposed that when people's self-worth is threatened, their desire to see themselves as good and appropriate affects their behaviour in a way that restores their positive self-image.

However, self-enhancement is not only evident on an individual level but can also be observed on a group level regarding intergroup behaviour. Tajfel and Turner (1986) posited in the Social Identity Theory that people derive parts of their selfconcept through group membership. Group members place the same or similar value on belonging to their group and are emotionally involved in their group membership. One consequence of identifying oneself with a group is that intergroup behaviour is affected: according to Tajfel (1982) people tend to favour their ingroup over the outgroup because it helps them to maintain positive feelings about themselves and their social identity. This strategy works as long as the ingroup is perceived as positively distinct. Ingroup favouritism is the consequence of the desire to see oneself in a positive light and consequently, this can lead to "depersonalization, dehumanization, and social stereotyping" (Tajfel, 1982, p. 13) and discrimination of the outgroup. This may enhance the positive perception of one's own group, its success and competence and thus increases self-esteem. 
It should be noted that the need for a positive self-regard is not equally strong and is also perhaps expressed differently across cultures. It appears to be more prevalent in Western than in Asian cultures when using the Western conceptualisation of the construct (Heine, Lehman, Markus, \& Kitayama, 1999).

Self-enhancement and the proposed motivations. The motive of self-enhancement is linked to both MCM and MCE. Migrants' self-image may be threatened by the experience of not quite fitting in to their host society. They find themselves in a situation in which they are the minority and this might be an unfamiliar and perhaps unexpected experience. To restore their positive self-image, they may choose to maintain their culture and favour their ingroup (i.e., migrants of the same heritage culture) above the outgroup (i.e., members of host culture). Conversely, migrants may try to self-enhance by trying to fit into the host culture and meet public expectations.

Belonging. Fiske (2008) suggested that the most current strand of motivational research investigates the motive of belonging to others. In her view early researchers, such as Floyd Allport, focused on the drives for contact and approval; John Bowlby formulated his Attachment Theory to investigate the relationship between infant and caregiver and thus pointed to the adaptive importance of social bonds. More recently, Baumeister and Leary (1995) concluded from a review of empirical literature that people tend to form social relations quickly and with ease but oppose the termination of relationships. People are often preoccupied with thoughts about relational issues. They experience positive affect when they are accepted in a group and experience negative affect when they are excluded. A lack of meaningful relationships can lead to a number of aversive outcomes, ranging from mental illness and behavioural issues to suicide. The authors concluded that humans have an omnipresent motivation to form enduring and close bonds with others and that this affects cognition and behaviour. Leary and Cox (2007) went as far as to suggest that the motive of belonging and social acceptance drives most of human behaviour. Fittingly, they termed this human drive "belongingness motivation" (p. 28). The authors maintained that people in all societies throughout the world form social bonds and that therefore, the need to belong appears to be innate and universal. However, they conceded that the nature of relationships may vary from culture to culture.

As was the case for the motive of self-enhancement, the motive of belonging is also reflected in Tajfel and Turner's (1986) Social Identity Theory because people's self-concept is influenced by which groups they belong to. If the values and attributes 
of a specific group are seen as positive, then the membership to this group is seen as equally positive. If the values associated with the group are negative, individuals might want to leave the group. Moreover, not only do individuals define themselves through group membership, but they are also defined through their group membership by others.

Belonging and the proposed motivations. Migrants' sense of belonging might be threatened due to the fact that their (extended) families and other social relations are not present in the new country of residence. For this reason the feeling of belonging to the group of people that share the same cultural heritage is strengthened. They serve as a reference point in an unfamiliar culture and as safe basis to operate from. In this sense high MCM may facilitate a sense of belonging to one's original cultural ingroup. Conversely, the MCE may facilitate a new sense of belonging to the host culture. People are motivated to venture out from the familiar context of their heritage culture to make new friends amongst host nationals and to learn to 'play by the rules' of the unfamiliar host society.

A motivational continuum. Ryan and Deci (2000a) outlined that "to be motivated means to be moved to do something" (p. 54). However, people do not only vary in the amount of motivation they have to do certain activities, but also in the kind of motivations that they have. For example, people can be highly motivated to eat healthily because they simply enjoy the taste of healthy food, while others eat healthily to get their doctor's approval or to keep their weight in check. An example in the context of this study is that some people live in foreign countries because they enjoy the excitement of experiencing another culture, while others go abroad because it looks good on their CV.

Extrinsic and intrinsic motivation. Ryan and Deci (2000a) proposed in their Self-Determination Theory that at the most basic level there is a distinction between extrinsic motivation and intrinsic motivation. First, individuals who are extrinsically motivated engage in an activity to reach a certain goal or outcome. These activities or behaviours are not done for their own sake, but they serve a specific purpose.

Contrarily, intrinsic motivation refers to doing an activity for the sake of the activity, for the pleasure one experiences while doing it and the satisfaction one gets from that activity (Deci, 1975, cited in Vallerand et al., 1992).

Extrinsic/intrinsic motivation and the proposed motivations. In the context of the present research Ryan and Deci's (2000b) definition of intrinsic motivation as the 
human "tendency to seek out novelty and challenges, to extend and exercise one's capacities, to explore, and to learn" (p. 70) is of particular interest because there is a parallel to the proposed motivational drive of cultural exploration. On the one hand migrants may want to explore their new environment for the sheer enjoyment of experiencing something novel or because they want to broaden their horizon. In this sense, MCE has an intrinsic component and may lead to intrinsic gains.

Csikszentmihalyi and Rathunde (1993, cited in Ryan \& Deci, 2000b) went as far as to suggest that the tendency to explore and to show spontaneous interest is a basis for the liveliness and enjoyment in people's lives. On the other hand MCE may also lead to the fulfilment of extrinsic gains. For example, people may decide to migrate because the new country offers better educational opportunities for their children. Furthermore, migrants may need to explore their new cultural environment and establish host national networks to be able to find a job. In these cases the motivation to explore the new culture serves a specific purpose and is therefore extrinsic.

The link between Self-Determination Theory (Ryan \& Deci, 2000a) and MCM seems to be less clear because the authors did not specifically discuss intrinsic and extrinsic motivation in the context of maintenance. However, similarly to Fiske (2008) they argued that relatedness is one of the basic human psychological needs. Furthermore, they labelled affiliation as one life goal that is intrinsically motivated (Deci \& Ryan, 2008). Therefore, MCM might be intrinsically driven because it establishes an affiliation with one's heritage culture and its members.

Cognitive theories of motivation. The cognitive approach to motivational theory is not new. It was first developed by William James in the late 1800s, but over the years cognitive views were replaced by behaviourism and information-processing approaches that rejected motivation as an explanation for behaviour. However, in the 1980s researchers acknowledged that cognition and motivation should not be seen as independent of each other but as intertwined (Sorrentino \& Yamaguchi, 2008). Current theories of motivation include the measurement of motives related to the present research, such as desire for novelty and need for closure.

Desire for novelty. Novelty seeking (or the desire for novelty) has been described as an individual's tendency to approach rather than to avoid novel situations (Pearson, 1970). Accordingly, Cloninger (1987) suggested that novelty seeking is the tendency toward exploratory action and excitement in the face of novel stimuli. He argued that individuals who have a strong tendency for novelty seeking are likely to be impulsive 
and engage in exploratory behaviour. Furthermore, novelty seeking has been referred to as a dislike of monotony (Kashdan \& Hofmann, 2008), as well as a search for the unfamiliar (Fischer, Fitzpatrick, \& Cleveland, 2007). People who enjoy changing and unexpected experiences and who have a tendency to approach (rather to avoid) novel experiences are likely to score high on the Novelty Seeking Scale (Pearson, 1970).

Desire for novelty and the proposed motivations. Novelty seeking appears to be related to MCE because this motivational drive refers to the need to explore the host culture and to be open to new experiences. It is related to a broadening of the sense of self. The approach aspect that can be found in novelty seeking can also be found in MCE in terms of the willingness to approach rather than to avoid the host culture. Inquisitiveness about the environment also appears to be a facet of both constructs.

Need for closure. The need for closure has been defined as people's desire to get clear and straightforward answers to questions and their preference to avoid ambiguity. Individuals may experience negative feelings when closure for open questions is not attained and positive feelings when closure is achieved (Kruglanski \& Webster, 1996). Need for closure reflects the desire for "an answer on a given topic, any answer, as compared to confusion and ambiguity" (Kruglanski, 1990, p. 337). Individuals who have a high need for closure tend to "seize and freeze" (p.727) the answer or solution to the problem at hand (Kashima \& Pillai, 2011). The need for closure may be heightened in instances when predictability is essential, when processing of information is effortful or when coming to a well-thought-out solution seems boring to the individual (Webster \& Kruglanski, 1994). In these cases, getting a quick rather than a well-founded answer to a question seems to be the preferred option. Furthermore, individuals with a high need for closure may have rigid rather than flexible thought patterns and are less likely than others to acknowledge views that are different than their own (Kruglanski \& Webster, 1996). Supporting this, past research linked the need for closure with individuals' resistance to be influenced. It correlates with comparatively little interest to seek new information, conservatism and resistance to change (Roets \& Van Hiel, 2007). Moreover, a high need for closure has been linked to poorer sociocultural and psychological adaptation outcomes in a study with international students in Australia (Kashima \& Loh, 2006). The authors concluded that individuals with a high need for closure are more stressed because of the ambiguity that is inherent in cultural transitions than those individuals with a lower need for closure. 
However, it needs to be acknowledged that individuals deal with uncertainty or ambiguity differently across cultures. For instance, uncertainty avoidance is one of the four cultural dimensions proposed by Hofstede (2001) that vary across cultures.

Need for closure and the proposed motivations. Individuals who score high on need for closure and MCM may deal similarly with certain aspects of life. For example, individuals with a strong MCM focus on preserving a link to their cultural heritage and maintaining a stable sense of self. They attempt to create a safe and familiar cultural environment. If the heritage culture serves as a benchmark for negotiating unfamiliar situations in the host country, people are using the seemingly 'quicker route' to problem solving, similarly to someone who is high on need for closure and who wants a quick answer to avoid ambiguity. Just as someone who has a strong need for closure, individuals with a high motivation to maintain their heritage culture may be less prepared to consider new perspectives and to incorporate novel ways of looking at the world into their thought patterns.

\section{Maintenance versus Exploration in the Psychological Literature}

Besides the links with other motives as discussed above, the motives of maintenance and exploration seem to reflect a fundamental distinction already identified in the extant literature. Theoretical models support the existence of the need for stability and the need to be open to new experiences in order to adapt to changes (see Table 2).

Table 2

Constructs of Maintenance versus Exploration

\begin{tabular}{lll}
\hline Study & $\begin{array}{c}\text { 'Cultural maintenance } \\
\text { motivation'-like }\end{array}$ & $\begin{array}{l}\text { 'Cultural exploration } \\
\text { motivation'-like }\end{array}$ \\
\hline DeYoung, 2006 & Stability & Plasticity \\
Schwartz, 1994a & Conservation & Openness to change \\
Rothbaum et al., 2000 & Proximity to safe haven & Exploration of environment \\
Higgins, 1997 & Prevention focus & Promotion focus \\
Minkov, 2007 & Monumentalism & Flexumility \\
\hline
\end{tabular}


Stability versus plasticity. The dichotomy between maintenance versus exploration has been postulated in personality traits. Based on the work of Digman (1997, cited in DeYoung, 2010), DeYoung (2006) argued that the Big Five personality factors have the two higher order factors of stability (i.e., incorporating conscientiousness, agreeableness and low neuroticism) and plasticity (i.e., incorporating extraversion and openness). Stability refers to the human need to maintain a stable psychosocial function, whereas plasticity refers to the human need to integrate new knowledge into the existing organisation. Plasticity is linked to behaviours that refer to "social or mental exploration" (Hirsh, DeYoung, \& Peterson, 2009, p. 1087) and is important because the environment and the individual change constantly.

Conservation versus openness to change. Another example of the distinction between maintenance versus exploration is Schwartz's (1994a) higher order values. According to Schwartz ten motivationally different types of values can be grouped under two overarching and opposing pairs of higher order values. One pair consists of the values of 'self-transcendence' (universalism, benevolence) versus 'selfenhancement' (achievement, power, a part of hedonism). The second pair, and of interest for the current study, comprises the opposing values of 'openness to change' (self-direction, stimulation, remainder of hedonism) versus 'conservation' (conformity, tradition, security). Schwartz (1994b) proposed that openness to change values focus on autonomous thought, change and action. Contrarily, conservatism values focus on the maintenance of traditions and the status-quo, stability and selfrestraint.

Safe haven versus exploration of environment. A third example for the distinction between maintenance and exploration is rooted in attachment theory. Bowlby (1969, cited in Elliot, 1999) proposed two distinct types of attachment. Secure attachment promotes exploration, whereas insecure attachment promotes safety and protection. Based on this distinction, Rothbaum, Pott, Azuma, Miyake and Weisz (2000) suggested a push and pull relationship between people's need for the proximity to a 'safe haven' on the one hand, and the need for the exploration of the environment and the establishment of new relationships on the other hand.

Prevention versus promotion focus. A fourth example for the distinction between maintenance on the one hand and exploration on the other hand stems from Regulatory Focus Theory, which suggests that people have a prevention focus or a 
promotion focus as underlying motivational principles when they try to self-regulate (Higgins, 1997). Individuals with a prevention focus prefer stability in their environment because for them change is associated with negative outcomes. These individuals are concerned with protection and safety. In contrast, individuals with a promotion focus prefer change because it may provide the opportunity for advancement and growth (Boldero \& Higgins, 2011).

Monumentalism versus flexumility. The distinction between maintenance and exploration can also be found in Minkov's (2007) concept of monumentalism versus flexumility in cultural differences. Minkov argued that in some cultures the self is seen as a 'monument' (i.e., stable and fixed), whereas the opposite is the case in other cultures. Monumentalism is expressed for example, as absolutist thinking, cultural preservation and low adaptability to other cultures. Flexumility on the other hand is expressed for example, in a flexible worldview and high adaptability to other cultures.

DeYoung's (2006) stability/plasticity factors, Schwartz's (1994a) conservation/openness to change values, Rothbaum et al.'s (2000) distinction between proximity versus exploration, Higgin's (1997) prevention/promotion, as well as Minkov's (2007) monumentalism/flexumility dimensions refer to the same dichotomy of maintenance versus exploration and are related to the motives proposed in the present research. Motives that refer to conservation, maintenance and stability are reflected in MCM, whereas motives of openness to change, exploration and plasticity are more likely to be reflected in MCE.

\section{Links between Motivational Drives, Acculturation Behaviours and Adaptation}

Having a high (or low) cultural maintenance motivation or cultural exploration motivation appears to be relevant for acculturating individuals. As outlined earlier, the interplay between maintenance and exploration is a common theme in the psychological literature. This theme is reflected in the proposed motivational drives of cultural maintenance and exploration. For example, the motivation to maintain a feeling of belonging to the heritage group is likely to influence whether migrants use their native language (maintenance) or the host language (exploration), or whether they prefer to socialise with their ethnic peers (maintenance) or with host nationals (exploration). In other words, the motivations to maintain and to explore are reflected in corresponding behaviours and ultimately in the way how migrants behave towards the host society, as well as their own society. In turn, as outlined earlier, previous 
research has shown that behaviours influence the psychological and sociocultural adaptation of migrants in the host country. Therefore, I propose a mediation model in which individuals' cultural motivations influence acculturation behaviours, which in turn influence sociocultural and psychological adaptation in the host culture. This model is depicted in Figure 2.

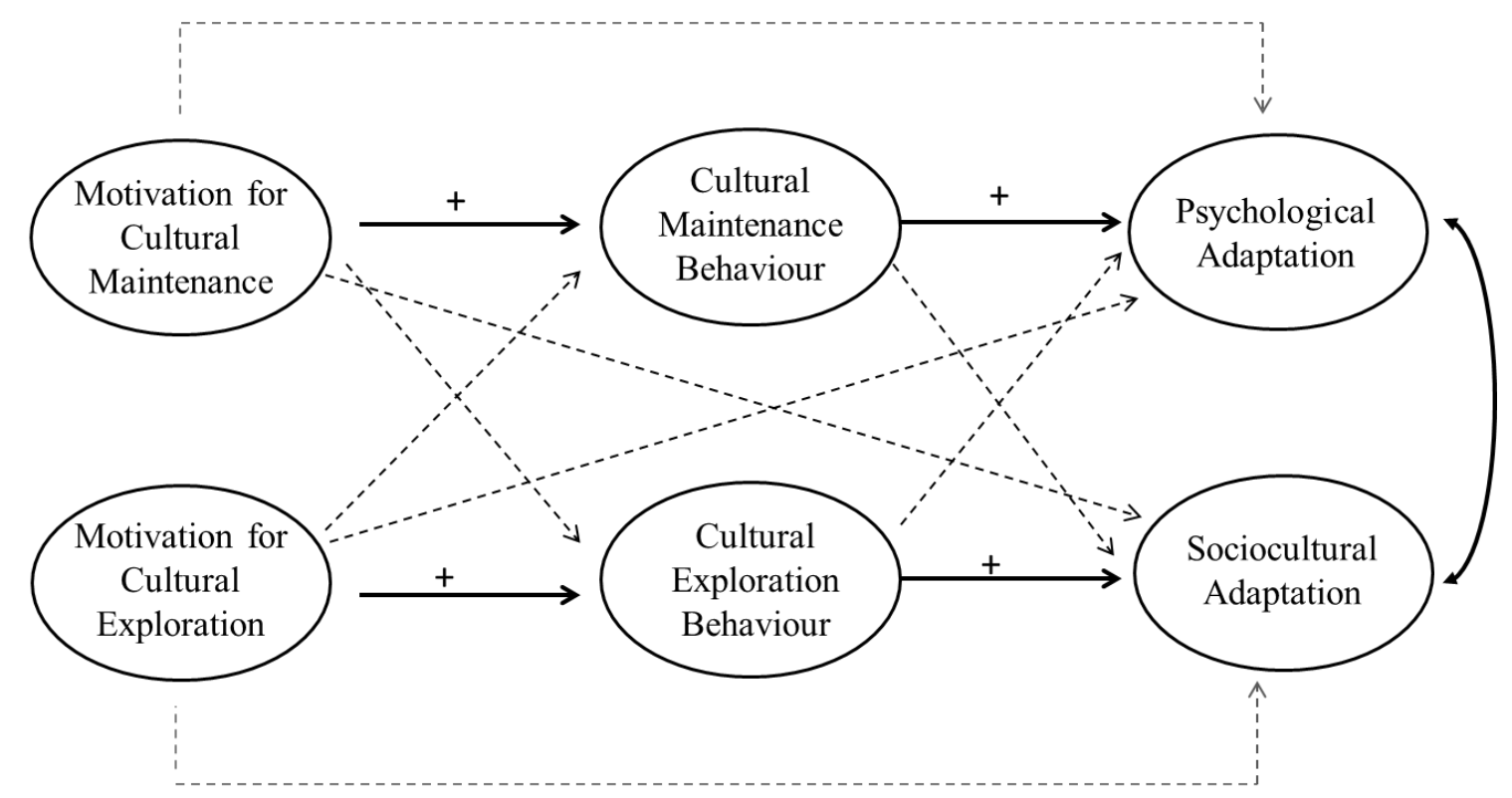

Note: The solid lines represent predicted relationships; the dotted lines represent alternative paths that will be empirically tested.

Figure 2: A mediation model of the relationship between two different motivational drives and adaptation outcomes as mediated by acculturation behaviours

\section{Hypotheses and Research Questions}

First, while the construct examples of maintenance versus exploration given in Table 2, consider the dimensions as opposite ends of a continuum, I posit that the two proposed motivations are in fact independent. This means that an individual can score independently on the motivations (i.e., high on both, low on both or high on one and low on the other), similar to Berry's (1997) conceptualisation of the independent questions underlying the four acculturation strategies (see Figure 1). Based on this argument I propose the following hypothesis.

Hypothesis 1: The MCM and MCE scales are orthogonal.

Second, I suggest that MCM and MCE will be expressed in corresponding acculturation behaviours. That is, both motivations will predict specific acculturation 
behaviours (i.e., motivation $\rightarrow$ acculturation behaviour). Cultural maintenance behaviours facilitate and safeguard a link with the heritage culture. For example, individuals may prefer to socialise with ethnic peers to maintain links with their heritage culture (e.g., language, normative behaviours, national celebrations, food). Conversely, cultural exploration behaviours facilitate the exploration of the host culture and individuals' participation in it. For example, individuals may seek more interactions with host nationals than with their ethnic peers to learn a new language and explore different normative behaviours, celebrations and food. Based on this argument I present the following hypotheses.

Hypothesis 2.1: There is a positive path between MCM and cultural maintenance behaviour.

Hypothesis 2.2: There is a positive path between MCE and cultural exploration behaviour.

Third, I theorise that both types of acculturation behaviours, driven by MCM and MCE as outlined above, impact the psychological and sociocultural adaptation of individuals to their host culture.

Hypothesis 3.1: There is a positive path between cultural maintenance behaviour and psychological adaptation.

Hypothesis 3.2: There is a positive path between cultural exploration behaviour and sociocultural adaptation.

The last four hypotheses focus on specific relationships between pairs of variables. As depicted in Figure 2, however, the relationship between the motivations and adaptation outcomes is expected to be mediated by acculturation behaviours. The following hypothesis is thus proposed.

Hypothesis 4: Acculturation behaviours will mediate the influence of MCM/MCE on adaptation outcomes as shown in Figure 2.

Additional research questions. Since the aim of this research is to shed light on the relationships between the three core constructs as outlined above, it will be also investigated whether any other mediated (i.e., indirect) effects are present. Furthermore, it will be investigated whether MCM and MCE influence psychological and sociocultural adjustment directly, and whether the cross-relationships between the motivations and acculturation behaviours emerge as significant. 
Two studies were conducted for this research. First, the reliability and validity of the newly developed MCM and MCE Scales were tested. Second, the relationships between the constructs as outlined above were explored. Ethics approval for both studies was granted by the School of Psychology Human Ethics Committee under delegated authority of the Victoria University of Wellington Human Ethics Committee.

\section{Study 1}

\section{Objective and Hypotheses}

The first objective of Study 1 was to develop items for the MCM and MCE scales. As outlined earlier, the proposed motivations of cultural maintenance and cultural exploration are theoretically conceptualised as being orthogonal. This means for example, that individuals can be highly motivated to preserve their heritage culture while being highly motivated to explore the host culture at the same time. This conceptualisation reflects Berry's (1997) acculturation model in which migrants choose between different levels of participation and maintenance. Therefore, it was hypothesised that MCM and MCE are not correlated or only very weakly positively correlated.

The second aim of Study 1 was to provide initial indicators of reliability and validity for the MCM and MCE scales. Validity was to be evaluated by assessing the correlations of the MCM and MCE scales with two constructs that have conceptual links and that therefore served as criterion measures: the need for closure and the desire for novelty seeking. This approach is based on the assumption that different measures of a similar hypothetical construct ought to correlate with each other (i.e., there is evidence of convergent validity).

MCM and need for closure seem to share cores aspects such as rigid thought patterns and little preparedness to consider new perspectives. Therefore, it was expected that MCM and need for closure will be positively correlated with a small to medium effect size. MCE and desire for novelty on the other hand seem to share core aspects such as inquisitiveness, a tendency to approach rather than to avoid and openness to new experiences. Following this line of reasoning, MCE and novelty seeking were expected to be positively correlated with a small to medium effect size. 


\section{Method}

\section{Participants}

The participants for this study were students from Victoria University in Wellington, New Zealand $(N=50 ; 33$ females, 17 males; $M$ age $=28.6$ years, $S D=$ 6.462). Forty-five of them were international students; five did not have international student status but were included in the sample because they were born outside of New Zealand. As inclusion criteria the participants had lived in New Zealand for at least six months at the time of the study; they were at least 18 years old when they came to New Zealand and lived here at the time when the study was conducted. Fifteen participants were born in Malaysia, six in the USA and three in China. The remainder came from Bolivia, Brazil, Chile, Ecuador, Finland, France, Germany, India, Indonesia, Iran, Japan, Kiribati, South Korea, Laos, Papua New Guinea, Philippines, South Africa, Spain, Tonga, and the UK. Sixteen participants intended to stay in New Zealand indefinitely, whereas 33 stated that they want to leave the country at some point in the future (one person made no statement). The majority of the sample (54\%) self-identified as Asian, 20\% as European, 12\% as Latin American, 4\% as Pacific Nations and $8 \%$ as 'Other' ( $2 \%$ made no statement). In regard to their religious affiliation, $34 \%$ of participants self-identified as being Christian, $28 \%$ as having no religion, $16 \%$ as Muslim, $10 \%$ Buddhist, $4 \%$ as Hindu and $8 \%$ as 'Other'.

\section{Procedure}

Snowball sampling was used to recruit the participants: I emailed the link to the anonymous online survey (using SurveyMonkey technology) to international students of my private network, asking them to forward the email to other potential participants. Consequently, 29 students filled out the online survey. In addition, I approached 21 participants on campus and asked them to fill in paper-and-pencil surveys. These students received a small chocolate bar as a sign of appreciation. Appendix A presents the information sheet, the questionnaire and the debriefing sheet.

\section{Materials}

Development of the initial MCM and MCE scales. To my best knowledge, neither cultural maintenance motivation nor cultural exploration motivation has been 
measured in previous research. Therefore, items were developed to measure both constructs. Considering the motivational focus of the measures, other motivational measures in the acculturation literature, as well as measures tapping into exploration and maintenance, were examined when developing the items, including the SelfRegulation Questionnaire - Study Abroad (Chirkov, Vansteenkiste, Tao, \& Lynch, 2007), the Need for Uniqueness Scale (Tepper \& Hoyle, 1996), and the Need for Cognition Scale (Cacioppo \& Petty, 1982). The aim of this approach was to develop motivation-type items for both measures.

Cultural maintenance motivation is operationally defined as the motivation to keep an enduring link with one's cultural heritage in order to maintain a stable psychosocial organisation (i.e., a person's motivation for a stable cultural heritage). Cultural exploration motivation is operationally defined as the motivation to explore and incorporate novel cultural knowledge into the psychosocial organisation (i.e., a person's motivation for a variable/adaptable cultural heritage). Seventeen items for the Motivation for Cultural Maintenance (MCM) Scale and sixteen items for the Motivation for Cultural Exploration (MCE) Scale were developed.

Pre-test. A small pre-test with three cross-cultural postgraduate students from the Centre for Applied Cross-Cultural Research (School of Psychology, Victoria University of Wellington) was conducted to ensure the clarity of the items and their fit with the operational definitions. Participants rated the clarity of the items on a scale ranging from 1 (not clear) to 5 (very clear) and the fit of the items to the operational definition on a scale rating from 1 (not well) to 5 (very well). Furthermore, the participants were asked to verbalise or write down any questions they had about each item. Items that were rated low on clarity and/or low on fit with the operational definition were removed from the measurement scales. This resulted in ten items for each scale that were subsequently used.

Measures. In addition to demographic questions about age, gender, ethnicity, religious affiliation and length of stay in New Zealand, the questionnaire included the following measures.

\section{Cultural Maintenance Motivation and Cultural Exploration Motivation. The} newly developed 10-item motivation for cultural maintenance (MCM) scale and the 10-item motivation for cultural exploration (MCE) scale were used. Respondents indicate their agreement with the items from both scales on a 7-point Likert-Scale, ranging from 1 (strongly disagree) to 7 (strongly agree). Higher scores indicate higher 
motivation for cultural maintenance and cultural exploration respectively. The items are presented in Table 3.

Table 3

Items of the Motivation for Cultural Maintenance (MCM) and Motivation for Cultural Exploration (MCE) Scales

\begin{tabular}{l} 
MCM \\
\hline $\begin{array}{l}\text { It is important for me to celebrate the } \\
\text { holidays of my country of origin. }\end{array}$ \\
2. It gives me a sense of security to \\
socialise with people who share my \\
cultural heritage. \\
3. $\quad \begin{array}{l}\text { It is important to keep my cultural } \\
\text { traditions because they are part of who I } \\
\text { am. }\end{array}$ \\
4. It makes sense to set aside the traditions \\
of my cultural heritage. (R) *
\end{tabular}

5. I feel the need to live according to the traditions of my cultural heritage, particularly because I now live in another culture.

6. I experience pleasure when my ethnic peers tell me stories from our country of origin.

7. Maintaining my cultural traditions helps me to structure my life here in New Zealand.

8. It is deeply satisfying for me to have an emotional link with my cultural heritage.

9. I do not feel the need to practice my ethnic traditions. (R)

10. It gives me pleasure to meet people who share my cultural heritage.

\section{MCE}

1. It is exciting for me to explore new cultures.

2. I enjoy contact with people from other cultures because it broadens my horizon.

3. It is important to me to understand the views of people from different cultural backgrounds.

4. Living in a country with a different culture gives me the opportunity to learn new ways of doing things.

5. It is exciting to go to places with a different cultural heritage, even though I don't know what might happen.

6. Sometimes it is important for me to put my own culture into perspective and acknowledge different views.

7. I do not feel any desire to learn about other cultures. (R)*

8. It gives me pleasure to meet people from other cultures.

9. It gives me pleasure to go to places where people from other countries display their culture (e.g. markets, arts festivals, concerts).

10. I do not feel the need to understand why people with different cultural heritage behave differently. (R)*

Scoring on 7-point Likert scales: 1 (strongly disagree) to 7 (strongly agree)

* The items were not retained in the final version of the scales, based on the results of the this study. 
Need for Closure (NFC). The 15-item Revised Need for Closure (R-NFC) scale was used which has been shown to be highly reliable $(\alpha=.87$, Roets $\&$ Van Hiel, 2011). Items are, for example, "I don't like situations that are uncertain", and "I enjoy having a clear and structured mode of life". The responses are rated on a 7-point scale ranging from 1 (strongly disagree) to 7 (strongly agree). Higher scores indicate a higher need for closure.

Novelty Seeking. The 10-item Desire for Novelty (DFN) Scale (Pearson, 1970) was used. Kohn and Annis (1975) calculated Kuder-Richardson $\alpha=.83$. Items are, for example, "I wish something new and exciting would happen", and "I often wish life were different than it is". The responses are rated on a 7-point scale ranging from 1 (strongly disagree) to 7 (strongly agree). Higher scores indicate higher desire for novelty.

\section{Results}

All statistical analyses were performed using IBM SPSS Statistics 19. All tests were performed at $\alpha=0.05$.

\section{Descriptive Statistics}

The descriptive statistics of the MCM and MCE scales, as well as for the Revised Need for Closure and the Desire for Novelty Seeking Scale are presented in Table 4.

Table 4

Descriptive Statistics $(N=50)$

\begin{tabular}{lrrrr}
\hline & No. of items & $\alpha$ & $M$ & $S D$ \\
\hline MCM & 9 & .82 & 4.99 & .91 \\
MCE & 8 & .94 & 6.14 & .97 \\
R-NFC & 15 & .82 & 4.18 & .85 \\
DFN & 10 & .91 & 3.70 & 1.34
\end{tabular}

Note: $\mathrm{M}=$ Mean item score; $\mathrm{MCM}=$ Motivation for cultural maintenance scale, $\mathrm{MCE}=$ Motivation for Cultural Exploration Scale; R-NFC = Revised Need for Closure scale; DFN = Desire for Novelty Seeking Scale 


\section{Reliability of the MCM and MCE Scales}

Cronbach's alpha was calculated as a measure of reliability for both the MCM and MCE scale.

MCM Scale. The Cronbach's alpha for the 10-item MCM scale was $\alpha=.79$, which is higher than the minimum recommended .70 value (Nunnally, 1978). However, not all items were worthy of retention: the greatest increase in alpha came from deleting item four ("It makes sense to set aside the traditions of my cultural heritage"). Moreover, the corrected item-total correlation for this item $(r=.01)$ was the only one well below the acceptable value of $r=.3$ (Field, 2009). Furthermore, inspection of the intercorrelation matrix between the items showed that this item had very low and also negative correlations with some of the other items, indicating that it does not relate well to the other items on the scale and that it might not measure the same construct as the other items (Bartee, Grandjean \& Bieber, 2004). The removal of this item increased alpha to .82 . Further analyses were performed with the remaining nine items.

MCE Scale. The 10-item MCE scale also appeared to have good internal consistency, $\alpha=.89$. However, alpha increased to .93 by deleting item ten ("I do not feel the need to understand why people with different cultural heritage behave differently.") which had a low corrected item total correlation $(r=.098)$. Item seven ("I do not feel any desire to learn about other cultures") also had a low corrected item total correlation $(r=.24)$ and its removal further increased alpha to .94. Both items had low and in some cases negative correlations with the other items. Further analyses were thus performed with the remaining eight items.

\section{Convergent Validity of the MCM and MCE Scales}

Convergent validity between the scales was assessed by examining the correlations between the measures, which are reported in Table 5. First, and contrary to the hypothesis that the scales are orthogonal, MCM and MCE were strongly positively correlated. The strength of the correlation was surprising but still shows individuals can have high maintenance motivation and high exploration motivation at the same time. 
A Dual-Process Motivational Model of Cross-Cultural Adaptation

Table 5

Correlations between MCM, MCE Scales, $R-N F C, D F N(N=50)$

\begin{tabular}{lllll}
\hline & MCM & MCE & R-NFC & DFN \\
\hline MCM & - & $.52^{*}$ & .22 & .01 \\
MCE & - & -.15 & -.08 \\
R-NFC & & & - & $.37^{*}$ \\
DFN & & & - \\
\hline$* p<.01$ & & &
\end{tabular}

Note: R-NFC $=$ Revised Need for Closure Scale; DFN = Desire for Novelty Scale

Second, the correlation between MCM and the need for closure was weak and statistically non-significant, however, the direction of the correlation was as expected. Third, the correlation between MCE and the desire for novelty was weak, nonstatistically significant and not in the expected direction. Overall, one cannot infer convergent validity between MCM, MCE and the criterion measures due to the small effect sizes and the statistically non-significant results.

\section{Discussion}

The purpose of this study was to investigate the reliability and validity of the MCM and MCE scales. The analysis of the Cronbach's alpha revealed that the reliability of the scales is acceptable. This suggests that the scales consistently reflect the constructs that they are supposed to measure. Following these results, the 9-item MCM and the 8-item MCE scales will be used in Study 2.

The hypothesis that MCM and MCE are empirically orthogonal was not confirmed. Still, it is possible that MCM and MCE are conceptually independent, even though they are empirically related in the context of this study. The level of relatedness may depend on the specific circumstances of the sample in their new country of residence. These circumstances (e.g., level of perceived discrimination, government policies of integration or assimilation) may affect the relationship between the motivation to maintain culture and the motivation to explore the host culture in positive or negative ways. It is possible that there is a positive relationship between traditional and mainstream (i.e., origin and host) cultural orientations in comparably tolerant, multicultural societies such as New Zealand. For example, Phinney et al. (2006) found that ethnic and national identity are positively correlated 
in New Zealand. This indicates that maintaining one's heritage culture while at the same time exploring the culture of the host country is a possible option for the migrants in the sample of the current study due to the New Zealand context.

The prediction of a positive correlation between MCE and desire for novelty seeking was not supported. It is possible that the items of the desire for novelty scale measure a type of novelty-seeking that is different from the novelty seeking that migrants experience. The scale includes items that capture the boring aspects of the respondents' lives (Pearson, 1970), whereas MCE taps into the openness to new experiences. Therefore, it may be the case that the scales have a different focus and that a significant positive correlation should not have been expected.

The correlation between MCM and need for closure was in the expected direction, albeit statistically non-significant. Small sample size might explain the fact that the correlation did not reach statistically significant levels. A theoretical explanation for the weak correlation may be that a high need for closure may not be conceptually related to MCM in the expected clear-cut way. As outlined earlier, a high need for closure is an expression of the desire to avoid ambiguity. Thus, need for closure might in fact drive migrants to explore the host culture and to make contact to host nationals because this will help them to learn the rules of the new environment. For example, Kosic, Kruglanski, Pierro and Mannetti (2004) suggested that migrants who have a high need for closure tend to adopt local ideologies quicker than those with a low need for closure (if they socialise with host nationals rather than conationals upon arrival in the host country). Furthermore, people from 'tight' cultures (e.g., Japan) value conformity and find it unsettling if rules are not followed (Triandis, 2000). Therefore, they may be particularly motivated to explore the new culture because they want to 'get up to speed' quickly to avoid misunderstandings and to fit in. In this context exploration may be a means of avoiding ambiguity rather than causing ambiguity.

This study provided some preliminary evidence for the psychometric properties of the newly developed MCM and MCE scales. Both scales had good reliability and validity evidence was more strongly obtained for the MCM scale. Study 2 was designed to provide further evidence for the psychometric properties of the scales and, more importantly, to explore the relationships between the main constructs of this research. 


\section{Study 2}

\section{Objective and Hypotheses}

The main purpose of Study 2 is to investigate the relationships between MCM, MCE, behaviours of maintenance and exploration, as well as psychological and sociocultural adaptation (Hypotheses 2-4). Moreover, this study further attempts to validate the MCM and MCE scales. Four related constructs were selected for that purpose.

Further validation of the MCM and MCE scales. First, motivation for ethnocultural continuity (Gezentsvey, 2008) was used to assess the validity of the MCM scale. Ethnocultural continuity is defined as people's desire to preserve their ethno-cultural heritage, to pass this heritage on to the next generation and to ensure the survival of the cultural collective. The construct emphasises the importance of the preservation of culture and tradition. Although the focus of motivation for ethnocultural continuity is on the continuity of the cultural collective, and the focus of MCM is on maintaining the cultural heritage for the individual, it is expected that both will be positively correlated (medium effect size).

Second, the motivational component of cultural intelligence (Ang et al., 2007) was used to assess the validity of the MCE scale. Broadly speaking, cultural intelligence is defined as an individual's ability to operate successfully in culturally diverse environments. The motivational component of cultural intelligence refers to a person's ability to "direct attention and energy toward learning about and functioning in situations characterised by cultural differences" (Ang et al., 2007, p.338). This construct and MCE seem to share the aspect of learning in a culturally new environment. Therefore, it is expected that the cultural intelligence motivational subscale will be positively correlated to MCE (medium effect size).

Third, components of the construct of the 'multicultural personality', measured with the Multicultural Personality Questionnaire (van der Zee \& Van Oudenhoven, 2000) were used to assess the validity of the MCE scale. This questionnaire was designed to assess individuals' effectiveness in multicultural settings, and predicts a person's international outlook and the desire of pursuing an international career. More specifically, its openmindedness subscale assesses openness to different cultural values and rules. This subscale and MCE seem to share the aspects of being open and 
inquisitive towards new cultures. Therefore, it was expected that MCE and the openness subscale will be positively correlated (medium effect size). Furthermore, its flexibility subscale refers to an individual's capacity to adjust behavioural patterns to unfamiliar cultural settings. Again, the aspect of adjusting behaviours to an unfamiliar cultural context appears to be related to MCE. Therefore, it was expected that MCE and the flexibility subscale will be positively correlated (medium effect size).

Fourth, the 'Big Five meta-traits' of stability and plasticity (DeYoung, 2010) were used to assess the validity of the MCM and MCE scale, respectively. Desire for stability is indicative of an individual's preference to avoid disruption of "goaldirected functioning" (De Young, 2010, p. 27). The desire to avoid disruption resembles the desire to maintain the status-quo that is inherent in MCM. Therefore, it is expected that stability will be positively correlated to MCM (medium effect size). Plasticity refers to an individual's tendency to generate new goals, to develop new interpretations of the status-quo and to develop new strategies to reach current goals. Plasticity resembles MCE in the sense that both constructs encompass the tendency to turn outward to broaden one's horizon. Therefore, is expected that plasticity will be positively correlated to MCE (medium effect size).

\section{Method}

\section{Procedure}

An online questionnaire (including an information- and debriefing sheet) based on SurveyMonkey technology was conducted. As inclusion criteria, the participants were non-refugee immigrants in New Zealand who came to the country as adults (at least 18 years old), who have lived in New Zealand for at least six months and resided in New Zealand at the time when the survey was conducted. Participation was anonymous and no incentives were given to the respondents. It took about 20 minutes to complete the questionnaire that was administered in the English language only. Since the questionnaire was set-up in a way that respondents had to answer every question in order to proceed to the next one, there are no missing data in the data set. Appendix B presents the information sheet, the questionnaire and the debriefing sheet. 


\section{Participants}

In total 333 participants responded to the survey. However, 50 responses had to be deleted from the dataset because the respondents did not complete the demographic questions and answers to questions about residency in New Zealand. Hence it was impossible to determine if they fulfil the inclusion criteria. Of the remaining 283 responses another three were excluded from the analysis because they did not fulfil the criteria for participation or gave improbable responses to the demographic questions. Consequently, 280 complete response sets were obtained. These participants came from 53 different countries. The eight largest immigrant groups (as per 'country of birth') were from Germany $(n=32)$, the UK $(n=31)$, Finland $(n=$ 19), Argentina, India and South Africa ( $n=18$ each), the Netherlands $(n=17)$ and the USA $(n=15)$. Appendix C provides a full sample overview.

The sample was composed of 181 women (64.6\%) and 99 men (35.4\%) and the average age was 39.28 years $(S D=10.31 ; \min =19 ; \max =90)$. On average the participants had lived in New Zealand for 8.11 years $(S D=8.85$; $\min =0.6$; $\max =$ 65). The sample consisted of 82 native English speakers and 198 participants who have English as a second language. The question "What is your native language?" was not asked in the questionnaire, so this information was based on their country of birth.

The majority of the participants (57.7\%) self-identified as European. Equally large groups had either no religious affiliation or were of Christian belief (41.1\% each). Appendix D gives a more detailed overview of the ethnic and religious composition of the sample. Furthermore, the sample included 21 international students and 244 respondents were citizens of countries other than New Zealand (i.e. 36 had obtained New Zealand citizenship). The majority of respondents (77.1\%) stated that they want to stay in New Zealand indefinitely.

Recruitment. The participants were recruited by snowball sampling. For that purpose I used my own network of migrants to pass on the link to the online survey. Organisations, such as the Office of Ethnic Affairs (OEA), the Multicultural Services Centre in Wellington and the Wellington Council of Social Services (WELCOSS) passed the link on to members of their network. Furthermore, the link was published on the websites of several organisations that work with migrants in New Zealand (i.e., Multicultural Services Centre Wellington, Community Sector Taskforce Wellington, 
New Zealand Federation of Multicultural Councils), as well as on the Diversity Issues website, in the online newsletters of the OEA and of Immigration New Zealand.

The link was also posted in the social networking sites Facebook and X-ing, as well as in an online forum for South African migrants ("SA going to NZ"). Moreover, I sent the link via email to a number of migrant community organizations who had previously agreed to pass my request on to their members (e.g., Afghan Association of Wellington, Assyrian Community, Auckland Finnish Society, Auckland Welsh Society). I also joined the Aotearoa Ethnic Network (AEN) that distributes relevant emails to approximately 500 listed members. The German Goethe-Society and two language clubs (Spanish and Italian) in Wellington, as well as a number of Embassies and High Commissions forwarded the link to their networks.

\section{Materials}

The questionnaire included demographic items, such as length of stay in New Zealand, ethnicity, country of origin, age, gender and religious affiliation, as well as measures of the three main constructs of interest, described below.

\section{Cultural maintenance and cultural exploration.}

\section{Motivation for Cultural Maintenance, Motivation for Cultural Exploration.}

The 9-item Motivation for Cultural Maintenance (MCM) Scale and the 8-item Motivation for Cultural Exploration (MCE) Scale were used (as outlined in Study 1). Additionally, as explained earlier, the following four criterion measures were used to assess the validity of the MCM and MCE scales.

Motivation for Ethnocultural Continuity. The Motivation for Ethno-Cultural Continuity Scale (Gezentsvey, 2008) consists of ten items. Items are, for example, "Continuing to practice my ethnic traditions and celebrations it important to me". The responses are rated on a 7-point scale ranging from 1 (strongly disagree) to 7 (strongly agree). Higher scores indicate a higher motivation for ethnocultural continuity.

Cultural Intelligence. The motivational subscale of the Cultural Intelligence Scale was used (Ang et al., 2007). This subscale consists of five statements, such as, "I enjoy interacting with people from different cultures". The responses are rated on a 7-point scale ranging from 1 (strongly disagree) to 7 (strongly agree). Higher scores indicate higher motivational cultural intelligence. 
Multicultural Personality Questionnaire. Of the fourteen items from various subscales of the Multicultural Personality Questionnaire (van der Zee \& Van Oudenhoven, 2000) that were included in the survey, seven items from the openmindedness subscale were used in the analysis. Statements are, for example, "Is interested in other cultures", and "Finds other religions interesting". Furthermore, five items from the flexibility subscale were used. Statements are, for example, "Enjoys unfamiliar experiences", and "Looks for regularity in life (R)". The responses are rated on a 4-point scale ranging from 1 (hardly applicable) to 4 (completely applicable). Higher scores indicate higher flexibility and openness.

Plasticity and Stability. Five items each measuring the Big Five meta-traits of stability and plasticity (DeYoung, 2010) were included in the questionnaire. Items are, for example, "Find life difficult" (stability) and "Look forward to the opportunity to learn and grow" (plasticity). The responses are rated on a 4-point scale ranging from 1 (hardly applicable) to 4 (completely applicable). Higher scores indicate higher plasticity and flexibility respectively.

2. Acculturation behaviours. The acculturation behaviours were operationalised following previous research (Phinney et al., 2006; Gardner, Winkleby, \& Viteri, 1995; Marín \& Gamba, 1996; Carrus, Nenci, \& Caddeo, 2009, Sutton-Brady, Davis, \& Jung, 2010; Laroche, Kim \& Tomiuk, 1998). First, cultural maintenance behaviours were operationalised as the frequency of ethnic peer contact, ethnic language proficiency and frequency of use, native media use, and a preference for ethnic food. Second, cultural exploration behaviours were operationalised as the frequency of national peer contact, national language proficiency and frequency of use, English media use, and a preference for national food.

Maintenance behaviour is thus operationally defined as the behaviour that results from cultural maintenance motivation, which drives individuals to keep an enduring link to their cultural heritage to uphold a stable psychosocial organisation. Exploration behaviour, on the other hand, is the behaviour that results from cultural exploration motivation and is geared towards participation in and exploration of the host culture and the incorporation of newly gained knowledge into the psychosocial organisation. Both acculturation behaviours were measured with items from existing studies that have been chosen to reflect the operationalisations. The specific items are described below and were adjusted to the context of the present study when necessary. 
Frequency of interaction with ethnic and national peers. I used Part F of the Immigrant Adolescent Questionnaire (Vedder \& Van de Vijver, 2006) to measure the frequency of interaction with ethnic and national peers. It consists of five questions with three sub-questions each, for example, "How often do you spend time at work with- ... a) ethnic members, b) national members, and c) other ethnic members?". Answers are rated on a 5-point scale, ranging from 1 (almost never) to 5 (almost always). Higher scores indicate more interaction with ethnic members, national members and other ethnic members.

Native and English language proficiency and frequency of use. I used 8 items of Part B of the Immigrant Adolescent Questionnaire (Vedder \& Van de Vijver, 2006) to assess ethnic and national language proficiency. A sample item is "How well do you a) understand, b) speak, c) read, and d) write the ethnic language?" The responses are rated on a 5-point scale ranging from 1 (not at all) to 5 (very well). Higher scores indicate higher proficiency.

The two items used to assess the frequency of ethnic language use ("[At home] I speak my ethnic language.”) and national language use (“[At home] I speak English.”) were rated on a 5-point scale ranging from 1 (not at all) to 5 (all the time). Higher scores indicate higher frequency of use.

Ethnic and English media use. Questions to assess ethnic and national media use were derived from Laroche et al.'s (1998) approach to measure mass-media exposure. The authors asked participants to estimate the percentage of times they use their ethnic language and the national language when watching television, listening to the radio, reading newspapers, magazines or books. The items were adjusted and questions were, for example, "How often do you watch television programs in English?". Additionally, items from the electronic media subscale of the Bidimensional Acculturation Scale for Hispanics (Marín \& Gamba, 1996) were adjusted. A sample item is "When reading books I read them in my native language." The responses are rated on a 5-point scale, ranging from 0 (almost never) to 5 (always).

Food preferences. The single-item measure to assess food preferences was taken from the Acculturation Scale for Mexican Americans (ARMSA) (Cuellar, Harris, \& Jasso, 1980). Respondents can select their food preference from five options, ranging from "Exclusively from my native country" to "Mostly from my host country". 
Despite the inclusion of these measures, in all future analyses, only national and ethnic peer contact will be used as indicators for acculturation behaviours for two main reasons. First, and perhaps most importantly, the inclusion of all these questions would mean a reduction in sample size of approximately 30\% (from 280 to 198 participants) due to questions that refer to the use of the English language (i.e., media use, language use, language proficiency) that are not applicable for native English speakers. The reason for this is that questions such as "How well do you understand your ethnic language?" and "How well do you understand English?" are not relevant for participants whose ethnic, first language is English (e.g., participants from the UK). If these questions are excluded, however, the full sample can be considered in further analyses because it is irrelevant for the national and ethnic peer contact indicator whether participants are native English speakers or have English as a second language.

Finally, as outlined in the introduction, there is ample theoretical and empirical support in the acculturation literature about the high relevance of social support from both national and ethnic peers for positive acculturation outcomes (e.g., Finch \& Vega, 2003; Oppedal, Røysamb, \& Lackland Sam, 2004; Ward \& Kennedy, 1994; Ward, Bochner, \& Furnham, 2001). The extant literature thus suggests that national and ethnic peer contacts are very important during the acculturation process. Interested readers can find descriptive information about the other acculturation behaviours in Appendix E. The correlations between the scales are presented in Appendix F.

3. Psychological and sociocultural adaptation. To assess the participants' adaptation to the host culture, their psychological and sociocultural adaptation was measured (Sam et al., 2006; Ward et al., 2001; Wilson \& Ward, 2010).

Psychological wellbeing. Psychological wellbeing was measured using the Satisfaction With Life Scale (SWLS) that assesses people's judgments of their own life satisfaction (Diener, Emmons, Larsen, \& Griffin, 1985). The SWLS is a 5-item inventory with questions such as "In most ways my life is close to my ideal" and "The conditions of my life are excellent". The responses are rated on a 7-point scale ranging from 1 (strongly disagree) to 7 (strongly agree), so that higher scores indicate higher satisfaction with life.

To measure participants' and emotional wellbeing the WHO (Five) WellbeingIndex (1998 version, WHO, 1998) was used. It is a 5-item questionnaire with 
questions such as "Over the last two weeks I have felt cheerful and in good spirits" and "Over the last two weeks I woke up feeling fresh and rested". The responses are rated on a 5-point scale ranging from 1 (at no time) to 5 (all of the time), so that higher scores indicate higher emotional wellbeing.

Sociocultural Adaptation. The participants' sociocultural adaptation was assessed using the Revised Sociocultural Adaptation Scale (SCAS-R, Wilson \& Ward, 2010). The 21-item inventory includes items such as, "Building and maintaining relationships" and "Maintaining my hobbies and interests". Responses are rated on a 5-point scale ranging from 1 (not at all competent) to 5 (extremely competent), so that higher scores indicate higher sociocultural adaptation.

\section{Results}

First, the normal distribution of the data will be evaluated. Second, the descriptive statistics of the scales used in the present study will be presented. Third, the validity of the MCM/MCE scales will be assessed. Lastly, the relationships between the MCM, MCE, acculturation behaviour of maintenance and exploration and psychological and sociocultural adaptation will be investigated using a structural equation modeling approach.

\section{Testing for Normal Distribution}

The relationships between the main constructs in this study will be investigated using structural equation modeling (SEM). According to Byrne (2010), it is a requirement for SEM that the data have a multivariate normal distribution. Two measures of normal distribution are the skewness and kurtosis statistics. Skewness refers to the symmetry of the distribution, whereas kurtosis refers to the 'peakedness' of the data. The further the values of skewness and kurtosis are away from zero, the more likely it is that the data are not normally distributed (Field, 2009). Curran, West and Finch (1996) proposed that skewness exceeding 2.0 and kurtosis exceeding 7.0 are problematic for SEM analyses. The results of the skewness and kurtosis statistics are presented in Appendix G. Overall, the results support the normality assumption of the variables. In other words the responses are distributed in such a way that SEM can be applied. 


\section{Descriptive Statistics of the Scales}

Descriptive statistics are presented in Table 6. The reliability of both MCM and MCE scales was acceptable with Cronbach's alphas higher than .80. Most scales also had Cronbach's alpha equal or higher than the recommended .70 value (Nunnally, 1978). Two scales had alphas close to .60 which might be due to their number of items. Cheek and Briggs (1982) proposed that an alpha coefficient of .63 for a 5-item scale seems appropriate. To explore the reliability further, the inter-item correlations of these two scales were investigated, as suggested by Cortina (1993, cited in Field, 2009). According to Field (2009), inter-item correlations larger than .3 are acceptable. Cheek et al. even considered an inter-item correlation of .26 acceptable for short scales. The inter-item correlations are presented in Appendix H. The results revealed that all but two inter-item correlations are above the acceptable value of .3. For one item of the ethnic peer contact scale it was above .26 and thus kept, but for item 3 of the flexibility scale ("Feels uncomfortable in a different culture", reverse coded) it was below .26 and this item was excluded from further analyses. Overall, the Cronbach's alpha and the inter-item correlations indicate that the scales used in the present study are sufficiently reliable.

Table 6

Descriptive Statistics $(N=280)$

\begin{tabular}{|c|c|c|c|c|}
\hline Scale & No. of items & $\alpha$ & $M$ & SD \\
\hline \multicolumn{5}{|l|}{ Exploration/Maintenance } \\
\hline MCM Scale & 9 & .90 & 4.65 & 1.19 \\
\hline MCE Scale & 8 & .87 & 6.07 & .72 \\
\hline Motivation Ethnocultural Continuity (MEC) Scale & 10 & .93 & 4.91 & 1.19 \\
\hline Cultural Intelligence Scale & 5 & .79 & 5.86 & .74 \\
\hline MPQ - Openmindedness subscale & 7 & .81 & 2.80 & .59 \\
\hline MPQ - Flexibility subscale & 5 & .56 & 2.96 & .48 \\
\hline Stability & 8 & .80 & 1.46 & .46 \\
\hline Plasticity & 8 & .81 & 3.08 & .52 \\
\hline \multicolumn{5}{|l|}{ Behaviours } \\
\hline Ethnic Peer Contact & 3 & .61 & 3.09 & .88 \\
\hline National Peer Contact & 3 & .70 & 3.83 & .80 \\
\hline \multicolumn{5}{|l|}{ Adjustment } \\
\hline WHO 5 Wellbeing Index & 5 & .87 & 3.69 & .77 \\
\hline Satisfaction with Life Scale & 5 & .89 & 5.29 & 1.17 \\
\hline Revised Sociocultural Adaptation Scale & 21 & .91 & 4.08 & .49 \\
\hline
\end{tabular}

Note: $\mathrm{M}=$ mean item scores; MPQ = Multicultural Personality Questionnaire

${ }^{\text {a }}$ Scale contains only one item 


\section{Validity of MCM and MCE Scales}

Similar to Study 1 but with a larger sample $(N=280)$, the correlations between the MCM and MCE scales and related constructs were investigated to assess the validity of the newly developed scales. Results are presented in Table 7.

Correlation between MCM and MCE. Similarly to Study 1, but not as strong, there was a positive correlation between MCM and MCE. Again, this result does not support the hypothesis that the scales are orthogonal. However, the positive correlation indicates that they are not on opposite ends of the same continuum but that people can be high on maintenance motivation and exploration motivation at the same time as originally proposed.

Correlations with MCM. The correlation between MCM and the stability items are in the expected direction, albeit very weak and statistically non-significant. Furthermore, the correlation between MCM and motivation for ethnocultural continuity is in the expected direction, but it is stronger than anticipated (.82), which suggests a high conceptual overlap between the constructs. To further examine whether MCM and ethnocultural continuity account for non-overlapping variance in maintenance behaviour, multiple regression analyses were performed. In the first step, ethnocultural continuity was entered as a predictor of maintenance behaviour (Adjusted $\mathrm{R}^{2}=.001$ ); in the second step MCM was added (Adjusted $\mathrm{R}^{2}=.012$ ). Adding MCM thus yielded a significant $\mathrm{R}$ square change $\left(\mathrm{R}^{2}\right.$ change $\left.=.015, p<.05\right)$. In other words, MCM predicts maintenance behaviour over and above ethnocultural continuity. Conversely, the R square change was not significant when MCM is entered in the first step and ethnocultural continuity is entered in the second step $\left(\mathrm{R}^{2}\right.$ change $=.00, \mathrm{p}>.05)$. These results support the assumption that even though MCM and ethnocultural continuity are highly related, they are not the same, i.e., MCM includes a domain that is not captured by motivation for ethnocultural continuity. 
A Dual-Process Motivational Model of Cross-Cultural Adaptation

Table 7

Correlations between the MCM and MCE Scales and Criterion Measures $(N=280)$

\begin{tabular}{|c|c|c|c|c|c|c|c|c|}
\hline & MCM & MCE & MEC & CQS & $\begin{array}{l}\text { MPQ- } \\
\text { OM }\end{array}$ & $\begin{array}{l}\text { MPQ- } \\
\text { Flex }\end{array}$ & Stability & Plasticity \\
\hline MCM & - & $.30 * *$ & $.82 * *$ & $.13 *$ & $.13^{*}$ & -.30 & .04 & -.03 \\
\hline MCE & & - & $.31 * *$ & $.63 * *$ & $.64 * *$ & $.30 * *$ & .05 & $.24 * *$ \\
\hline MEC & & & - & $.14^{*}$ & $.13^{*}$ & $-.26 * *$ & .01 & .01 \\
\hline CQS & & & & - & $.66^{* *}$ & $.34 * *$ & $-.13 *$ & $.35^{* *}$ \\
\hline MPQ-OM & & & & & - & $.37 * *$ & -.10 & $.51 * *$ \\
\hline MPQ-Flex & & & & & & - & -.11 & $.30 * *$ \\
\hline Stability & & & & & & & - & -.08 \\
\hline Plasticity & & & & & & & & - \\
\hline
\end{tabular}

$* \mathrm{p}<.05 \quad * * \mathrm{p}<.01$

Note . MEC $=$ Motivation for Ethnocultural Continuity; $\mathrm{CQS}=$ Motivational Subscale of

Cultural Intelligence Scale; MPQ-OM = Multicultural Personality Questionnaire

openmindedness subscale; MPQ-Flex = Multicultural Personality Questionnaire flexibility

subscale

Correlations with MCE. The correlation coefficients between MCE and plasticity scores, the cultural intelligence motivational subscale, openmindedness and flexibility are statistically significant and in the expected direction. Although the correlations with cultural intelligence and openmindedness are higher than expected $(r$ $>$.60), the results provide support for the expected pattern of associations.

Overall, the results provide some preliminary evidence for convergent validity between of the MCE scale and its criterion measures. However future research is needed to confirm these findings and to further investigate the validity of the MCM scale.

\section{Confirmatory Factor Analysis (CFA) for MCM and MCE Scales}

CFA was conducted for the MCM and MCE scale using IBM AMOS 19 statistical software. It has been suggested that multiple criteria should be used to assess the goodness-of-fit of SEM models (e.g., Hu \& Bentler, 1999). For this reason, four indices were investigated in the present study: Tucker-Lewis Index (TLI), Comparative Fit Index (CFI), Root Mean Squared Error of Approximation (RMSEA) and the ratio between the chi-square and the degrees of freedom $\left(\chi^{2} / \mathrm{df}\right)$. Cut-off 
values close to and above .95 for TLI and CFI are indicative of good model fit (Hu \& Bentler, 1999). For RMSEA a value lower than .08 suggests a good fit (Jöreskog \& Sörbom, 1993, cited in Martín-Albo, Núñez, Navarro, \& Grijalvo, 2007). A $\chi^{2} / d f$ ratio lower than 5 suggests an approximately good fit (Marsh \& Hocevar, 1985) and a ratio in the 2-3 range indicates acceptable fit (Carmines \& McIver, 1981).

CFA revealed that the hypothesised 2-factor model did not have a very good fit to the data, $\chi^{2}(n=280, d f=118)=348.20, p=.000$; TLI $=.892$; CFI $=.906$; RMSEA $=$ $.084 ; \chi^{2} / \mathrm{df}=2.95$. Based on modification indices, which are used to modify models to improve the fit (MacCallum, 1995), a covariance between two items of the MCM scale was added. However, in general, modifications to the model need to be justifiable. In this model the added covariance is understandable, given the similar wording of the items (item MCM_2: "socialise with people who share my cultural heritage"; Item MCM_4: "meet people who share my cultural heritage"). The resulting model is depicted in Figure 3, and has an acceptable fit to the data, $\chi^{2}(n=$ $280, d f=117)=309.41, p=.000 ; \mathrm{TLI}=.909 ; \mathrm{CFI}=.921 ; \mathrm{RMSEA}=.077 ; \chi^{2} / \mathrm{df}=$ 2.64. All factor loadings were significant at $p<.001$ and the standardised loadings ranged from a low .40 to a high .85 . 


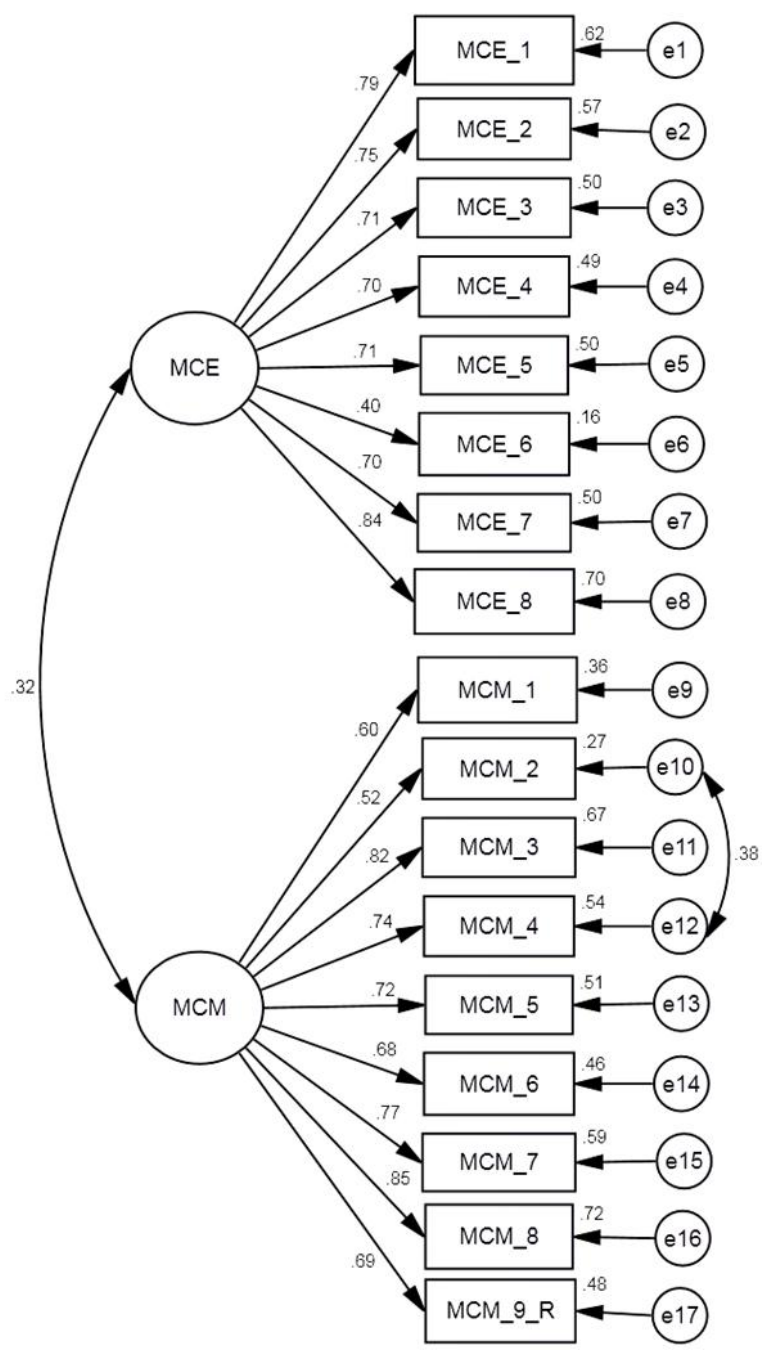

Figure 3: Two-factor model of MCM and MCE scales

\section{Model Testing with Structural Equation Modeling (SEM)}

Finally, the predictive relationships between the constructs in the proposed model were explored by conducting path analyses using the SEM program IBM AMOS 19.

Item parcelling. First, items of the MCM, MCE and SCAS-R scales were parcelled. Creating parcels of items has some advantages over item-level data. For example, item parcelling creates more parsimonious models; second, it is less likely that residuals are correlated or that double loadings occur; third, sources of sampling error are reduced because fewer parameters need to be calculated in the model (Little, Cunningham, Shahar \& Widaman, 2002; MacCallum, Widaman, Zhang \& Hong, 1999). Three parcels for each of the MCM and MCE scales were created. Each parcel contains three items, with the exception of the third parcel of the MCE scale, which 
only contains two items. Items were parcelled in the order in which they appear on the scale, except for the two MCM-items that covaried; these were put in the same parcel. Moreover, three parcels were created for the 21 items of the SCAS-R scale. Each parcel contains seven items, and they were parcelled in the order in which they appear on the scale.

Testing the model components. As depicted in Figure 2, there are two main pathways of association. One pathway links MCM to behaviour of maintenance (i.e., ethnic peer connections), which in turn is linked to psychological adaptation. The second pathway links MCE to behaviours of exploration (i.e., national peer connections) and the behaviour in turn to sociocultural adaptation. In the first step of the SEM analyses the fit of the two main pathways of association were tested separately. First, the partial model consisting of maintenance motivation, ethnic peer connections and psychological adaptation fitted the data well (see Appendix I). In this model the path between ethnic peer connections and psychological adaptation was marginally significant $(\beta=.29 ; p=.051)$ and maintenance motivation did not directly predict psychological adaptation. That is, the influence of maintenance motivation on psychological adaptation happens via ethnic peer connections. The findings provide partial support for the predicted model.

Second, the partial model consisting of exploration motivation, national peer connections and sociocultural adaptation also fitted the data well (see Appendix J). In this model exploration motivation did not predict national peer connections but had a direct effect on sociocultural adaptation $(\beta=.25, p<.001)$. Thus, the proposed mediation model was not supported, and both exploration motivation and national peer connections had a direct effect on sociocultural adaptation.

Testing the full model. Next, the two pathways of associations (i.e., maintenance and exploration as outlined above) were combined in one single model. The nonsignificant paths that were found in the previous analyses were dropped. However, the marginally significant path between ethnic peer connections and psychological adaptation was kept because of its theoretical relevance and the moderately high beta. Additionally, the following cross-relationships were investigated: maintenance motivation $\rightarrow$ national peer connections; exploration motivation $\rightarrow$ ethnic peer connections; maintenance motivation $\rightarrow$ sociocultural adaptation; exploration motivation $\rightarrow$ psychological adaptation; ethnic peer connections $\rightarrow$ sociocultural adaptation; national peer connections $\rightarrow$ psychological adaptation. The resulting 
model (Appendix K) fits the data reasonably well (see Model 1 in Table 8). Only one of the six cross-relationships was significant: national peer connections also predicted psychological adaptation $(\beta=.60, p<.001)$. In contrast to the partial model, the relationship between ethnic peer connections and psychological adaptation reached significance in this model $(\beta=.19, p<.05)$.

The next and final model tested is depicted in Figure 4. It was based on the assumption that sociocultural adaptation leads on to psychological adaptation, as was found by Vedder et al. (2006) and mentioned in the introduction. The previously nonsignificant paths were dropped. The resulting model fit the data well (Model 2 in Table 8).

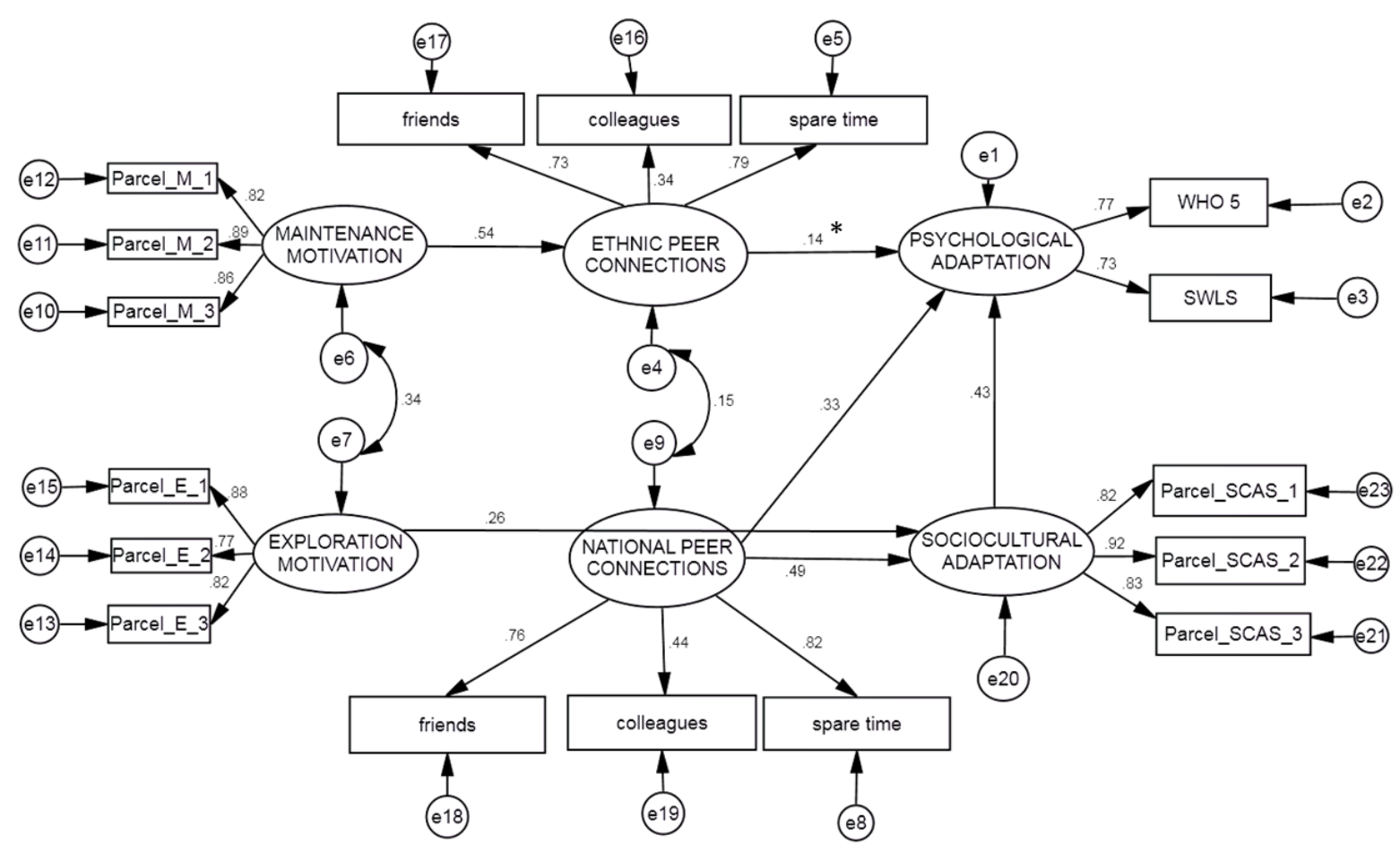

$* \mathrm{p}=.048$; all other paths significant at .001 level

Note: $n=280$. Standardised regression coefficients (betas) are presented to indicate the strength of relationships.

Figure 4: Final structural equation model testing the strength of the relationships between maintenance/exploration motivation, peer connectedness and adaptation

The model depicted in Figure 4 provides overall support for the predicted theoretical model. First, maintenance motivation predicts cultural maintenance behaviour (i.e., ethnic peer connections), which in turn predicts psychological adaptation (albeit weakly). Second, exploration motivation predicts sociocultural 
adaptation, which in turn predicts psychological adaptation. Contrary to expectations, however, exploration motivation does not directly predict cultural exploration behaviour (i.e., national peer connections). Third, cultural exploration behaviour (i.e., national peer connections) is predictive of sociocultural adaptation and, fourth, predicts psychological adaptation directly.

Table 8

Fit Indices for Alternative Models Testing the Relationships between

Maintenance/Exploration Motivation, Peer Connectedness and Adaptation

\begin{tabular}{lllllll}
\hline & $\chi^{2}$ & $\mathrm{df}$ & TLI & CFI & RMSEA & $\chi^{2} / \mathrm{df}$ \\
\hline Model 1 & 237.13 & 107 & .924 & .940 & .066 & 2.22 \\
Model 2 & 214.73 & 111 & .941 & .952 & .058 & 1.93
\end{tabular}

Note: RMSEA = Root mean square error of approximation; TLI = Tucker-Lewis Index; CGI

$=$ Comparative Fit Index

Mediating effects. The final model suggests that there may be three mediating (i.e., indirect) effects: (1) the relationship between MCM and psychological adaptation may be mediated by ethnic peer connections, and (2) sociocultural adaptation may mediate the relationship between MCE and psychological adaptation, and between (3) national peer connections and psychological adaptation. The Monte Carlo parametric bootstrap with 500 bootstrap samples in AMOS was used to test whether these indirect effects were statistically significant. The results are presented in Table 9. All indirect effects from the bootstrap analyses were positive and statistically significant with $95 \%$ confidence interval excluding zero, which indicates a significant mediation effect (Zhao, Lynch, \& Chen, 2010). First, there is an indirect effect of maintenance motivation on psychological adaptation through ethnic peer connections. Second, there is an indirect effect of exploration motivation on psychological adaptation through sociocultural adaptation. Moreover, an indirect effect of national peer connections on psychological adaptation through sociocultural adaptation was observed. 
Table 9

Mediation Effects in the Final Model

\begin{tabular}{lccccc}
\hline & $\begin{array}{c}\text { Indirect } \\
\text { effect }\end{array}$ & $S E$ & Lower CI & Upper CI & $p$ \\
\hline MCM $\rightarrow$ Psychological adaptation & .08 & .04 & .01 & .16 & .032 \\
MCE $\rightarrow$ Psychological adaptation & .11 & .04 & .05 & .20 & .002 \\
National peer connections $\rightarrow$ & .21 & .05 & .13 & .32 & .001 \\
Psychological adaptation & & & & &
\end{tabular}

Note: $\mathrm{CI}=$ Confidence Interval

\section{General Discussion}

The ultimate purpose of the present research was to shed light on an underresearched field in the psychological acculturation literature. Are the behaviours and ultimately the adaptation outcomes of migrants influenced by their motivation to maintain their heritage culture and by their motivation to explore the culture of their new country of residence? To my best knowledge, these motivations have not been investigated in previous research. However, as outlined in the introduction, these motivations appear to be grounded in other motivational drives, such as the need for understanding, the need to belong and the need to self-enhance. Furthermore, the dimensions of maintenance and exploration seem to be almost ubiquitous in the psychological literature and have a clear link to the proposed motivations. Therefore, the first aim of this research was to develop measurement scales for the proposed constructs of motivation for cultural maintenance (MCM) and motivation for cultural exploration (MCE) so that the research question could be addressed.

The second aim was to use the newly developed scales to investigate the relationships between migrants' motivation to maintain their heritage culture, motivation to explore the culture of their host country, acculturation behaviours and adaptation outcomes, thereby testing if the proposed motivations have any predictive power. A dual-process motivational model was proposed in which the motivation for cultural maintenance and the motivation for cultural exploration impact acculturation behaviours, which in turn impact sociocultural and psychological adaptation. 


\section{MCM and MCE scales}

For the purpose of measuring the proposed motivations, items for the MCM scale and the MCE scale were developed. After preliminary analyses of the psychometric characteristics of the data in Study $1(n=50)$ nine items were selected for the MCM scale and eight items for the MCE scale. Both scales had acceptable internal reliability to be used in the second study. The internal reliability of both scales was confirmed and confirmatory factor analysis supported the proposed two-factor model in Study 2.

Furthermore, the results of Study 2 revealed that the MCM and MCE scales are moderately positively correlated. Therefore, Hypothesis 1 (i.e., the two scales are orthogonal) was not confirmed. However, it still means that individuals can have high maintenance and high exploration motivation at the same time as originally proposed. An explanation for this finding, as suggested earlier, might be that in New Zealand, where policies supporting multiculturalism exist, migrant and host national cultural orientations are not opposed to each other. Broadly speaking, in this environment migrants have the opportunity to maintain their cultural heritage while exploring New Zealand culture at the same time. This is the strategy that Berry (1997) referred to as 'integration'. Past research has shown that this is indeed the preferred strategy of most migrants, including those in New Zealand (Phinney et al., 2006), if the context of the new country of residence permits it.

Preliminary evidence of convergent validity for both the MCM and MCE scales was established in Study 2. First, the MCM scale was strongly correlated to a measure of motivation for ethnocultural continuity (Getzensvey \& Ward, 2008), but at the same time the MCM scale explained additional variance over and above motivation for ethnocultural continuity. Similarly, the MCE scale was correlated to related constructs, including the motivational subscale of the Cultural Intelligence Questionnaire (Ang et al., 2007), and the openmindedness- and flexibility subscales of the Multicultural Personality Questionnaire (van der Zee \& Van Oudenhoven, 2000).

\section{The Relationships between MCM/MCE, Acculturation Behaviour and} Adaptation.

Overall, SEM analysis revealed that the proposed dual-process model was largely supported by the data. MCM predicted cultural maintenance behaviour (i.e., ethnic peer connections), which in turn predicted psychological adaptation. MCE however, did not predict cultural exploration behaviour (i.e., national peer connection), but it 
predicted sociocultural adaptation directly. Furthermore, cultural exploration behaviour was predictive of both sociocultural adaptation and psychological adaptation. Therefore, I draw the careful conclusion that the two proposed motivations have predictive power and the potential to contribute to the existing acculturation literature. Below I first discuss the specific findings between the pairs of variables and then turn the attention to the full model.

MCM/MCE and acculturation behaviours. As expected and in line with Hypothesis 2.1., MCM predicted cultural maintenance behaviour (i.e., ethnic peer connections) which indicates that migrants with a high motivation to maintain their heritage culture tend to socialise with ethnic peers. In other words, this result suggests that the motivation to preserve one's heritage culture influences who migrants socialise with. Baumeister and Leary (1995) proposed that people are motivated to form bonds with those who they have something in common with and with whom they share experiences. This finding may further explain the link between MCM and ethnic peer connections: MCM may be an expression of the need of migrants to belong to a familiar group in an unfamiliar cultural setting. Migrants and peers from the same cultural background potentially share the same understanding of their environment and building relationships with people who had the same or similar migration experience may be easier than forming relationships with those who do not share that experience. Furthermore, the ethnic peer group can be a safe haven from which to operate and also a place where cultural traditions can be expressed (e.g. through traditional dance and music).

Unexpectedly, and not in line with Hypothesis 2.2, MCE was not found to predict cultural exploration behaviour (i.e., national peer connections). A potential explanation for this finding can be derived from research by Masgoret, Bernaus and Gardner (2000) who investigated a temporal aspect of adaptation. The researchers found that the adjustment of English sojourners in Spain increased in as little as four weeks. Furthermore, Masgoret and Ward (2006) found that the sociocultural learning curve has the steepest increase in the first four to six months of the acculturation experience and then levels off towards the end of the first year. The participants of the present study had been in New Zealand for approximately eight years on average at the time when the study was conducted. Taking Masgoret et al.'s findings into account, it is possible that by that time their sociocultural learning had progressed to a level where they did not need to seek national peer contact to facilitate their 
sociocultural learning. It seems intuitively plausible that social networks are established after eight years of living in a new country and that by this time the sociocultural learning curve has long levelled off. The motivation of migrants to explore the new cultural setting may not be expressed anymore in building relationships with host nationals; instead this behaviour may be more typical in the early stages of arrival.

Furthermore, it is possible that the migrants were motivated to establish contacts to host nationals, but that the host nationals were not very open to that. For example, research has shown that $70 \%$ of international students in New Zealand wished they had more friendships with New Zealanders but less than $50 \%$ believed that New Zealanders had favourable views about them (Ward \& Masgoret, 2004).

Even though the path between MCE and national peer connections was nonsignificant in the final model, it seems that MCM and MCE may lead to different patterns of intergroup contact. The cross-relationships between MCM and national peer connections (i.e., exploration) and between MCE and ethnic peer connections (i.e., maintenance) were non-significant (see Appendix K), which means that the motivation to maintain culture does not predict socialising with host-nationals and the motivation to explore the host culture does not predict socialising with ethnic peers. In other words, the lack of cross-relationship suggests that MCM is not related to whether migrants do or do not seek contact with host nationals. Similarly, MCE does not appear to predict whether migrants do or do not seek contact with ethnic peers. In the present study, the findings indicate that motivations to maintain and to explore may lead to very specific maintenance and exploration behaviours, with each motivation predicting one type of behaviour but not the other. These findings largely support the proposed dual-process model, as discussed in more detail below.

The predictors of psychological and sociocultural adaptation. As predicted in Hypothesis 3.1 and 3.2, there were positive paths between the acculturation behaviours and adaptation. More specifically, first, ethnic peer connections predicted psychological adaptation (i.e., life satisfaction and emotional wellbeing as measured by the Satisfaction with Life Scale and the WHO-5 Wellbeing Index, respectively). Therefore, the overall findings relating to the top-part of the proposed model (Figure 4) suggest that migrants who are high on MCM tend to socialise with ethnic peers, and this in turn affects their satisfaction with life and their emotional wellbeing. This 
finding is relevant because, for example, high life satisfaction has been linked to positive physical and mental health outcomes (Pavot \& Diener, 2008).

Second, national peer connections predicted sociocultural adaptation.

Sociocultural adaptation, as measured by the Revised Sociocultural Adaptation Scale, refers to migrants' ability to negotiate life in the new country. The finding therefore suggests that migrants who have contacts with host nationals may have developed a higher ability to 'fit in', which means that they have fewer sociocultural adaptation problems and higher behavioural competence in the new cultural setting. Through interactions with host nationals they have the opportunity not only to learn the rules of social interactions in the host country, but also to understand unfamiliar cultural values. A recent meta-analysis of 66 studies supports this finding. The results suggested that the quantity of contact with host nationals, rather than the quality of those contacts, is a predictor of sociocultural adaptation (Wilson, Ward, \& Fischer, 2012).

Third, national peer connections also predicted psychological adaptation. Considering that making friends and acquaintances with host nationals may give migrants the feeling of being more settled and more at home in their new country of residence, this finding makes intuitive sense. Empirical support was also obtained by Jasinskaja-Lathi, Liebkind, Jaakkola and Reuter (2006). The researchers stressed the importance of active contact with host nationals for the psychological wellbeing of immigrants. In a sample of immigrants of Russian, Estonian or Finnish descent who migrated to Finland, they found that little contact with host nationals predicted higher anxiety levels, whereas more active contact with host nationals predicted lower levels of depression. Thus little contact with host nationals negatively impacted psychological wellbeing, whereas more contact with host nationals positively impacted psychological wellbeing.

Generally, these linkages are reflected in previous research. There appears to be agreement in the literature that social support in general is an important predictor of successful adaptation overall (Berry, 2006), potentially because it protects individuals against the adverse effects of stress that is inherent in moving to a foreign country (Searle \& Ward, 1990). Both national and ethnic peers provide social support networks; however, they are likely to provide different kinds of support. Broadly speaking, ethnic peers appear to provide the safe familiar environment that increases psychological wellbeing (stress and coping framework), whereas national peers are 
more likely to provide informational support that enables migrants to learn the rules of the host society (social learning framework) (Searle \& Ward, 1990). However, and in line with previous research, the present study found that contact with host nationals is beneficial not only for culture learning and 'fitting in' but also emotional wellbeing and migrants' satisfaction with their lives in the host society.

However, contrary to expectations, ethnic peer connections only weakly predicted psychological adaptation. It is possible that the relationship between ethnic peer connections and psychological adaptation is confounded by two characteristics of the present sample. First, a considerable proportion of the participants' countries of origin are quite similar to New Zealand in some cultural dimensions. For example, Hofstede (2001) suggested that Australia, Finland, Germany, Ireland, Israel, the Netherlands, the UK and the USA (i.e., $44 \%$ of participants of the current study) score similarly to New Zealand in terms of high individualism and low power distance. It is possible that ethnic peer connections do not contribute that much to psychological wellbeing, if the host culture is similar to the heritage culture. Therefore, ethnic peer contact may be a stronger predictor of psychological adaptation under conditions of large cultural distance.

Second, as outlined earlier, a time factor might be at play. The participants have been in New Zealand on average for approximately eight years. This might diminish the importance of ethnic peers for psychological wellbeing because migrants have potentially made a sufficient number of friendships with host nationals who provide emotional support. Unfortunately, the sample was not big enough to distinguish between participants with large and small cultural distance to New Zealand or between those who recently came to New Zealand compared to those who have resided in the country for a longer period of time.

Another explanation for the weak relationship between ethnic peer connections and psychological adaptation might be that the items that were used to assess ethnic peer connections did not tap into the wellbeing aspect of psychological adaptation. They assessed the frequency of ethnic peer contacts rather than the quality of those contacts. Research has shown that frequent contact with ethnic peers might actually be detrimental for psychological adaptation. For example, migrants who socialise with co-nationals a lot run the risk of excessively discussing their negative experiences in the host country with each other, thus creating an emotional downward spiral that is detrimental for psychological wellbeing (Adelman, 1988). Furthermore, migrants who 
frequently socialise with ethnic peers build fewer relationships with host nationals and live on an 'ethnic island' instead that is not sustainable and where relationships with co-nationals may become taxing over time. This has been found with Samoan migrants in the USA (Barker, 1991). It is thus possible that the positive and negative effects of ethnic peer contacts have cancelled each other out in the present study.

Notwithstanding these alternative explanations, it should be noted that very few studies report the actual effect sizes between ethnic peer contact and psychological adaptation. Furthermore, the way ethnic peer contact and psychological adaptation are operationalised vary. I only found five studies that investigate adaptation outcomes of migrants, international students, refugees or sojourners, and that report effects sizes for the relationship between ethnic peer contact and psychological adaptation. More importantly, the reported effect sizes are small to moderate (see Appendix L). In conjunction, these empirical findings suggest that the relationship between ethnic peer connections (as a measure of cultural maintenance behaviour) and psychological adaptation may not as important as theoretically assumed. Future studies should explore this further.

The analysis also revealed a direct association between MCE and sociocultural adaptation. This finding is interesting because it indicates that the motivation to explore the host culture impacts sociocultural adaptation directly and not through the behaviour of seeking national peer contacts. Therefore, MCE in the current study is not a predictor of acculturation behaviour as such, but a direct predictor of sociocultural adaptation. So far, factors such as length of residence, cultural distance and quantity of contact with host nationals have been outlined in the literature as being predictive of sociocultural adaption (see Ward \& Kennedy, 1994). The findings of the current study suggest that MCE might be added to that list of predictors. The finding also makes theoretical sense because, as outlined earlier, sociocultural adaptation is situated in a social learning framework. It seems plausible that the exploration of the host culture and the openness to the novel experiences that are associated with the exploration experience facilitate the social learning that is inherent in sociocultural adaptation. As outlined by Gezentsvey and Ward (2008) sociocultural learning requires "the motivation to learn new skills and behavioural repertoires" (p. 221) and potentially MCE is a reflection of this. 
Mediating effects. There is some controversy in the literature about the most effective source of social support. Some studies indicate that ethnic peers are more important for emotional support and psychological adjustment than national peers, whereas other studies suggest that relationships with national peers are better predictors of adjustment (Searle \& Ward, 1990). Both viewpoints are plausible: On the one hand, relationships with ethnic peers give migrants a sense of belonging and safety that increases their psychological wellbeing. On the other hand, relationships with national peers may have the same effect, by providing migrants with a sense of 'fitting in". The present study found support for both views but goes beyond these findings. First, as expected and outlined above, ethnic peer connections predicted psychological adaptation. Moreover, the influence of MCM on psychological adaptation was mediated by ethnic peer connections. Because the direct path between MCM and psychological adaptation was statistically non-significant, this effect represents an indirect-only mediation (Zhao, Lynch \& Chen, 2010), or full mediation in the Baron and Kenny (1986) terminology. That is, ethnic peer connections fully mediate the influence of MCM on psychological adaptation. This result suggests that contact with co-nationals is a mechanism by which migrants who are motivated to maintain their culture attain psychological wellbeing and life satisfaction in the new cultural milieu.

Second, the relationship between national peer connections and psychological adaptation was mediated by sociocultural adaptation, and national peer connections also influenced psychological adaptation directly. According to Zhao et al. (2010) this relationship is considered a complementary mediation (or partial mediation in the Baron and Kenny, 1986, terminology). In other words, the effect of national peer connections on psychological adaptation was not only direct, but was also exerted through sociocultural adaptation. The finding appears plausible in the sense that migrants increase their psychological wellbeing through skills acquisition (i.e., sociocultural adaptation). For example, if migrants learn the local language or learn how to interact with locals in social situations, their self-efficacy increases, and this positively affects psychological adaptation. Additionally, contact with host nationals affects psychological wellbeing and life satisfaction directly, potentially because having friends amongst host nationals makes migrants feel more at home in the new country. 
Moreover, an indirect-only or full mediation (Baron \& Kenny, 1986; Zhao, Lynch \& Chen, 2010) was also observed in the relationship between MCE and psychological adaptation, which was fully mediated by sociocultural adaptation. This result suggests that adaptation to the new cultural environment is a mechanism by which migrants who are motivated to explore the host culture attain psychological wellbeing in the new cultural milieu. This supports the idea that MCE might be seen in a sociocultural learning framework because it does not predict psychological wellbeing directly, which refers more to stress and coping issues. Rather, the impact of the motivation to explore the host culture on the psychological wellbeing of migrants is exerted through sociocultural learning. The finding suggests that psychological adaptation is influenced by variables relating to sociocultural learning and is similar to Vedder at al.'s (2006) finding from the ICSEY study. This is also reflected by the relatively strong direct link between sociocultural adaptation and psychological adaptation. Consequently, as indicated by Vedder and colleagues, psychological adaptation could be considered as the ultimate outcome of the proposed model.

The results of the mediation analyses point to the importance of sociocultural adaptation as a mediating variable that impacts psychological adaptation, thereby providing more detailed information about the underlying processes that contribute to migrant wellbeing. In this context it should be noted that these results emphasise the usefulness of the recently developed Revised Sociocultural Adaptation Scale (Wilson $\&$ Ward, 2010) to investigate the mechanisms relating to adaptation outcomes.

\section{The Value of the Proposed Model}

Overall, the results suggest that MCM and MCE have significant value within the acculturation literature. SEM analyses showed that migrants' adaptation outcomes are influenced by their motivation to preserve the culture of their country of origin and their motivation to explore the culture of their new country of residence. The dualprocess model suggests that on the one hand, the motivation to maintain the heritage culture predicts whom migrants socialise with, and in line with previous research, this in turn predicts their psychological adaptation. On the other hand, the motivation to explore the host culture directly predicts the ability of migrants to negotiate life in the host country and this in turn affects their psychological adaptation, i.e., their emotional wellbeing and their level of satisfaction while settling in. 
More generally, the benefit of the proposed dual-process model is that it integrates two types of processes that predict migrants' adaptation in a new cultural setting. In the broadest sense the model suggests that while the motivation to preserve one's heritage culture influences psychological outcomes of migrants, the motivation to explore the culture of the host country impacts social learning and 'fitting in'. The model thus increases the understanding of the factors that influence adaptation and sheds light on the underlying mechanisms that lead to adaptation (e.g., the role of acculturation behaviour). Moreover, it should be emphasised that the starting points of the processes that are illustrated in the model are motivational drives. Since motivational theory has not played an important role in the acculturation literature so far, the model has the potential to provide a new framework for the investigation of migrants' adaptation outcomes.

\section{Implications of the Current Study}

Broadly speaking, the newly developed motivations for cultural maintenance and cultural exploration and their interplay with peer connections and adaptation contribute both to a better understanding of people's migration experience and to a better understanding of the factors that contribute to immigrant wellbeing and sociocultural learning in an unfamiliar cultural milieu. As can be seen in the model, both motivations are directly (or indirectly through behaviour) linked to adaptation outcomes and therefore, their relevance needs to be acknowledged. These important findings have implications for theory, policy makers and, for migrants.

Implications for theory. This study put what Berry (1997) referred to as "striving for cultural maintenance" and "seek[ing] daily interaction" (p. 9) with host nationals in a theoretical motivational framework that may provide a starting point for future research that investigates other motivational drives in the context of acculturation and adaptation. Furthermore, the study provides measurement tools to assess the motivations of migrants to maintain their heritage culture and to explore the host culture. Additionally, the findings indicate that the proposed motivations are linked to adaptation outcomes and therefore, the newly developed scales have the potential to complement existing measurement tools that are used in acculturation research to assess other predictors of adaptation.

Implications for policy makers. The findings are also relevant for policy makers. In some countries, such as Germany, migrants who want to preserve their 
culture are often frowned upon. It is largely an expectation of the majority culture that migrants should blend in and assimilate to the mainstream, or segregate and eventually return to their countries of origin. This view is often reflected in immigration policies that are not supportive of cultural diversity (Zick, Wagner, van Dick, \& Petzel, 2001). However, the findings of the current study suggest that both the motivation to maintain culture and the motivation to explore the host culture are linked to positive adaptation outcomes (at least in New Zealand). Therefore, governments would be well advised to provide a policy framework that allows and encourages migrants to maintain their culture, while at the same time encourages them to explore the culture of their new country of residence. This may include working towards a paradigm shift in regard to the openness of host society towards the migrant newcomers and towards the acknowledgement of cultural diversity in policy making. Both appear to be crucial factors for migrant integration. For example, past research found that the integration process is influenced by the discrimination against migrants by the host society (Ruggiero, Taylor, \& Lambert, 1996) and by integration policies (Bourhis, Montaruli, El-Geledi, Harvey, \& Barrette, 2010). However, discrimination and policy making are factors that acculturating individuals cannot influence by themselves. In other words, migrants can be highly motivated to explore the host culture but will not succeed in doing so if the host culture is not receptive to it.

Implications for migrants. Potentially, the findings of the present study could be used to increase the awareness of migrants of their own motivations in regard to cultural maintenance and exploration. For example, the MCM and MCE scales could be used in cross-cultural trainings to start discussions about the effects of cultural maintenance and exploration. Being mindful about the issue might contribute to a more balanced view on the benefits of maintenance and exploration of culture. Moreover, reflecting on the items of the two scales and what the motivations entail in regard to adaptation can be helpful for individuals who consider living in another culture. Self-awareness about one's own position in regard to questions relating to one's cultural heritage and one's openness towards a new culture may help to make the decision if living in an unfamiliar cultural environment is really a good idea. Similarly, the new scales could be used by employers to 'screen' employees before sending them on expatriate assignments. For example, if people score high on cultural 
maintenance and lower on cultural exploration they (and their employers) should consider that this motivational pattern might impede sociocultural adaptation.

\section{Limitations and Directions for future Research}

When considering the results and potential theoretical and practical implications outlined above, it is necessary to be aware of some important limitations. To overcome some of the limitations and to further enhance the understanding of the interplay between MCM/MCE acculturation behaviour and psychological/ sociocultural adaptation, directions for future research will also be suggested.

First, the psychometric validity of the new MCM and MCE scales has not been fully established. In Study 1 the correlations between the two scales and the criterion measures did not reach significance levels, possibly because the study was conducted with a small sample $(n=50)$. Similarly, the results of Study 2 were not fully conclusive. Particularly, the relationships between MCM and its criterion measures should be further investigated. Future research should therefore focus on the psychometric properties of both scales. The use of additional criterion measures would be advisable to establish discriminant and convergent validity.

A second limitation that merits comment is that even though considerable care went into the construction of the questionnaire for Study 2, some of the questions regarding language and media use were not relevant for participants whose first language is English. Linked to this issue, some of the behavioural variables had to be dropped in the course of the Study 2 in order to use the whole sample. Even though this can be justified through empirical and theoretical support in the acculturation literature, the dropped variables would have contributed to a broader understanding of the impacts of the proposed motivations. Therefore, future research should investigate the influence of MCM and MCE on other acculturation behaviours that contribute to adaptation outcomes.

Furthermore, it needs to be acknowledged that the sample in Study 2 is not representative of the New Zealand migrant population in general. Numbers that were obtained in 2004 and 2005 for the Longitudinal Immigration Survey New Zealand revealed that amongst the migrants with permanent residency in New Zealand, 12\% self-identified as Pacific Islanders, $42 \%$ as European and approximately $31 \%$ as Asian (Department of Labour, n.d.). However, in the present sample, only $0.5 \%$ of permanent residents self-identified as being from the Pacific, $60.6 \%$ as European and 
$17.8 \%$ as Asian. In other words, Europeans are over-represented and Pacific Islanders and Asian migrants are under-represented. Therefore, the findings of this study should not be generalised without further consideration. To be able to draw valid conclusions about migrants in New Zealand, future studies should attempt to select a sample that matches the composition of the migrant population in the country.

Lastly and perhaps more importantly, this study is cross-sectional in nature. As Ward et al. (1998) outlined, a longitudinal approach is more suitable than a crosssectional approach to investigate adaptation because of its temporal aspect. For example, participants' scores on measures of psychological wellbeing may change over time, partly because wellbeing increases as language proficiency increases (Church, 1982). Therefore, future research should attempt to investigate the effects of the proposed motivations on adaptation using a longitudinal design. Such design will allow conclusions about causality in regard to the relationships between motivations, behaviour and adaptation, and will allow a proper test of the mediation effects observed.

Moreover, researchers could focus on factors that might moderate the relationship between MCM/MCE, acculturation behaviours and psychological and sociocultural adaptation. First, as indicated earlier, length of residence in the host country may affect the relationship between MCM/MCE and acculturation behaviours. For example, MCE might be a stronger predictor of sociocultural adaptation in the early stages of acculturation (compared to the later stages of acculturation) because the sociocultural learning curve is steepest in the first four to six months after arrival in the host country.

Second, the potentially moderating effect of cultural distance on adaptation outcomes could also be examined. The results indicated that ethnic peer contact may be a stronger predictor of psychological adaptation under conditions of large cultural distance. Even though the effects of cultural distance have been subject of past research (i.e., sociocultural adaptation is more difficult if the cultural distance is high; e.g., Ward \& Kennedy, 1993b) it should be investigated how this factor affects the proposed model.

\section{Conclusion}

In summary, the present studies sought to investigate a dual-process model on the relationships between the novel motivations of cultural maintenance (MCM) and 
cultural exploration (MCE), acculturation behaviours and sociocultural and psychological adaptation. Scales to measure the new constructs of MCM and MCE were developed and tested in a small sample of 50 international students (Study 1) and then used in a survey with 280 migrants in New Zealand (Study 2). The analyses of the data revealed that migrants' adaptation outcomes are in various ways predicted by MCM and MCE (directly or via acculturation behaviours). In particular, the findings suggest that MCM predicts migrants' tendency to socialise with ethnic peers, which in turn weakly predicted psychological adaptation. MCE on the other hand did not predict contact with national peers, but directly predicted sociocultural adaptation, which in turn predicted psychological adaptation. Both motivations are therefore linked to adaptation outcomes and do have predictive power. The proposed motivations of MCE and MCM therefore contribute to the acculturation literature by enhancing our understanding of the mechanisms that influence the wellbeing and cultural learning of migrants in an unfamiliar cultural milieu. 
A Dual-Process Motivational Model of Cross-Cultural Adaptation

\section{References}

Adelman, M.B. (1988). Cross-cultural adjustment: A theoretical perspective on social support. International Journal of Intercultural Relations, 12, 183-204.

Ang, S., Van Dyne, L., Koh, C., Ng, K.Y., Templer, K.J., Tay, C., \& Chandrasekar, N.A. (2007). Cultural intelligence: Its measurement and effects of cultural judgment and decision making, cultural adaptation and task performance. Management and Organization Review, 3, 335-371.

Barker, J.C. (1991). Pacific Island Migrants in the United States. Some implications for aging services. Journal of Cross-Cultural Gerontology, 6, 173-192.

Barron, R.M., \& Kenny, D.A. (1986). Moderator-mediator variables distinction in social psychological research: Conceptual, strategic, and statistical consideration. Journal of Personality and Social Psychology, 51, 1173-1183.

Bartee, R.T., Grandjean, B.D., \& Bieber, S.L. (2004). Confirming the reliability of a theory-based questionnaire. American Journal of Health Studies, 19, 175-180.

Baumeister, R.F., \& Leary, M.R. (1995). The need to belong: Desire for interpersonal attachment as a fundamental human motivation. Psychological Bulletin, 117, 497529.

Berry, J.W. (1997). Immigration, acculturation, and adaptation. Applied Psychology: An International Review, 46, 5-34.

Berry, J.W. (2003). Conceptual approaches to acculturation. In K.M. Chun, P. Balls Organista, G. Marín (Eds.), Acculturation: Advances in theory, measurement, and applied research (pp. 17-37). Washington: American Psychological Association.

Berry, J.W. (2005). Acculturation: Living successfully in two cultures. International Journal of Intercultural Relations, 29, 697-712.

Berry, J.W. (2006). Stress perspectives on acculturation. In D.L. Sam \& J.W. Berry (Eds.), The Cambridge handbook of acculturation psychology (pp. 43-57).

Cambridge, UK: Cambridge University Press.

Berry, J.W., Phinney, J.S., Sam, D. L., \& Vedder, P. (2006). Immigrant youth: Acculturation, identity, and adaptation. Applied Psychology: An International Review, 55, 303-332.

Berry, J.W., \& Sabatier, C. (2011). Variations in the assessment of acculturation attitudes: their relationships with psychological wellbeing. International Journal of Intercultural Relations, 35, 658-669. 
Bhagat, R.S., \& London, M. (1999). Getting started and getting ahead: Career dynamics of immigrants. Human Resource Management Review, 9, 349-365.

Boldero, J.M., \& Higgins, E.T. (2011). Regulatory focus and political decision making: When people favour reform over status quo. Political Psychology, 32, $399-418$.

Boneva, B.S., \& Frieze, I. (2001). Toward a concept of a migrant personality. Journal of Social Issues, 57, 477-491.

Bourhis, R.Y., Montaruli, E., El-Geledi, S., Harvey, S.-P., \& Barrette, G. (2010). Acculturating in multiple host community settings. Journal of Social Issues, 66, 780-802.

Buddington, S.A. (2002). Acculturation, psychological adjustment (stress, depression, self-esteem) and academic achievement of Jamaican immigrant college students. International Social Work, 45, 447-464.

Byrne, B.M. (2010). Structural equation modeling with AMOS ( $2^{\text {nd }}$ ed.). London: Psychology Press.

Cacioppo, J.T., \& Petty, R.E. (1982). The need for cognition. Journal of Personality and Social Psychology, 42, 116-131.

Carmines, E.G., \& McIver, J.P. (1981). Analyzing models with unobserved variables: Analysis of covariance structures. In G.W. Bohrnstedt \& E.F. Borgatta (Eds.), Social Measurement: Current issues (pp. 65-115). Beverly Hills: Sage Publications.

Carrus, G., Nenci, A.M., \& Caddeo, P. (2009). The role of ethnic identity and perceived ethnic norms in the purchase of ethnical food products. Appetite, 52, 65-71.

Castigan, C.L., \& Dokis, D.P. (2006). Relations between parent-child acculturation differences and adjustment within immigrant Chinese families. Child Development, 77, 1252-1267.

Cheek, J.M., \& Briggs, S.R. (1982). Self-consciousness and aspects of identity. Journal of Research in Personality, 16, 401- 408.

Chirkov, V., Vansteenkiste, M., Tao, R., \& Lynch, M. (2007). The role of selfdetermined goals for study abroad in the adaptation of international students. International Journal of Intercultural Relations, 31, 199-222.

Church, A.T. (1982). Sojourner Adjustment. Psychological Bulletin, 91, 540-572. 
Clément, R. (1986). Second language proficiency and acculturation: An investigation of the effects of language status and individual characteristics. Journal of Language and Social Psychology, 5, 271-290.

Cloninger, C. R. (1987). Neurogenetic adaptive mechanisms in alcoholism. Science, 236, 410-416.

Cuellar, I., Harris, L.C., \& Jasso, R. (1980). An acculturation scale for Mexican American normal and clinical populations. Hispanic Journal of Behavioral Sciences, 2, 199-217.

Curran, P.J., West, S.G., \& Finch, J.F. (1996). The robustness of test statistics to nonnormality and specification error in confirmatory factor analysis. Psychological Methods, 1, 16-29.

Deci, E.L., \& Ryan, R.M. (2008). Self-determination theory: A macrotheory of human motivation, development and health. Canadian Psychology, 49, 182-185.

Department of Labour (n.d.). Fast facts 1: Demographic characteristics of permanent migrants. Retrieved from http://www.dol.govt.nz/research/migration/lisnz/fastfacts.asp

DeYoung, C.G. (2006). Higher-order factors of the Big Five in a multi-informant sample. Journal of Personality and Social Psychology, 91, 1138-1151.

DeYoung, C.G. (2010). Toward a theory of the Big Five. Psychological Inquiry, 21, 26-33.

Diener, E., Emmons, R.A., Larsen, R.J., Griffin, S. (1985). The satisfaction with life scale. Journal of Personality Assessment, 49, 71-75.

Elliot, A.J. (1999). Approach and avoidance motivation and achievement goals. Educational Psychologist, 34, 169-189.

Field, A. (2009). Discovering statistics using SPSS (3rd ed.). London: Sage Publications Ltd.

Finch, B.K., \& Vega, W.A. (2003). Acculturation stress, social support, and self-rated health among Latinos in California. Journal of Immigrant Health, 5, 109 - 117.

Fischer, J.L., Fitzpatrick, J., \& Celveland, H.H. (2007). Linking family functioning to dating relationship quality via novelty-seeking and harm-avoidance personality pathways. Journal of Social and Personal Relationships, 24, 575-590.

Fiske, S.T. (2004). Social beings. A core motives approach so social psychology. Hoboken, NJ: Wiley. 
Fiske, S. T. (2008). Core social motivations. Views from the couch, consciousness, classroom, computers, and collectives. In J.Y. Shah \& W.L. Gardner (Eds.), Handbook of motivation science (pp. 3-22). New York: Guildford Press.

Fiske, S.T., \& Taylor, S.E. (2008). Social cognition. From Brains to Culture. Boston: McGraw-Hill.

Furnham, A., \& Li, Y.H. (1993). The psychological adjustment of the Chinese community in Britain. A study of two generations. The British Journal of Psychiatry, 162, 109-113.

Gardener, C., Winkleby, M.A., \& Viteri, F.E. (1995). Dietary intake patterns and acculturation levels of Hispanic immigrant men: A pilot study. Hispanic Journal of Behavioral Sciences, 17, 347-361.

Gezentsvey, M. A. (2008). Journeys of ethno-cultural continuity: Comparing the long-term acculturation of Jews with Maori and Chinese (PhD-Thesis). Victoria University of Wellington, New Zealand.

Gezentsvey, M., \& Ward, C. (2008). Unveiling agency: A motivational perspective on the acculturation and adaptation. In R.M. Sorrentino \& S. Yamaguchi (Eds.), Handbook of motivation and cognition across cultures (pp. 213-235). London: Academic Press.

Guinote, A. (2001). The perception of group variability in a non-minority and a minority context: when adaptation leads to out-group differentiation. British Journal of Social Psychology, 40, 117-132.

Heine, S.J., Lehman, D.R., Markus, H.R., \& Kitayama, S. (1999). Is there a universal need for positive self-regard? Psychological Review, 106, 766-794.

Higgins, E.T. (1997). Beyond pleasure and pain. American Psychologist, 52, 12801300.

Hirsh, J.B., DeYoung, C.G., \& Peterson, J.B. (2009). Metratraits of the Big Five differentially predict engagement and restraint of behaviour. Journal of Personality, 77, 1085-1101.

Hofstede, G. (2001). Culture's consequence: Comparing values, behaviours, and organisations across nations. Thousand Oaks, CA: Sage Publications.

Hu, L., \& Bentler, P.M. (1999). Cutoff criteria for fit indices in covariance structure analysis: Conventional criteria versus new alternatives. Structural Equation Modeling: A Multidisciplinary Journal, 6, 1-55. 
Ibañez, G.E., Kuperminc, G.P., Jurkovic, G., \& Perilla, J. (2004). Cultural attributes and adaptations linked to achievement motivation among Latino adolescents. Journal of Youth and Adolescence, 33, 559-568.

Immigration New Zealand Settlement Services (2012). The Kiwi way. Retrieved from http://www.ssnz.govt.nz/living-in-new-zealand/way-of-life/

International Organization for Migration (2011). About migration. Retrieved from http://www.iom.int/jahia/Jahia/about-migration/lang/en

Jasinskaja-Lathi, I., Liebkind, K., Jaakkola, M., \& Reuter, A. (2006). Perceived discrimination, social support networks, and psychological well-being among three immigrant groups. Journal of Cross-Cultural Psychology, 27, 293-311.

Kail, B., Zayas, L.H., \& Malgady, R.G. (2000). Depression, acculturation, and motivations for alcohol use among young Colombian, Dominican, and Puerto Rican men. Hispanic Journal of Behavioral Sciences, 22, 64-77.

Kashdan, T.B., \& Hofmann, S.G. (2008). The high-novelty-seeking, impulsive subtype of generalized social anxiety disorder. Depression and Anxiety, 25, 535541.

Kashima, E.S., \& Loh, E. (2006). International students' acculturation: Effects of international, conational, and local ties and need for closure. International Journal of Intercultural Relations, 30, 471-485.

Kashima, E.S., \& Pillai, D. (2011). Identity development in cultural transition: The role of need for closure. Journal of Cross-Cultural Psychology, 42, 725 - 739.

Kohn, P.M., \& Annis, H.M. (1975). Validity data on a modified version of Pearson's novelty experiencing scale. Canadian Journal of Behavioural Science, 7, 274278.

Kosic, A., Kruglasnki, A.W., Pierro, A., \& Mannetti, L. (2004). The social cognition of immigrants' acculturation: Effects of the need for closure and reference group at entry. Journal of Personality and Social Psychology, 86, 796-813.

Kruglanski, A.W. (1990). Motivations for judging and knowing. In E.T. Higgins \& R.M. Sorrentino (Eds.), Handbook of motivation and cognition (pp. 333- 368). New York: Guildford Press.

Kruglanski, A.W., \& Webster, D.M. (1996). Motivated closing of the mind: "Seizing" and "Freezing". Psychological Review, 103, 263-283. 
Laroche, M., Kim, C., \& Tomiuk, M.A. (1998). Italian ethnic identity and its relative impact on the consumption of convenience and traditional foods. Journal of Consumer Marketing, 15, 125-151.

Leary, M.R., \& Cox, C.B. (2007). Belongingness motivation. A mainspring of social action. In J.Y. Shah \& W.L. Gardner (Eds.), Handbook of motivation science (pp. 27-40). New York: Guildford Press.

Li, A., \& Gasser, M.B. (2005). Predicting Asian international students' sociocultural adjustment: A test of two mediation models. International Journal of Intercultural Relations, 29, 561-576

Little, T.D., Cunningham, W.A., Shahar, G., \& Widaman, K.F. (2002). To parcel or not to parcel: Exploring the question, weighing the merits. Structural Equation Modeling: A Multidisciplinary Journal, 9, 151-173.

MacCallum, R.C. (1995). Model specification. Procedures, strategies and related issues. In R.H. Hoyle (Ed.), Structural equation modeling. Concepts, issues and applications (pp. 16-36). Thousand Oaks, CA: Sage Publications Inc.

MacCallum, R.C., Widaman, K.F., Zhang, S., \& Hong, S. (1999). Sample size in factor analysis, 4, 84-99.

Marín, G., \& Gamba, R.J. (1996). A new measurement of acculturation for Hispanics: the bidimensional acculturation scale for Hispanics (BAS). Hispanic Journal of Behavioral Sciences, 18, 297-316.

Marsh, H.W., \& Hovecar, D. (1985). Application of confirmatory factor analysis to the study of self-concept. First- and higher order factor models and their invariance across groups. Psychological Bulletin, 3, 562-582.

Martín-Albo, J., Núñez, J.L., Navarro, J.G., \& Grijalvo, F. (2007).The Rosenberg self-esteem scale: Translation and validation in university students. The Spanish Journal of Psychology, 2, 458-467.

Masgoret, A.M., Bernaus, M., \& Gardner, R.C. (2000). A study of cross-cultural adaptation by English-speaking sojourners in Spain. Foreign Language Annals, $33,548-558$.

Masgoret, A.M., \& Ward, C. (2006). Culture learning approach to acculturation. In D.L. Sam \& J.W. Berry (Eds.), The Cambridge handbook of acculturation psychology (pp. 58-77). Cambridge: Cambridge University Press. 
Minkov, M. (2007). What makes different and what makes us similar. A new interpretation of the World Values Survey and other cross-cultural data. Sofia, Bulgaria: Klasika I Stil Publishing House Ltd.

Nunnally, J.C. (1978). Psychometric theory (2nd ed.). New York: McGraw-Hill.

Oppedal, B., Røysamb, E., \& Lackland Sam, D. (2004). The effect of acculturation and social support on change in mental health among young immigrants. International Journal of Behavioral Development, 28, 481-494.

Pavot, W., \& Diener, E. (2008). The satisfaction with life scale and the emerging construct of life satisfaction. The Journal of Positive Psychology, 3, 137-152.

Pearson, P.H. (1970). Relationships between global and specified measures of novelty seeking. Journal of Consulting and Clinical Psychology, 34, 199-204.

Phinney, J.S., Berry, J.W., Vedder, P., \& Liebkind, K. (2006). The acculturation experience: Attitudes, identities, and behaviors of immigrant youth. In Berry, J.W., Phinney, J.S., Sam, D. L., \& Vedder, P. (Eds.). Immigrant youth in cultural transition: Acculturation, identity and adaptation across national contexts (pp. 71-116). London: Lawrence Erlbaum Associates.

Plunkett, S.W. \& Bámaca-Gómez, M., Y. (2003). The relationship between parenting, acculturation, and adolescent academics in Mexican-origin immigrant families in Los Angeles. Hispanic Journal of Behavioral Sciences, 25, 222-239.

Reece, D., \& Palmgreen, P. (2000). Coming to America: need for acculturation and media use motives among Indian sojourners in the US. International Journal of Intercultural Relations, 24, 807-824.

Roets, A., \& Van Hiel, A. (2007). Separating ability from need: Clarifying the dimensional structure of the need for closure scale. Personality and Social Psychology Bulletin, 33, 266-280.

Roets, A., \& Van Hiel, A. (2011). Item selection and validation of a brief, 15-item version of the need for closure scale. Personality and Individual Differences, 50, 90-94.

Rothbaum, F., Pott, M., Azuma, H., Miyake, K., \& Weisz, J. (2000). The development of close relationships in Japan and the United States: Paths of symbiotic harmony and generative tension. Child Development, 71, 1121-1142. Ruggiero, K.M., Taylor, D.M., \& Lambert, W.E. (1996). A model of heritage culture maintenance. International Journal of Intercultural Relations, 20, 47-67. 
Ryan, R.M. \& Deci, E.L. (2000a). Intrinsic and extrinsic motivations: Classic definitions and new directions. Contemporary Educational Psychology, 25, 5467.

Ryan, R.M., \& Deci, E.L. (2000b). Self-determination theory and the facilitation of intrinsic motivation, social development and well-being. American Psychologist, $55,68-78$.

Ryska, T.A. (2001). The impact of acculturation on sport motivation among MexicanAmerican adolescent athletes. The Psychological Record, 51, 533-547.

Sam, D.L. (2006). Acculturation: Conceptual background and core components. In D.L. Sam \& J.W. Berry (Eds.), The Cambridge handbook of acculturation psychology (pp. 11-26). Cambridge, UK: Cambridge University Press.

Sam, D.L., Vedder, P., Ward, C., \& Horenczyk, G. (2006). Psychological and sociocultural adaptation of immigrant youth. In J.W. Berry, J.S. Phinney, D.L. Sam, \& P. Vedder (Eds.). Immigrant youth in cultural transition: Acculturation, identity and adaptation across national contexts (pp. 117-141). London: Lawrence Erlbaum Associates.

Schwartz S.H. (1994a). Beyond individualism/collectivism. New cultural dimensions of values. In U.Kim, H.C. Triandis, C. Kagitcibasi, S.C. Choi, \& G. Yoon (Eds.), Individualism and collectivism: Theory, methods and applications (pp. 85-119). London: Sage.

Schwartz, S.H. (1994b). Are there universal aspects in the structure and contents of human values? Journal of Social Issues, 50, 19-45.

Searle, W., \& Ward, C. (1990). The prediction of psychological and sociocultural adjustment during cross-cultural transitions. International Journal of Intercultural Relations, 14, 449-464.

Sherman, D.K., \& Cohen, G.L. (2006). The psychology of self-defense: Selfaffirmation theory. In M.P. Zanna (Ed.), Advances in experimental social psychology (Vol. 38, pp. 183-242). San Diego, CA: Academic Press. Retrieved from http://www.psych.ucsb.edu/ d_sherma/advances.final.pdf

Sorrentino, R.M., \& Yamaguchi, S. (2008). Motivation and cognition across cultures. In R.M. Sorrentino \& S. Yamaguchi (Eds.), Handbook of motivation and cognition across cultures (pp. 1-15). London: Academic Press. 
Statistics New Zealand (2007). Profile of New Zealander responses, ethnicity question: 2006 census. Retrieved from http://www.stats.govt.nz/Census/about2006-census/profile-of-nzer-responses-ethnicity-question-2006-census.aspx

Stilling, E.A. (1996). The electronic melting pot hypothesis: The cultivation of acculturation among Hispanics through television viewing. The Howard Journal of Communication, 8, 77-100.

Sutton-Brady, C., Davis, T., \& Jung, M. (2010). Perceived cultural spaces and cultural in-betweens: Consumption among Korean Australians. Journal of Consumer Behaviour, 9, 349-363.

Tabor, A.S., \& Milfont, T.L. (2011). Migration change model: Exploring the process of migration on a psychological level. International Journal of Intercultural Relations, 35, 818-832.

Takeda, J. (2000). Psychological and economic adaptation for Iraqi adult male refugees: Implications for social work practice. Journal of Social Service Research, 26, 1-21.

Tajfel, H. (1982). Social psychology of intergroup relations. Annual Review of Psychology, 33, 1-39.

Tajfel, H., \& Turner, J.C. (1986). The social identity theory of intergroup behaviour. In S. Worchel \& W.G. Austin (Eds.), Psychology of Intergroup Relations (pp. 724). Chicago: Nelson-Hall.

Taylor, S.E., \& Sherman, D.K. (2008). Self-enhancement and self-affirmation. The consequences of positive self-thoughts for motivation and health. In J.Y. Shah \& W.L. Gardner (Eds.), Handbook of motivation science (pp. 3-22). New York: Guildford Press.

Tepper, K., \& Hoyle, R.H. (1996). Latent variable models of need for uniqueness. Multivariate Behavioral Research, 31, 467-494.

Triandis, H.C. (2000). Culture and conflict. International Journal of Psychology, 35, 145-152.

Vallerand, R.J., Pelletier, L.G., Blais, M.R., Briere, N.M. Senecal, C., \& Vallieres, E.F. (1992). The academic motivation scale: A measure of intrinsic, extrinsic, and amotivation in education. Educational and Psychological Measurement, 52, 1003- 1017. 
Van der Zee, K.I., \& Van Oudenhoven , J.P. (2000). The Multicultural personality questionnaire: A multidimensional instrument of multicultural effectiveness. European Journal of Personality, 14, 291-309.

Vedder, P., \& Van de Vijver (2006). Methodological aspects: Studying adolescents in 13 countries. In J.W. Berry, J.S. Phinney, D.L. Sam, \& P. Vedder (Eds.). Immigrant youth in cultural transition: Acculturation, identity and adaptation across national contexts (pp. 47-70). London: Lawrence Erlbaum Associates.

Vedder, P., Van de Vijver, F.J.R., \& Liebkind, K. (2006). Predicting immigrant youth's adaptation across countries and ethnocultural groups. In J.W. Berry, J.S. Phinney, D.L. Sam, \& P. Vedder (Eds.). Immigrant youth in cultural transition: Acculturation, identity and adaptation across national contexts. (pp. 143-165). London: Lawrence Erlbaum Associates.

Vedder, P., \& Virta, E. (2005). Language, ethnic identity, and the adaptation of Turkish immigrant youth in the Netherlands and Sweden. International Journal of Intercultural Relations, 29, 317-337.

Walker, G.J., Deng, J., \& Dieser, R.B. (2001). Ethnicity, acculturation, self-construal, and motivations for outdoor recreation. Leisure Sciences, 23, 263-283.

Ward, C. (2001). The A, B, Cs of acculturation. In D. Matsumoto (Ed.), The Handbook of Culture and Psychology (pp. 411-445). Oxford, UK: Oxford University Press.

Ward, C., Bochner, S., \& Furnham, A. (2001). The psychology of culture shock (2nd ed.). New York: Routledge.

Ward, C. \& Kennedy, A. (1993a). Psychological and socio-cultural adjustment during cross-cultural transitions: a comparison of secondary students overseas and at home. International Journal of Psychology, 28, 129-147.

Ward, C., \& Kennedy, A. (1993b). Where's the "culture' in cross-cultural transition? Comparative studies of sojourner adjustment. Journal of Cross-Cultural Psychology, 24, 221-249.

Ward, C., \& Kennedy, A. (1994). Acculturation Strategies, psychological adjustment, and sociocultural competence during cross-cultural transitions. International Journal of Intercultural Relations, 18, 329-343.

Ward, C., Okura, Y., Kennedy, A. \& Kojima, T. (1998). The u-curve on trial: A longitudinal study of psychological and sociocultural adaptation adjustment 
during cross-cultural transition. International Journal of Intercultural Relations, 22, 277-291.

Ward, C. \& Masgoret, A.M. (2004). The Experiences of international students in New Zealand. Report on the results of the national survey. Prepared for the Ministry of Education. Retrieved from http://www.educationcounts.govt.nz/publications/international/14700

Ward, C., Wilson, J., \& Fischer, R. (2011). Assessing the predictive validity of cultural intelligence over time. Personality and Individual Differences, 51, 138142.

Ward, C., \& Searle, W. (1991). The impact of cultural discrepancies and cultural identity on psychological adjustment of sojourners. International Journal of Intercultural Relations, 15, 209-225.

Webster, D.M., \& Kruglanski, A.W. (1994). Individual differences in need for cognitive closure. Journal of Personality and Social Psychology, 67, 1049-1062.

WHO (1998). WHO (Five) Well-Being Index (1998 version). Retrieved from http://www.who-5.org/

Wilson, J., \& Ward, C. (2010). Revision and expansion of the sociocultural adaptation scale, unpublished manuscript.

Wilson, J., Ward, C., \& Fischer, R. (2012). Beyond culture learning theory: What can Personality tell us about cultural competence? Manuscript submitted for publication.

Zhao, X., Lynch J.G., \& Chen, Q. (2010). Reconsidering Baron and Kenny: Myths and truths about mediation analysis. Journal of Consumer Research, 37, 197206).

Zick, A., Wagner, U. van Dick, R., \& Petzel, T. (2001). Acculturation and prejudice in Germany: Majority and minority perspectives. Journal of Social Issues, 3, 541557.

Zusho, A. (2008). Cultural variation in the motivational standards of selfenhancement and self-criticism among bicultural Asian American and Anglo American students. International Journal of Psychology, 43, 904-911. 
We would like to invite you to participate in a study that is designed to help us gain a better understanding of how immigrants settle into New Zealand society.

\section{Who is conducting the research?}

This research is conducted by Claudia Recker, a Masters student of the School of Psychology at Victoria University of Wellington under the supervision of Dr Taciano Milfont. This research has been approved by the School of Psychology Human Ethics Committee under delegated authority of the VUW Human Ethics Committee.

\section{To complete the following survey you must}

- be an international student

- have been born outside of New Zealand

- have lived in this country for at least six months

- have come to New Zealand when you were at least 18 years old

- currently live in New Zealand.

If you agree to participate in this study you will be asked to complete a questionnaire where you will respond to questions or statements such as "It is exciting for me to explore new cultures." We anticipate that the survey will take you no more than 10 minutes to complete.

\section{Privacy and Confidentiality:}

- This survey is completely anonymous. Please do not put your name on it anywhere.

- We will keep your data for at least five years after publication.

- You will never be identified in the research project or in any other presentation or publication. The information you provide will be identifiable by number only.

- In accordance with the requirements of some scientific journals and organisations, your anonymous responses may be shared with other competent researchers.

- Your survey responses may be used in other, related studies.

- Your response data will remain in the custody of Claudia Recker and Dr Taciano Milfont.

During the research you are free to withdraw at any point before your survey has been completed.

What happens to the information that you provide?

- The overall findings will be part of a Masters thesis that will be submitted for assessment.

- The survey response you provide may be submitted for publication in a scientific journal, or presented at scientific conferences. 
A Dual-Process Motivational Model of Cross-Cultural Adaptation

\section{Consent for Participation:}

Please note that by completing and returning the questionnaire to the researchers you agree that your survey responses will be used and analysed.

If you have any further questions regarding this study, please feel free to contact one of the investigators listed below.

Thank you for considering participation in this research.

Claudia Recker (email: Claudia.Recker@vuw.ac.nz)

Dr Taciano L. Milfont (email: Taciano.Milfont@vuw.ac.nz) 
Read each statement and select the response that best BEST describes you AS YOU REALLY ARE (1=strongly disagree; 7=strongly agree).

\begin{tabular}{|c|c|c|c|c|c|c|c|}
\hline $\begin{array}{c}1 \\
\text { Strongly } \\
\text { disagree }\end{array}$ & $\begin{array}{c}2 \\
\text { Disagree }\end{array}$ & $\begin{array}{c}3 \\
\text { Somewhat } \\
\text { disagree }\end{array}$ & $\begin{array}{c}4 \\
\text { Unsure/neutral }\end{array}$ & $\begin{array}{c}5 \\
\text { Somewhat } \\
\text { agree }\end{array}$ & $\begin{array}{c}6 \\
\text { Agree }\end{array}$ & $\begin{array}{r}7 \\
\text { Strong } \\
\text { agree }\end{array}$ & \\
\hline \multicolumn{5}{|c|}{$\begin{array}{l}\text { It is important for me to celebrate the holidays of my country of } \\
\text { origin. }\end{array}$} & 12 & 4567 & 7 \\
\hline \multicolumn{5}{|c|}{ It is exciting for me to explore new cultures. } & 12 & 4567 & 7 \\
\hline \multicolumn{5}{|c|}{$\begin{array}{l}\text { It gives me a sense of security to socialise with people who share } \\
\text { my cultural heritage. }\end{array}$} & 12 & 4567 & 7 \\
\hline \multicolumn{5}{|c|}{$\begin{array}{l}\text { I enjoy contact with people from other cultures because it broadens } \\
\text { my horizon. }\end{array}$} & 12 & 4567 & 7 \\
\hline \multicolumn{5}{|c|}{$\begin{array}{l}\text { It is important to keep my cultural traditions because they are part } \\
\text { of who I am. }\end{array}$} & 12 & 4567 & 7 \\
\hline \multicolumn{5}{|c|}{$\begin{array}{l}\text { It is important to me to understand the views of people from } \\
\text { different cultural backgrounds. }\end{array}$} & 12 & 4567 & 7 \\
\hline \multicolumn{5}{|c|}{ It makes sense to set aside the traditions of my cultural heritage. } & 12 & 4567 & 7 \\
\hline \multicolumn{5}{|c|}{$\begin{array}{l}\text { It gives me pleasure to meet people who share my cultural } \\
\text { heritage. }\end{array}$} & 12 & 4567 & 7 \\
\hline \multicolumn{5}{|c|}{$\begin{array}{l}\text { Living in a country with a different culture gives me the } \\
\text { opportunity to learn new ways of doing things. }\end{array}$} & 12 & 4567 & 7 \\
\hline \multicolumn{5}{|c|}{$\begin{array}{l}\text { I feel the need to live according to the traditions of my cultural } \\
\text { heritage, particularly because I now live in another culture. }\end{array}$} & 12 & 4567 & 7 \\
\hline \multicolumn{5}{|c|}{$\begin{array}{l}\text { I experience pleasure when my ethnic peers tell me stories from } \\
\text { our country of origin. }\end{array}$} & 12 & 4567 & 7 \\
\hline \multicolumn{5}{|c|}{$\begin{array}{l}\text { It is exciting to go to places with a different cultural heritage, even } \\
\text { though I don't know what might happen. }\end{array}$} & 12 & 4567 & 7 \\
\hline \multicolumn{5}{|c|}{$\begin{array}{l}\text { Sometimes it is important for me to put my own culture into } \\
\text { perspective and acknowledge different views. }\end{array}$} & 12 & 4567 & 7 \\
\hline
\end{tabular}


A Dual-Process Motivational Model of Cross-Cultural Adaptation

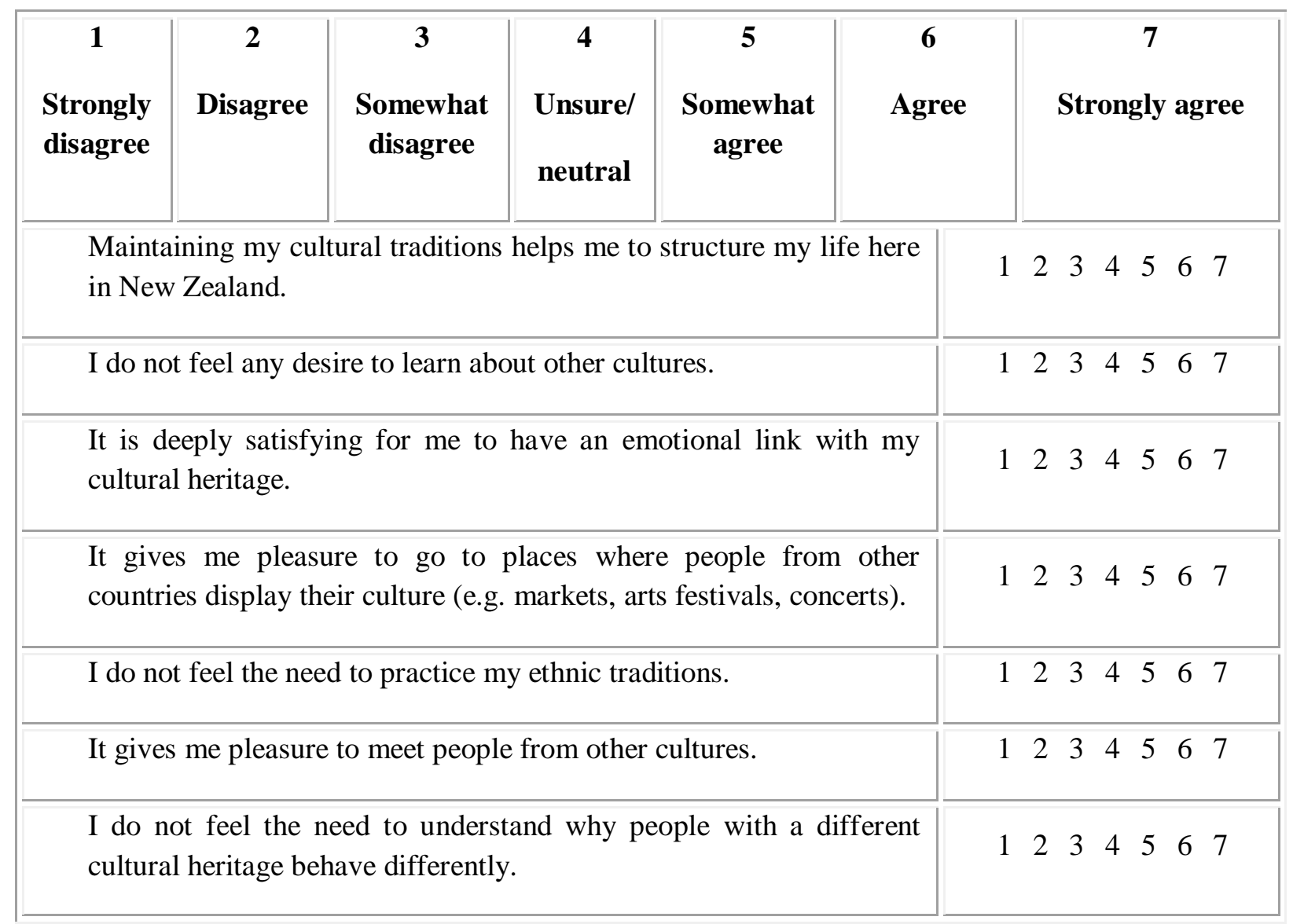

Please continue on the next page! 
Read each statement and select the answer that BEST describes you AS YOU REALLY ARE (1=strongly disagree; $7=$ strongly agree).

\begin{tabular}{|c|c|c|c|c|c|c|c|}
\hline $\begin{array}{c}1 \\
\text { Strongly } \\
\text { disagree }\end{array}$ & $\begin{array}{c}2 \\
\text { Disagree }\end{array}$ & $\begin{array}{c}3 \\
\text { Somewhat } \\
\text { disagree }\end{array}$ & $\begin{array}{c}4 \\
\text { Unsure/neutral }\end{array}$ & $\begin{array}{c}5 \\
\text { Somewhat } \\
\text { agree }\end{array}$ & $\begin{array}{c}6 \\
\text { Agree }\end{array}$ & $\begin{array}{c}7 \\
\text { Strongl! } \\
\text { agree }\end{array}$ & \\
\hline \multicolumn{5}{|c|}{ I don't like situations that are uncertain. } & 12 & 34556 & 7 \\
\hline \multicolumn{5}{|c|}{ I dislike questions which could be answered in many different ways. } & 12 & 34556 & 7 \\
\hline \multicolumn{5}{|c|}{ I find that a well ordered life with regular hours suits my temperament. } & 12 & $3456 \quad 6$ & 7 \\
\hline \multicolumn{5}{|c|}{$\begin{array}{l}\text { I feel uncomfortable when I don't understand the reason why an event } \\
\text { occurred in my life. }\end{array}$} & 12 & $3 \quad 456$ & 7 \\
\hline \multicolumn{5}{|c|}{$\begin{array}{l}\text { I feel irritated when one person disagrees with what everyone else in a } \\
\text { group believes. }\end{array}$} & 12 & 3456 & 7 \\
\hline \multicolumn{5}{|c|}{ I don't like to go into a situation without knowing what I can expect from it. } & 12 & $345 \quad 5 \quad 6$ & 7 \\
\hline \multicolumn{5}{|c|}{ When I have made a decision, I feel relieved. } & 12 & 3456 & \\
\hline \multicolumn{5}{|c|}{$\begin{array}{l}\text { When I am confronted with a problem, I'm dying to reach a solution very } \\
\text { quickly. }\end{array}$} & 12 & $3 \quad 456$ & 7 \\
\hline \multicolumn{5}{|c|}{$\begin{array}{l}\text { I would quickly become impatient and irritated if I would not find a } \\
\text { solution to a problem immediately. }\end{array}$} & 12 & $3 \quad 4 \quad 5 \quad 6$ & 7 \\
\hline \multicolumn{5}{|c|}{ I don't like to be with people who are capable of unexpected actions. } & 12 & 34556 & 7 \\
\hline \multicolumn{5}{|c|}{ I dislike it when a person's statement could mean many different things. } & 12 & 3456 & 7 \\
\hline \multicolumn{5}{|c|}{ I find that establishing a consistent routine enables me to enjoy life more. } & 12 & 3456 & 7 \\
\hline \multicolumn{5}{|c|}{ I enjoy having a clear and structured mode of life. } & 12 & 34556 & \\
\hline \multicolumn{5}{|c|}{$\begin{array}{l}\text { I do not usually consult many different opinions before forming my own } \\
\text { view. }\end{array}$} & 12 & 3456 & 7 \\
\hline \multicolumn{5}{|c|}{ I dislike unpredictable situations. } & 12 & 3456 & 7 \\
\hline
\end{tabular}

Please turn the page over! 
Read each statement and select the answer that BEST describes you AS YOU REALLY ARE (1=strongly disagree; $7=$ strongly agree).

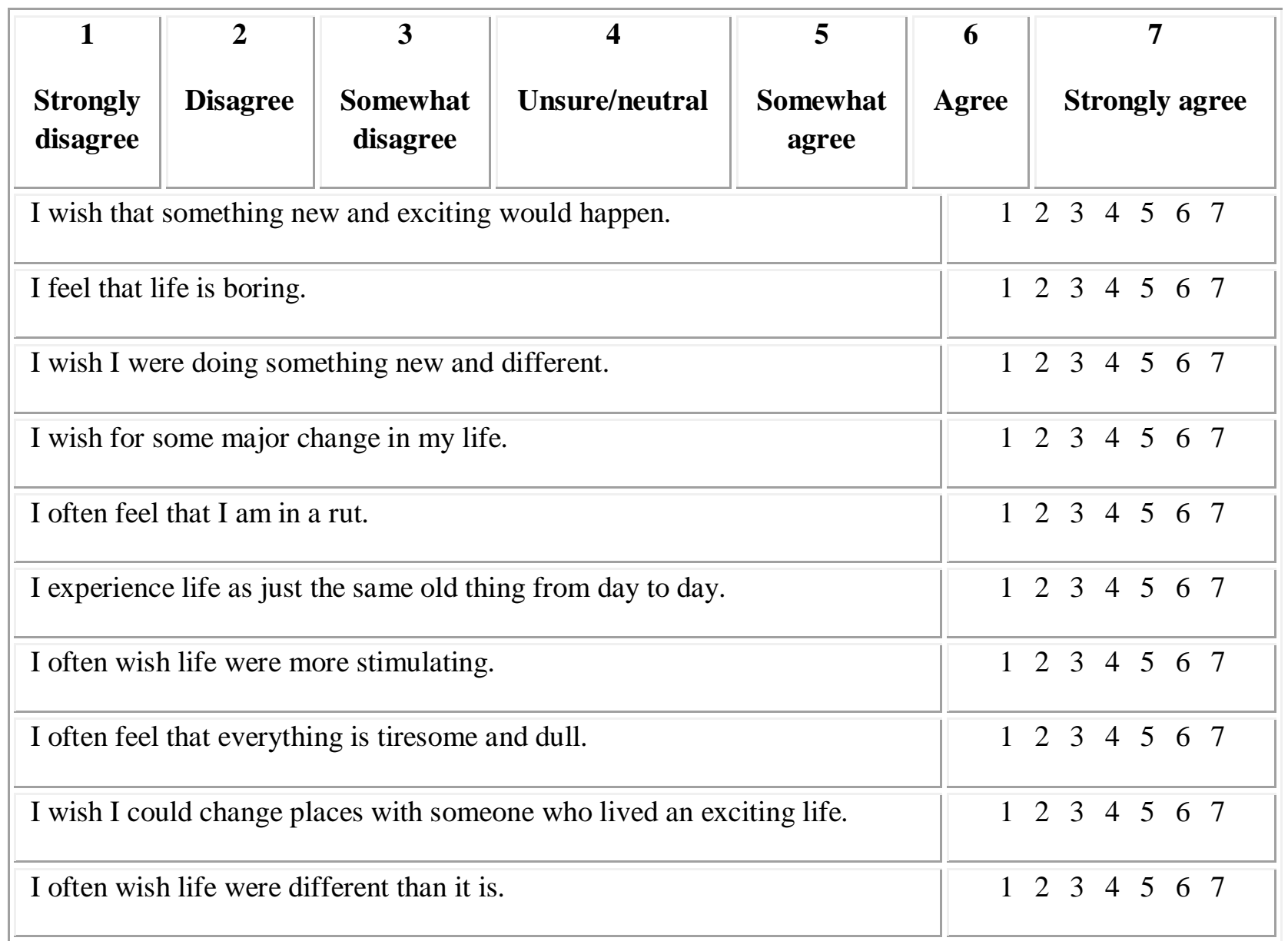

The following questions refer to your personal background. Please remember that your responses are anonymous.

1. How old are you? years.

2. What is your gender?

[ ] Female

[ ] Male

3. Which country were you born in?

4. For how many years have you been in New Zealand? years
5. Are you an international student?
[ ] yes
[ ] no 
A Dual-Process Motivational Model of Cross-Cultural Adaptation

6. Of what country are you a citizen?

7. Do you intend to stay in New Zealand indefinitely?
[ ] yes
[ ] no

8. If you do not intend to stay in New Zealand indefinitely, how long do you intend to stay?

years

9. Which ethnic group do you belong to?

\begin{tabular}{lll} 
[ & ] European & [ ] Pacific Nations \\
[ & ] Asian & [ $]$ Middle Eastern \\
[ ] Latin American & [ ] African \\
[ & ] Other (please specify) & \\
\hline
\end{tabular}

10. What is your religion?

\begin{tabular}{|c|c|}
\hline ] Christian & [ ] Buddhist \\
\hline ] Hindu & [ ] Muslim \\
\hline ] Jewish & [ ] no religion \\
\hline
\end{tabular}




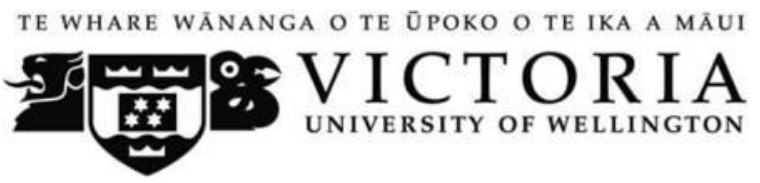

Thank you for participating in this research!

The survey was designed to investigate the psychometric properties of the first 20 questions that you answered and that are part of a newly developed measurement scale. However, how reliable is the scale? How do the questions relate to the other measurement scales used in the survey? These are important questions to ask when a new measurement tool is developed. The answers provide researchers with statistical information that is necessary to validate the measurement scale.

The results of this survey will determine which items (or questions) of the first part of the questionnaire will make it into the main study of my Masters thesis research project. Overall, the project is designed to increase our understanding of how immigrants settle into New Zealand society and it will generally help us to understand people's migration experience better.

The preliminary results of this study will be posted as a downloadable PDF by December 2012 on the CACR website: http://www.vuw.ac.nz/cacr. This research project is being conducted by Claudia Recker and Dr. Taciano L. Milfont. If you have any questions regarding your involvement in the research, or issues regarding the research in general, please do not hesitate to contact us via e-mail:

Claudia.Recker@vuw.ac.nz

Taciano.Milfont@vuw.ac.nz 
A Dual-Process Motivational Model of Cross-Cultural Adaptation

Appendix B

Study 2: Information Sheet, Questionnaire and Debriefing Sheet

\section{WELCOME}

Welcome!

This is an online survey about cultural aspects of immigration. The research is being conducted by a Masters student at Victoria University Wellington. It takes approximately 20 minutes to complete the survey.

If you are at least 18 years of age and interested in participating, please read through the consent form and more information on the following page. Please click "Next" to proceed.

Thank you for your interest!

Claudia Recker \& Dr. Taciano L. Milfont

\section{INFORMATION FOR PARTICIPANTS}

Welcome to a research project organized through Victoria University of Wellington's Centre for Applied Cross-Cultural Research.

We would like to invite you to participate in a study that is designed to help us gain a better understanding of how immigrants settle into New Zealand society.

Who is conducting the research?

This research is conducted by Claudia Recker, a Masters student of the School of Psychology at Victoria University of Wellington under the supervision of Dr Taciano Milfont. This research has been approved by the School of Psychology Human Ethics Committee under delegated authority of the VUW Human Ethics Committee.

To complete the following survey you must

- have been born outside of New Zealand

- have lived in this country for at least six months

- have come to New Zealand when you were at least 18 years old

- currently live in New Zealand.

What is involved if you agree to participate?

If you agree to participate in this study you will be asked to complete an anonymous online questionnaire where you will respond to questions or statements such as "It is exciting for me to explore new cultures." We anticipate that the survey will take you no more than 20 minutes to complete.

During the research you are free to withdraw at any point before your survey has been completed.

Privacy and Confidentiality: 
- This survey is completely anonymous. Please do not put your name on it anywhere.

- We will keep your data for at least five years after publication.

- You will never be identified in the research project or in any other presentation or publication. The information you provide will be identifiable by number only.

- In accordance with the requirements of some scientific journals and organisations, your anonymous responses may be shared with other competent researchers.

- Your survey responses may be used in other, related studies.

- Your response data will remain in the custody of Claudia Recker and Dr Taciano Milfont.

What happens to the information that you provide?

- The overall findings will be part of a Masters thesis that will be submitted for assessment.

- The survey response you provide may be submitted for publication in a scientific journal, or presented at scientific conferences.

Consent for Participation:

Please note that by completing and returning the questionnaire to the researchers online you agree that your survey responses will be used and analysed.

If you have any further questions regarding this study, please feel free to contact one of the investigators listed below.

Thank you for considering participation in this research.

Claudia Recker (email: Claudia.Recker@vuw.ac.nz)

Dr Taciano L. Milfont (email: Taciano.Milfont@ vuw.ac.nz) 


\section{Section A:}

Please read each statement and select the response that BEST describes you AS YOU REALLY ARE (from "strongly disagree" to "strongly agree").

\begin{tabular}{|c|c|c|c|c|c|c|}
\hline $\begin{array}{c}1 \\
\begin{array}{c}\text { Strongly } \\
\text { disagree }\end{array}\end{array}$ & $\begin{array}{c}2 \\
\text { Disagree }\end{array}$ & $\begin{array}{c}\mathbf{3} \\
\text { Somewhat } \\
\text { disagree }\end{array}$ & $\begin{array}{c}\text { Unsure/ } \\
\text { neutral }\end{array}$ & $\begin{array}{c}\text { Somewhat } \\
\text { agree }\end{array}$ & $\begin{array}{c}\mathbf{6} \\
\text { Agree }\end{array}$ & $\begin{array}{c}\text { Strongly } \\
\text { agree }\end{array}$ \\
\cline { 1 - 6 } & &
\end{tabular}

It is important for me to celebrate the holidays of my country of origin.

It is exciting for me to explore new cultures.

$\begin{array}{lllllll}1 & 2 & 3 & 4 & 5 & 6 & 7\end{array}$

It gives me a sense of security to socialise with people who share my cultural heritage.

I enjoy contact with people from other cultures because it broadens my horizon.

$\begin{array}{llllllll}1 & 2 & 3 & 4 & 5 & 6 & 7\end{array}$

It is important to keep my cultural traditions because they are part of who I am.

It is important to me to understand the views of people from different cultural backgrounds.

$\begin{array}{lllllll}1 & 2 & 3 & 4 & 5 & 6 & 7\end{array}$

It gives me pleasure to meet people who share my cultural heritage.

$\begin{array}{lllllll}1 & 2 & 3 & 4 & 5 & 6 & 7\end{array}$

Living in a country with a different culture gives me the opportunity to learn new ways of doing things.

I feel the need to live according to the traditions of my cultural heritage, particularly because I now live in another culture.

$\begin{array}{lllllll}1 & 2 & 3 & 4 & 5 & 6 & 7\end{array}$

I experience pleasure when my ethnic peers tell me stories from our country of origin.

It is exciting to go to places with a different cultural heritage, even though I don't know what might happen.

Sometimes it is important for me to put my own culture into perspective and acknowledge different views.

Maintaining my cultural traditions helps me to structure my life here in New Zealand.

$\begin{array}{lllllll}1 & 2 & 3 & 4 & 5 & 6 & 7\end{array}$

$\begin{array}{lllllll}1 & 2 & 3 & 4 & 5 & 6 & 7\end{array}$

$\begin{array}{lllllll}1 & 2 & 3 & 4 & 5 & 6 & 7\end{array}$

$\begin{array}{lllllll}1 & 2 & 3 & 4 & 5 & 6 & 7\end{array}$

$\begin{array}{lllllll}1 & 2 & 3 & 4 & 5 & 6 & 7\end{array}$

$\begin{array}{lllllll}1 & 2 & 3 & 4 & 5 & 6 & 7\end{array}$

It is deeply satisfying for me to have an emotional link with my cultural heritage.

It gives me pleasure to go to places where people from other countries display their culture (e.g. markets, arts festivals, concerts).

$\begin{array}{lllllll}1 & 2 & 3 & 4 & 5 & 6 & 7\end{array}$

I do not feel the need to practice my ethnic traditions.

$\begin{array}{lllllll}1 & 2 & 3 & 4 & 5 & 6 & 7\end{array}$

It gives me pleasure to meet people from other cultures.

$\begin{array}{lllllll}1 & 2 & 3 & 4 & 5 & 6 & 7\end{array}$

$\begin{array}{lllllll}1 & 2 & 3 & 4 & 5 & 6 & 7\end{array}$

$\begin{array}{lllllll}1 & 2 & 3 & 4 & 5 & 6 & 7\end{array}$

$\begin{array}{lllllll}1 & 2 & 3 & 4 & 5 & 6 & 7\end{array}$ 
Here are a number of statements concerning what people think about their ethnic heritage. Please read each statement carefully and indicate what best represents your personal response (from "strongly disagree" to "strongly agree"). There are no right or wrong answers, and your first responses are usually the most accurate. Remember, we want to know what you think about your heritage.

\begin{tabular}{|c|c|c|c|c|c|c|}
\hline $\begin{array}{c}1 \\
\begin{array}{c}\text { Strongly } \\
\text { disagree }\end{array}\end{array}$ & $\begin{array}{c}2 \\
\text { Disagree }\end{array}$ & $\begin{array}{c}3 \\
\text { Somewhat } \\
\text { disagree }\end{array}$ & $\begin{array}{c}4 \\
\text { Unsure/ } \\
\text { neutral }\end{array}$ & $\begin{array}{c}5 \\
\text { Somewhat } \\
\text { agree }\end{array}$ & $\begin{array}{c}6 \\
\text { Agree }\end{array}$ & $\begin{array}{c}7 \\
\text { Strongly agree }\end{array}$ \\
\hline
\end{tabular}

Continuing to practice my ethnic traditions and celebrations is important to me.

Ultimately, I would like my children to identify as being part of our ethnic culture.

$\begin{array}{lllllll}1 & 2 & 3 & 4 & 5 & 6 & 7\end{array}$

The future continuity of our ethnic community is NOT a concern of mine.

Maintaining my ethnic heritage is NOT something I care about.

I would like to encourage my children to learn our ethnic language.

Long-term, I would like my grandchildren and great-grandchildren to continue our ethnic heritage.

I do NOT mind setting aside the traditions of my ethnic heritage.

$\begin{array}{lllllll}1 & 2 & 3 & 4 & 5 & 6 & 7\end{array}$

I would like to keep on living according to the traditions of my ethnic heritage.

I want to transmit to my children a love for and interest in their ethnic heritage.

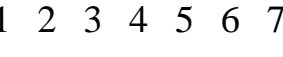

I think it's good to create an environment at home where my ethnic traditions can be a normal part of life for my children.

$\begin{array}{lllllll}1 & 2 & 3 & 4 & 5 & 6 & 7\end{array}$

Read each statement and select the response that best describes your capabilities. Select the answer that BEST describes you AS YOU REALLY ARE (from "strongly disagree" to "strongly agree").

\begin{tabular}{|c|c|c|c|c|c|c|}
\hline $\begin{array}{l}1 \\
\text { Strongly } \\
\text { disagree }\end{array}$ & $\begin{array}{c}2 \\
\text { Disagree }\end{array}$ & $\begin{array}{c}3 \\
\text { Somewhat } \\
\text { disagree }\end{array}$ & $\begin{array}{c}4 \\
\text { Unsure/ } \\
\text { neutral }\end{array}$ & $\begin{array}{l}5 \\
\text { Somewhat } \\
\text { agree }\end{array}$ & $\begin{array}{c}6 \\
\text { Agree }\end{array}$ & $\begin{array}{c}7 \\
\text { Strongly agree }\end{array}$ \\
\hline \multicolumn{6}{|c|}{ I enjoy interacting with people from different cultures. } & $\begin{array}{lllllll}1 & 2 & 3 & 4 & 5 & 6 & 7\end{array}$ \\
\hline \multicolumn{6}{|c|}{$\begin{array}{l}\text { I am confident that I can socialize with locals in a culture that is } \\
\text { unfamiliar to me. }\end{array}$} & $\begin{array}{lllllll}1 & 2 & 3 & 4 & 5 & 6 & 7\end{array}$ \\
\hline \multicolumn{6}{|c|}{$\begin{array}{l}\text { I am sure I can deal with the stresses of adjusting to a culture that is } \\
\text { new to me. }\end{array}$} & $\begin{array}{lllllll}1 & 2 & 3 & 4 & 5 & 6 & 7\end{array}$ \\
\hline \multicolumn{6}{|c|}{ I enjoy living in cultures that are unfamiliar to me. } & $\begin{array}{lllllll}1 & 2 & 3 & 4 & 5 & 6 & 7\end{array}$ \\
\hline \multicolumn{6}{|c|}{$\begin{array}{l}\text { I am confident that I can get accustomed to the shopping conditions in } \\
\text { a different culture. }\end{array}$} & $\begin{array}{lllllll}1 & 2 & 3 & 4 & 5 & 6 & 7\end{array}$ \\
\hline
\end{tabular}


Please indicate to what extent each of these statements in general applies to you. There are no 'correct' or 'incorrect' answers. There is no need to think very long about each answer.

To what extent does the following statement apply to you?

\begin{tabular}{|c|c|c|c|c|c|c|}
\hline $\begin{array}{c}1 \\
\text { Hardly } \\
\text { applicable }\end{array}$ & $\begin{array}{c}2 \\
\text { Moderately } \\
\text { applicable }\end{array}$ & $\begin{array}{c}3 \\
\text { Largely } \\
\text { applicable }\end{array}$ & \multicolumn{4}{|c|}{$\stackrel{4}{\text { Completely Applicable }}$} \\
\hline \multicolumn{3}{|c|}{ Is interested in other cultures. } & 1 & 2 & 3 & 4 \\
\hline \multicolumn{3}{|c|}{ Avoids from adventure. } & 1 & 2 & 3 & 4 \\
\hline \multicolumn{3}{|c|}{ Is fascinated by other people's opinions. } & 1 & 2 & 3 & 4 \\
\hline \multicolumn{3}{|c|}{ Tries to understand other people's behaviour. } & 1 & 2 & 3 & 4 \\
\hline \multicolumn{3}{|c|}{ Wants to know exactly what will happen. } & 1 & 2 & 3 & 4 \\
\hline \multicolumn{3}{|c|}{ Easily approaches other people. } & 1 & 2 & 3 & 4 \\
\hline \multicolumn{3}{|c|}{ Finds other religions interesting. } & 1 & 2 & 3 & 4 \\
\hline \multicolumn{3}{|c|}{ Feels uncomfortable in a different culture. } & 1 & 2 & 3 & 4 \\
\hline \multicolumn{3}{|c|}{ Starts a new life easily. } & 1 & 2 & 3 & 4 \\
\hline \multicolumn{3}{|c|}{ Gets involved in other cultures. } & 1 & 2 & 3 & 4 \\
\hline \multicolumn{3}{|c|}{ Has a feeling for what is appropriate in other cultures. } & 1 & 2 & 3 & 4 \\
\hline \multicolumn{3}{|c|}{ Seeks contact with people from a different cultural background. } & 1 & 2 & 3 & 4 \\
\hline \multicolumn{3}{|c|}{ Enjoys unfamiliar experiences. } & 1 & 2 & 3 & 4 \\
\hline \multicolumn{3}{|c|}{ Looks for regularity in life. } & 1 & 2 & 3 & 4 \\
\hline
\end{tabular}

Please indicate to what extent each of these statements in general applies to you. There are no 'correct' or 'incorrect' answers. There is no need to think very long about each answer.

\begin{tabular}{|c|c|c|c|c|c|c|}
\hline \multirow{2}{*}{$\begin{array}{c}\begin{array}{c}1 \\
\text { Hardly } \\
\text { applicable }\end{array} \\
\text { Get out of control. }\end{array}$} & \multirow[t]{2}{*}{$\begin{array}{c}2 \\
\text { Moderately } \\
\text { applicable }\end{array}$} & \multirow[t]{2}{*}{$\begin{array}{c}3 \\
\text { Largely } \\
\text { applicable }\end{array}$} & \multicolumn{4}{|c|}{$\stackrel{4}{\text { Completely Applicable }}$} \\
\hline & & & 1 & 2 & 3 & 4 \\
\hline \multicolumn{3}{|c|}{ Find myself in the same kinds of trouble, time after time. } & 1 & 2 & 3 & 4 \\
\hline \multicolumn{3}{|c|}{ Am self-destructive. } & 1 & 2 & 3 & 4 \\
\hline \multicolumn{3}{|c|}{ Talk even when I know I shouldn't. } & 1 & 2 & 3 & 4 \\
\hline \multicolumn{3}{|c|}{ Grumble about things. } & 1 & 2 & 3 & 4 \\
\hline \multicolumn{3}{|l|}{ Feel desperate. } & 1 & 2 & 3 & 4 \\
\hline \multicolumn{3}{|l|}{ Find life difficult. } & 1 & 2 & 3 & 4 \\
\hline \multicolumn{3}{|c|}{ Am not sure where my life is going. } & 1 & 2 & 3 & 4 \\
\hline \multicolumn{3}{|c|}{ Have a strong personality. } & 1 & 2 & 3 & 4 \\
\hline \multicolumn{3}{|l|}{ Have little to say. } & 1 & 2 & 3 & 4 \\
\hline \multicolumn{3}{|c|}{ Have a natural talent for influencing people. } & 1 & 2 & 3 & 4 \\
\hline
\end{tabular}




\begin{tabular}{|c|c|c|c|c|}
\hline When with a group, have difficulties selecting a good topic to talk about. & 1 & 2 & 3 & 4 \\
\hline Express myself easily. & 1 & 2 & 3 & 4 \\
\hline Am able to come up with new and different ideas. & 1 & 2 & 3 & 4 \\
\hline Look forward to the opportunity to learn and grow. & 1 & 2 & 3 & 4 \\
\hline Am interested in many things. & 1 & 2 & 3 & 4 \\
\hline
\end{tabular}

\section{Section B}

Here are some questions about your friends and people you know. Please indicate the answer that applies best.

How many close ethnic (from your culture), national (from the country that you now live in), and other ethnic friends (from other cultures) do you have?

\begin{tabular}{|c|c|c|c|c|}
\hline $\begin{array}{c}1 \\
\text { None }\end{array}$ & $\begin{array}{c}2 \\
\text { Only one }\end{array}$ & $\begin{array}{c}3 \\
\text { A few }\end{array}$ & $\begin{array}{c}4 \\
\text { Some }\end{array}$ & $\begin{array}{c}5 \\
\text { Many }\end{array}$ \\
\hline \multicolumn{4}{|c|}{ Close ethnic friends (from your culture) } & $\begin{array}{lllll}1 & 2 & 3 & 4 & 5\end{array}$ \\
\hline \multicolumn{4}{|c|}{ Close national friends (from New Zealand) } & $\begin{array}{lllll}1 & 2 & 3 & 4 & 5\end{array}$ \\
\hline \multicolumn{4}{|c|}{ Close other ethnic friends (from other cultures) } & $\begin{array}{lllll}1 & 2 & 3 & 4 & 5\end{array}$ \\
\hline
\end{tabular}

How often do you spend time at work with ...

\begin{tabular}{|c|c|c|c|c|}
\hline $\begin{array}{c}1 \\
\text { Almost never }\end{array}$ & $\begin{array}{c}2 \\
\text { Seldom }\end{array}$ & $\begin{array}{c}3 \\
\text { Sometimes }\end{array}$ & $\begin{array}{c}4 \\
\text { Often }\end{array}$ & $\begin{array}{c}5 \\
\text { Always }\end{array}$ \\
\hline \multicolumn{4}{|c|}{ Ethnic members (from your culture) } & $\begin{array}{lllll}1 & 2 & 3 & 4 & 5\end{array}$ \\
\hline \multicolumn{4}{|c|}{ National members (from New Zealand) } & $\begin{array}{lllll}1 & 2 & 3 & 4 & 5\end{array}$ \\
\hline \multicolumn{4}{|c|}{ Other ethnic members (from other cultures) } & $\begin{array}{lllll}1 & 2 & 3 & 4 & 5\end{array}$ \\
\hline
\end{tabular}

In your spare time how often do you spend time with ...

\begin{tabular}{|c|c|c|c|c|}
\hline $\begin{array}{c}1 \\
\text { Almost never }\end{array}$ & $\begin{array}{c}2 \\
\text { Seldom }\end{array}$ & $\begin{array}{c}3 \\
\text { Sometimes }\end{array}$ & $\begin{array}{c}4 \\
\text { Often }\end{array}$ & $\begin{array}{c}5 \\
\text { Always }\end{array}$ \\
\hline \multicolumn{4}{|c|}{ Ethnic members (from your culture) } & $\begin{array}{lllll}1 & 2 & 3 & 4 & 5\end{array}$ \\
\hline \multicolumn{4}{|c|}{ National members (from New Zealand) } & $\begin{array}{lllll}1 & 2 & 3 & 4 & 5\end{array}$ \\
\hline \multicolumn{4}{|c|}{ Other ethnic members (from other cultures) } & $\begin{array}{lllll}1 & 2 & 3 & 4 & 5\end{array}$ \\
\hline
\end{tabular}


Here are some questions about languages. Please indicate the answer that applies best.

What language do you speak at home?

\begin{tabular}{|c|c|c|c|c|}
\hline $\begin{array}{c}1 \\
\text { Not at all }\end{array}$ & $\begin{array}{c}2 \\
\text { A little }\end{array}$ & $\begin{array}{c}3 \\
\text { Half the time }\end{array}$ & $\begin{array}{c}4 \\
\text { A lot }\end{array}$ & $\begin{array}{c}5 \\
\text { All the time }\end{array}$ \\
\hline \multicolumn{4}{|c|}{ I speak my ethnic language. } & 12345 \\
\hline \multicolumn{4}{|c|}{ I speak English. } & $\begin{array}{lllll}1 & 2 & 3 & 4 & 5\end{array}$ \\
\hline
\end{tabular}

How well do you ...

\begin{tabular}{|c|c|c|c|c|}
\hline 1 & 2 & 3 & 4 & 5 \\
Not at all & A little & Somewhat & Fairly well & Very well \\
\hline
\end{tabular}

Understand your ethnic language?

Speak your ethnic language?

$\begin{array}{lllll}1 & 2 & 3 & 4 & 5\end{array}$

Read your ethnic language?

$\begin{array}{lllll}1 & 2 & 3 & 4 & 5\end{array}$

Write your ethnic language?

$\begin{array}{llllll}1 & 2 & 3 & 4 & 5\end{array}$

Understand English?

Speak English?

$\begin{array}{lllll}1 & 2 & 3 & 4 & 5\end{array}$

Read English?

$\begin{array}{lllll}1 & 2 & 3 & 4 & 5\end{array}$

Write English?

$\begin{array}{llll}2 & 3 & 4 & 5\end{array}$

$\begin{array}{lllll}1 & 2 & 3 & 4 & 5\end{array}$

$\begin{array}{llllll}1 & 2 & 3 & 4 & 5\end{array}$

The following questions concern the media you use. Please indicate the answer that applies best.

\begin{tabular}{|c|c|c|c|c|}
\hline $\begin{array}{c}\text { Almost } \\
\text { never }\end{array}$ & $\begin{array}{c}2 \\
\text { Seldom }\end{array}$ & $\begin{array}{c}3 \\
\text { Sometimes }\end{array}$ & $\begin{array}{c}4 \\
\text { Often }\end{array}$ & $\begin{array}{c}5 \\
\text { Always }\end{array}$ \\
\hline
\end{tabular}

How often do you watch television programs in English?

How often do you listen to music in English?

How often do you watch television programs in your native language?

How often do you listen to music in your native language?

When reading (online) newspapers I read them in my native language.

When reading (online) newspapers I read them in English.

When reading books I read them in my native language.

When reading books I read them in English.

\begin{tabular}{|lllll|}
\hline 1 & 2 & 3 & 4 & 5 \\
\hline 1 & 2 & 3 & 4 & 5 \\
\hline 1 & 2 & 3 & 4 & 5 \\
\hline 1 & 2 & 3 & 4 & 5 \\
\hline 1 & 2 & 3 & 4 & 5 \\
\hline 1 & 2 & 3 & 4 & 5 \\
\hline 1 & 2 & 3 & 4 & 5 \\
\hline 1 & 2 & 3 & 4 & 5 \\
\hline
\end{tabular}


The following question concerns your food preferences. Please indicate the answer that applies best.

What is your food preference?

Exclusively from my native country

Mostly from my native country, some from my host country

About equally

Mostly from my host country

Exclusively from my host country

\section{Section C:}

Please indicate for each of the five statements which is closest to how you have been feeling over the last two weeks. Notice that higher numbers mean better wellbeing.

Over the last two weeks ...

\begin{tabular}{|c|c|c|c|c|}
\hline $\begin{array}{c}1 \\
\text { At no time }\end{array}$ & $\begin{array}{c}2 \\
\text { Some of the } \\
\text { time }\end{array}$ & $\begin{array}{c}3 \\
\text { Less than half } \\
\text { of the time }\end{array}$ & $\begin{array}{c}4 \\
\text { More than half } \\
\text { of the time }\end{array}$ & $\begin{array}{c}5 \\
\text { All of the time }\end{array}$ \\
\hline \multicolumn{4}{|c|}{ I have felt cheerful and in good spirits. } & $\begin{array}{lllll}1 & 2 & 3 & 4 & 5\end{array}$ \\
\hline \multicolumn{4}{|c|}{ I have felt calm and relaxed. } & $\begin{array}{lllll}1 & 2 & 3 & 4 & 5\end{array}$ \\
\hline \multicolumn{4}{|c|}{ I have felt active and vigorous. } & $\begin{array}{lllll}1 & 2 & 3 & 4 & 5\end{array}$ \\
\hline \multicolumn{4}{|c|}{ I woke up feeling fresh and relaxed. } & $\begin{array}{lllll}1 & 2 & 3 & 4 & 5\end{array}$ \\
\hline \multicolumn{4}{|c|}{ My daily life has been filled with things that interest me. } & $\begin{array}{lllll}1 & 2 & 3 & 4 & 5\end{array}$ \\
\hline
\end{tabular}

The following questions refer to how satisfied you are with your life. Please indicate the answer that applies best.

\begin{tabular}{|c|c|c|c|c|c|c|}
\hline $\begin{array}{c}\text { Strongly } \\
\text { disagree }\end{array}$ & $\begin{array}{c}2 \\
\text { Disagree }\end{array}$ & $\begin{array}{c}\text { S } \\
\text { Slightly } \\
\text { disagree }\end{array}$ & $\begin{array}{c}4 \\
\text { Neither } \\
\text { agree } \\
\text { nor } \\
\text { disagree }\end{array}$ & $\begin{array}{c}\text { Slightly } \\
\text { agree }\end{array}$ & $\begin{array}{c}6 \\
\text { Agree }\end{array}$ & Strongly agree \\
\hline
\end{tabular}

In most ways my life is close to my ideal.

The conditions of my life are excellent.

$\begin{array}{lllllll}1 & 2 & 3 & 4 & 5 & 6 & 7\end{array}$

I am satisfied with my life.

$\begin{array}{llllllll}1 & 2 & 3 & 4 & 5 & 6 & 7\end{array}$

So far have gotten the important things I want in life.

$\begin{array}{llllllll}1 & 2 & 3 & 4 & 5 & 6 & 7\end{array}$

If I could live my life over, I would change almost nothing.

$\begin{array}{llllllllll}1 & 2 & 3 & 4 & 5 & 6 & 7\end{array}$

$\begin{array}{lllllll}1 & 2 & 3 & 4 & 5 & 6 & 7\end{array}$ 
Living in a different culture often involves learning new skills and behaviours. Thinking about life in your host country please rate your competence at each the following behaviours $(1=$ Not at all competent; 5 = Extremely competent $)$.

\begin{tabular}{|c|c|c|c|c|}
\hline $\begin{array}{c}1 \\
\text { Not at all } \\
\text { competent }\end{array}$ & $\begin{array}{c}2 \\
\text { Somewhat } \\
\text { competent }\end{array}$ & $\begin{array}{c}3 \\
\text { Unsure/neutral }\end{array}$ & $\begin{array}{c}4 \\
\text { Competent }\end{array}$ & $\begin{array}{c}5 \\
\text { Extremely } \\
\text { competen }\end{array}$ \\
\hline \multicolumn{4}{|c|}{ Building and maintaining relationships. } & $\begin{array}{lllll}1 & 2 & 3 & 4 & 5\end{array}$ \\
\hline \multicolumn{4}{|c|}{ Managing my academic/ work responsibilities. } & $\begin{array}{lllll}1 & 2 & 3 & 4 & 5\end{array}$ \\
\hline \multicolumn{4}{|c|}{ Interacting at social events. } & $\begin{array}{lllll}1 & 2 & 3 & 4 & 5\end{array}$ \\
\hline \multicolumn{4}{|c|}{ Maintaining my hobbies and interests. } & $\begin{array}{lllll}1 & 2 & 3 & 4 & 5\end{array}$ \\
\hline \multicolumn{4}{|c|}{ Adapting to the noise level in my neighbourhood. } & $\begin{array}{lllll}1 & 2 & 3 & 4 & 5\end{array}$ \\
\hline \multicolumn{4}{|c|}{$\begin{array}{l}\text { Accurately interpreting and responding to other people's gestures } \\
\text { and facial expressions. }\end{array}$} & $\begin{array}{lllll}1 & 2 & 3 & 4 & 5\end{array}$ \\
\hline \multicolumn{4}{|c|}{ Working effectively with other students/ work colleagues. } & $\begin{array}{lllll}1 & 2 & 3 & 4 & 5\end{array}$ \\
\hline \multicolumn{4}{|c|}{ Obtaining community services I require. } & $\begin{array}{lllll}1 & 2 & 3 & 4 & 5\end{array}$ \\
\hline \multicolumn{4}{|c|}{ Adapting to the population density. } & $\begin{array}{lllll}1 & 2 & 3 & 4 & 5\end{array}$ \\
\hline \multicolumn{4}{|c|}{ Understanding and speaking English. } & $\begin{array}{lllll}1 & 2 & 3 & 4 & 5\end{array}$ \\
\hline \multicolumn{4}{|c|}{ Varying the rate of my speaking in a culturally appropriate manner. } & $\begin{array}{lllll}1 & 2 & 3 & 4 & 5\end{array}$ \\
\hline \multicolumn{4}{|c|}{$\begin{array}{l}\text { Gaining feedback from other students/work colleagues to help } \\
\text { improve my performance. }\end{array}$} & $\begin{array}{lllll}1 & 2 & 3 & 4 & 5\end{array}$ \\
\hline \multicolumn{4}{|c|}{ Accurately interpreting and responding to other people's emotions. } & $\begin{array}{lllll}1 & 2 & 3 & 4 & 5\end{array}$ \\
\hline \multicolumn{4}{|c|}{ Attending or participating in community activities. } & $\begin{array}{lllll}1 & 2 & 3 & 4 & 5\end{array}$ \\
\hline \multicolumn{4}{|c|}{ Finding my way around. } & $\begin{array}{lllll}1 & 2 & 3 & 4 & 5\end{array}$ \\
\hline \multicolumn{4}{|c|}{ Interacting with members of the opposite sex. } & $\begin{array}{lllll}1 & 2 & 3 & 4 & 5\end{array}$ \\
\hline \multicolumn{4}{|c|}{$\begin{array}{l}\text { Expressing my ideas to other students/ work colleagues in a } \\
\text { culturally appropriate manner. }\end{array}$} & $\begin{array}{lllll}1 & 2 & 3 & 4 & 5\end{array}$ \\
\hline \multicolumn{4}{|c|}{ Dealing with bureaucracy. } & $\begin{array}{lllll}1 & 2 & 3 & 4 & 5\end{array}$ \\
\hline \multicolumn{4}{|c|}{ Adapting to the pace of life. } & $\begin{array}{lllll}1 & 2 & 3 & 4 & 5\end{array}$ \\
\hline \multicolumn{4}{|c|}{ Reading and writing English. } & $\begin{array}{lllll}1 & 2 & 3 & 4 & 5 \\
\end{array}$ \\
\hline \multicolumn{4}{|c|}{$\begin{array}{l}\text { Changing my behaviour to suit social norms, rules, attitudes, beliefs } \\
\text { and customs. }\end{array}$} & $\begin{array}{lllll}1 & 2 & 3 & 4 & 5\end{array}$ \\
\hline
\end{tabular}

\section{$\underline{\text { Section D: }}$}

The following questions refer to your personal background. Please remember that your responses are anonymous.

1. What is your age (in years)? years.

2. What is your gender?

[ ] Female [ ] Male

3. Which country were you born in?

4. For how many years have you been in New Zealand? years 
A Dual-Process Motivational Model of Cross-Cultural Adaptation

5. Are you a New Zealand citizen?

[ ] yes

[ ] no

6. If you are not a New Zealand citizen, do you have permanent residency?

[ ] yes [ ] no

7. Are you an international student?

[ ] yes [ ] no

8. Are you a citizen of another country? [ ] yes

[ ] no

9. If yes, of what other country are you a citizen?

10. Do you intend to stay in New Zealand indefinitely?
[ ] yes
[ ] no

11. If you do not intend to stay in New Zealand indefinitely, how long do you intend to stay?

years [ ] not sure

12. Which ethnic group do you belong to?
[ ] European
[ ] Pacific Nations
[ ] Asian
[ ] Middle Eastern
[ ] Latin American
[ ] African
[ ] Other (please specify)

13. What is your religion?
[ ] Christian
[ ] Buddhist
[ ] Hindu
[ ] Muslim
[ ] Jewish
[ ] no religion
[ ] Other (write in ) 


\section{DEBRIEFING}

Thank you for participating in this research.

What happens when people move to a different culture? Do they stick to the cultural norms they are used to, or do they try to learn as much as possible about the new culture?

Past research has found that migrants are relatively inclined to either maintain their cultural heritage and identity, or to engage with the people in the host society and be part of that society (Berry, 2005).

However, no study has previously examined whether these 'inclinations' are in fact distinct motivations: the motivation to maintain one's cultural heritage and the motivation to explore the host culture. With this research we hope to understand these motivations better (hence the questions in Section 1 about your ethnic traditions and your experience with the new culture).

Furthermore, we are trying to answer the question whether the motivation to maintain the heritage culture and the motivation to explore the host culture influence the behaviour of migrants. We expect that, for instance, people with a high motivation to maintain their heritage culture behave in a way that facilitates cultural maintenance (e.g., having a lot of friends from their country of origin -- hence the questions in Section 2 about whether your friends are New Zealanders or migrants).

Lastly, we want to find out if the behaviours that facilitate the maintenance of the heritage culture and the behaviours that facilitate the exploration of the host culture influence how people adapt in New Zealand (hence the questions in Section 3 about how satisfied you are with your life, for example).

The results of this research will allow us to determine if there are indeed links between migrants' motivations of cultural maintenance and exploration, their behaviour and their adaptation in the host country. Generally, this knowledge will help us to gain a better understanding of people's migration experience.

Thank you for participating in this research. The preliminary results of this study will be posted as a downloadable PDF by December 2012 on the CACR website:

http://www.vuw.ac.nz/cacr. This research project is being conducted by Claudia Recker and Dr. Taciano L. Milfont. If you have any questions regarding your involvement in the research, or issues regarding the research in general, please do not hesitate to contact us via e-mail:

Claudia.Recker@vuw.ac.nz

Taciano.Milfont@vuw.ac.nz

\section{Reference:}

Berry, J.W. (2005). Acculturation: Living successfully in two cultures. International Journal of Intercultural Relations, 29, 697-712. 
A Dual-Process Motivational Model of Cross-Cultural Adaptation

Appendix C

Participants' Countries of Birth, $N=280$

\begin{tabular}{|c|c|c|}
\hline Country of Birth & $n$ & \% of total sample \\
\hline Germany & 32 & 11.4 \\
\hline UK & 31 & 11.1 \\
\hline Finland & 19 & 6.8 \\
\hline Argentina, India, South Africa ${ }^{a}$ & 18 & 6.4 \\
\hline Netherlands & 17 & 6.1 \\
\hline USA & 15 & 5.4 \\
\hline Indonesia & 9 & 3.2 \\
\hline China & 8 & 2.9 \\
\hline Malaysia & 6 & 2.1 \\
\hline Australia, Italy, Philippines, Sri Lanka ${ }^{a}$ & 5 & 1.8 \\
\hline $\begin{array}{l}\text { Belgium, Brazil, Canada, Fiji, Hungary, } \\
\text { Russia, Spain }^{\text {a }}\end{array}$ & 4 & 1.4 \\
\hline Ireland, Singapore ${ }^{a}$ & 3 & 1.1 \\
\hline $\begin{array}{l}\text { Chile, Colombia, France, Hong Kong, } \\
\text { Japan, Mexico a }\end{array}$ & 2 & .7 \\
\hline $\begin{array}{l}\text { Algeria, Burma (Myanmar), Croatia, Czech } \\
\text { Republic, Ethiopia, Guam, Israel, } \\
\text { Kyrgyzstan, Nepal, Nigeria, Northern } \\
\text { Rhodesia, Panama, Serbia, South America, } \\
\text { South Korea, Switzerland, Taiwan, } \\
\text { Thailand, Tonga, Ukraine, Uzbekistan, } \\
\text { Vietnam, Zimbabwe }^{\text {a }}\end{array}$ & 1 & .4 \\
\hline
\end{tabular}


A Dual-Process Motivational Model of Cross-Cultural Adaptation

\section{Appendix D}

Participants' Ethnicity and Religious Affiliation, $N=280$

\begin{tabular}{lrr}
\hline & $n$ \% of total sample \\
\hline Ethnicity & 161 & 57.5 \\
European & 49 & 17.5 \\
Asian & 41 & 14.6 \\
Other ${ }^{\text {a }}$ & 24 & 8.6 \\
Latin American & 3 & 1.1 \\
Pacific Nation & 2 & .7 \\
African & 117 & \\
Religion & 117 & 41.8 \\
No religion & 17 & 41.8 \\
Christian & 13 & 6.1 \\
Hindu & 9 & 4.6 \\
Buddhist & 6 & 3.2 \\
Other & 1 & 2.1 \\
Muslim & .4 \\
Jewish & This category includes, for example, Indian, Sri Lankan, \\
American, Dutch, Indonesian, Russian, Scandinavian &
\end{tabular}


A Dual-Process Motivational Model of Cross-Cultural Adaptation

\section{Appendix E}

Descriptive Statistics (Non-English Language Sub-Sample, $n=198$ )

\begin{tabular}{lcccr}
\hline Scale & No. of items & $\alpha$ & $M$ & SD \\
\hline Behaviours & & & & \\
Language Use (Ethnic) & 1 & $-^{--^{\mathrm{a}}}$ & 3.47 & 1.34 \\
Language Use (English) & 1 & $-^{-}$ & 3.84 & 1.28 \\
Language Proficiency (Ethnic) & 4 & .90 & 4.85 & .48 \\
Language Proficiency (English) $^{\text {Food Preference }}{ }^{\mathrm{b}}$ & 4 & .91 & 4.75 & .42 \\
Media Use (English) & 1 & $--^{\mathrm{a}}$ & 3.03 & .79 \\
Media Use (Ethnic) & 4 & .66 & 4.15 & .71 \\
& 4 & .67 & 2.59 & .87
\end{tabular}

Note: $\mathrm{M}=$ mean item scores; ${ }^{\mathrm{a}}$ Scale contains only one item; ${ }^{\mathrm{b}}$ calculated on basis $n=280$ (i.e., including native English speakers) 
A Dual-Process Motivational Model of Cross-Cultural Adaptation

Appendix F

Correlations ( $n=198$, English as $2^{\text {nd }}$ language speakers only)

\begin{tabular}{|c|c|c|c|c|c|c|c|c|c|c|c|c|c|c|}
\hline & MCM & MCE & $\begin{array}{l}\text { Ethnic } \\
\text { Peer } \\
\text { Contact }\end{array}$ & $\begin{array}{l}\text { National } \\
\text { Peer } \\
\text { Contact }\end{array}$ & $\begin{array}{l}\text { Media } \\
\text { Use - } \\
\text { English }\end{array}$ & $\begin{array}{l}\text { Media } \\
\text { Use - } \\
\text { Native }\end{array}$ & Food & $\begin{array}{l}\text { English } \\
\text { Language } \\
\text { Proficiency }\end{array}$ & $\begin{array}{l}\text { Language } \\
\text { Use } \\
\text { (Ethnic) }\end{array}$ & $\begin{array}{l}\text { Language } \\
\text { Use } \\
\text { (English) }\end{array}$ & $\begin{array}{l}\text { SCAS- } \\
\mathrm{R}\end{array}$ & $\begin{array}{l}\text { Psychological } \\
\text { Adaptation }\end{array}$ & $\begin{array}{l}\text { WHO- } \\
5\end{array}$ & SWLS \\
\hline MCM & - & $.26 * *$ & $.45 * *$ & -.01 & -.08 & $.38 * *$ & $-.29 * *$ & -.02 & $.28 * *$ & -.10 & -.01 & .05 & .05 & .04 \\
\hline MCE & & - & .13 & .06 & .13 & .09 & -.02 & .09 & .11 & .34 & $.15^{*}$ & .09 & .07 & .08 \\
\hline $\begin{array}{l}\text { Ethnic Peer } \\
\text { Contact }\end{array}$ & & & - & .107 & .07 & $.17^{*}$ & $-.23 * *$ & -.05 & $.30 * *$ & -.07 & .13 & $.16^{*}$ & .13 & $.15^{*}$ \\
\hline $\begin{array}{l}\text { National Peer } \\
\text { Contact }\end{array}$ & & & & - & $.36 * *$ & -.03 & .13 & $.28 * *$ & $-.21 * *$ & $.32 * *$ & $.46 * *$ & $.43 * *$ & $.43 * *$ & $.32 * *$ \\
\hline $\begin{array}{l}\text { Media Use - } \\
\text { English }\end{array}$ & & & & & - & $-.28 * *$ & $.15^{*}$ & $.40 * *$ & $-.16^{*}$ & $.37 * *$ & $.35 * *$ & $.23 * *$ & $.28 * *$ & .13 \\
\hline $\begin{array}{l}\text { Media Use - } \\
\text { Native }\end{array}$ & & & & & & - & $-.18^{*}$ & -.09 & $.33 * *$ & $-.18 *$ & -.09 & -.06 & -.08 & -.02 \\
\hline Food & & & & & & & - & -.00 & $-.19 * *$ & .13 & .13 & .04 & .06 & .01 \\
\hline $\begin{array}{l}\text { English } \\
\text { Language } \\
\text { Proficiency }\end{array}$ & & & & & & & & - & $-.17 *$ & $.32 * *$ & $.32 * *$ & $.18 * *$ & $.16^{*}$ & $.16^{*}$ \\
\hline $\begin{array}{l}\text { Language } \\
\text { Use (Ethnic) }\end{array}$ & & & & & & & & & - & $-.57 * *$ & $-.24 * *$ & $-.18 *$ & $-.18 *$ & $-.15^{*}$ \\
\hline $\begin{array}{l}\text { Language } \\
\text { Use (English) }\end{array}$ & & & & & & & & & & - & $.26 * *$ & .06 & .13 & -.02 \\
\hline SCAS-R & & & & & & & & & & & - & $.54 * *$ & $.49 * *$ & $.47 * *$ \\
\hline $\begin{array}{l}\text { Psychological } \\
\text { Adaptation }\end{array}$ & & & & & & & & & & & & - & $.88 * *$ & $.88 * *$ \\
\hline WHO 5 & & & & & & & & & & & & & - & $.55 * *$ \\
\hline SWLS & & & & & & & & & & & & & & - \\
\hline
\end{tabular}

Note: SCAS-R = Revised Sociocultural Adaptation Scale; WHO 5 = WHO (Five) Wellbeing Index; SWLS = Satisfaction with Life Scale; Psychological Adaptation is constructed of WHO 5 and SWLS 
A Dual-Process Motivational Model of Cross-Cultural Adaptation

Appendix G

Skewness and Kurtosis

\begin{tabular}{|c|c|c|}
\hline Scale & Skewness & Kurtosis \\
\hline \multicolumn{3}{|l|}{ Full sample $(N=280)$} \\
\hline MCM Scale & -.36 & -.42 \\
\hline MCE Scale & -1.32 & 2.63 \\
\hline Motivation Ethnocultural Continuity (MEC) Scale & -.47 & -.14 \\
\hline Cultural Intelligence Scale & -.73 & .85 \\
\hline MPQ - Openmindedness ${ }^{a}$ & -.17 & -.43 \\
\hline MPQ - Flexibility ${ }^{a}$ & -.13 & -.65 \\
\hline Stability & 1.72 & 4.28 \\
\hline Plasticity & -.25 & -.38 \\
\hline Ethnic Peer Contact & -.29 & -.17 \\
\hline National Peer Contact & -.70 & .37 \\
\hline Other Peer Contact & -.47 & .50 \\
\hline Food Preference & -.27 & .17 \\
\hline WHO 5 Wellbeing Index & -.68 & .24 \\
\hline Satisfaction with Life Scale & -1.05 & .83 \\
\hline Revised Sociocultural Adaptation Scale & -.42 & .46 \\
\hline \multicolumn{3}{|l|}{ English as $2^{\text {nd }}$ language speakers $(n=198)^{b}$} \\
\hline Language Use (Ethnic) & -.37 & -1.16 \\
\hline Language Use (English) & -.74 & -.76 \\
\hline Language Proficiency (Ethnic) & -4.61 & 27.04 \\
\hline Language Proficiency (English) & -1.81 & 3.33 \\
\hline Media Use (Ethnic) & .09 & -.47 \\
\hline Media Use (English) & -.78 & .31 \\
\hline
\end{tabular}


A Dual-Process Motivational Model of Cross-Cultural Adaptation

\section{Appendix $\mathrm{H}$}

Inter-item Total Correlations for Scales with Cronbach's Alpha $<.7$

\begin{tabular}{ll}
\hline Scale & Inter-Item Total Correlation \\
\hline$M P Q-$ Flexibility Subscale $(N=280)$ & .36 \\
Item 1 & .35 \\
Item 2 & .18 \\
Item 3 & .34 \\
Item 4 & .38 \\
Item 5 & \\
Ethnic Peer Contact $(N=280)$ & .46 \\
Item 1 & .27 \\
Item 2 & .55 \\
Item 3 & \\
Media Use - English $(n=198)^{a}$ & .47 \\
Item 1 & .43 \\
Item 2 & .45 \\
Item 3 & .44 \\
Item 4 & \\
Media Use - Ethnic $(n=198)^{a}$ & .44 \\
Item 1 & .44 \\
Item 2 & .41 \\
Item 3 & .55 \\
Item 4 &
\end{tabular}


A Dual-Process Motivational Model of Cross-Cultural Adaptation

Appendix I

Structural Equation Model testing the Strength of the Relationships between Motivation for Cultural Maintenance, Ethnic Peer Connections and Psychological Adaptation

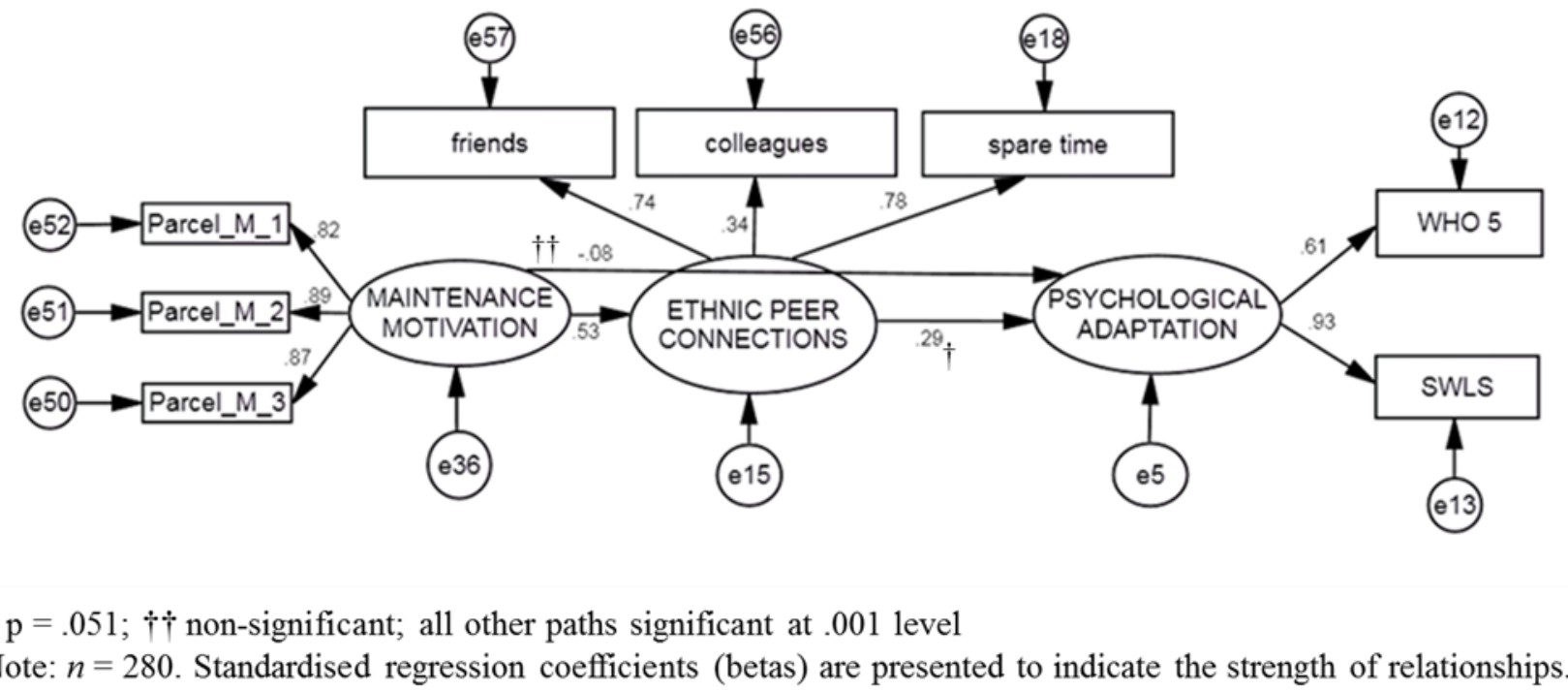

Fit indices for this model were: $\chi^{2}(n=280, \mathrm{df}=17)=38.69, p=.00 ; \mathrm{TLI}=.956$; CFI $=.974 ;$ RMSEA $\left.=.068 ; \chi^{2} / \mathrm{df}=2.28\right)$. 
A Dual-Process Motivational Model of Cross-Cultural Adaptation

Appendix $\mathbf{J}$

Structural Equation Model testing the Strength of the Relationships between Motivation for Cultural Exploration, National Peer Connections and Sociocultural Adaptation

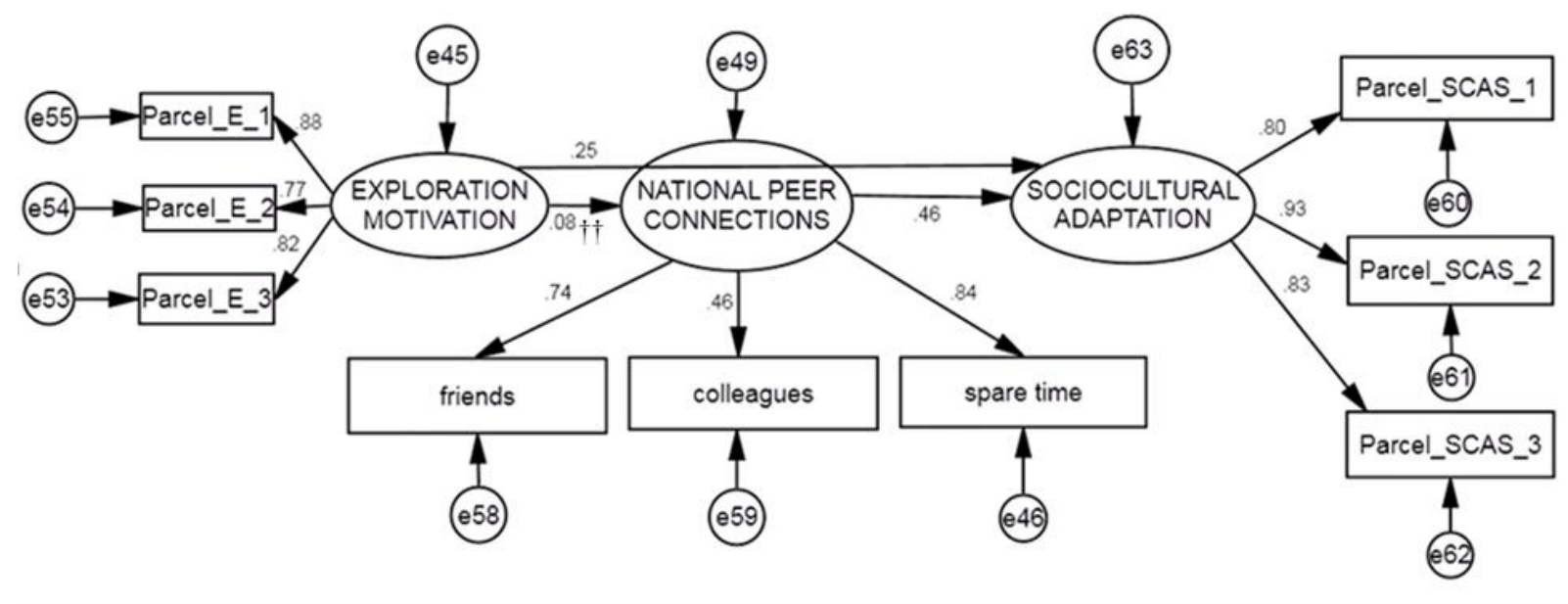

$\dagger \dagger$ non-significant; all other paths significant at .001 level

Note: $n=280$. Standardised regression coefficients (betas) are presented to indicate the strength of relationships.

Fit indices for this model were: $\chi^{2}(n=280, \mathrm{df}=24)=41.29, p=.02$; TLI $=.978$; CFI $\left.=.985 ; \operatorname{RMSEA}=.051 ; \chi^{2} / \mathrm{df}=1.72\right)$. 
A Dual-Process Motivational Model of Cross-Cultural Adaptation

\section{Appendix K}

Model 1: Structural Equation Model testing the Strength of the Relationships between Maintenance/Exploration Motivation, Ethnic/National Peer Connections and Psychological and Sociocultural Adaptation

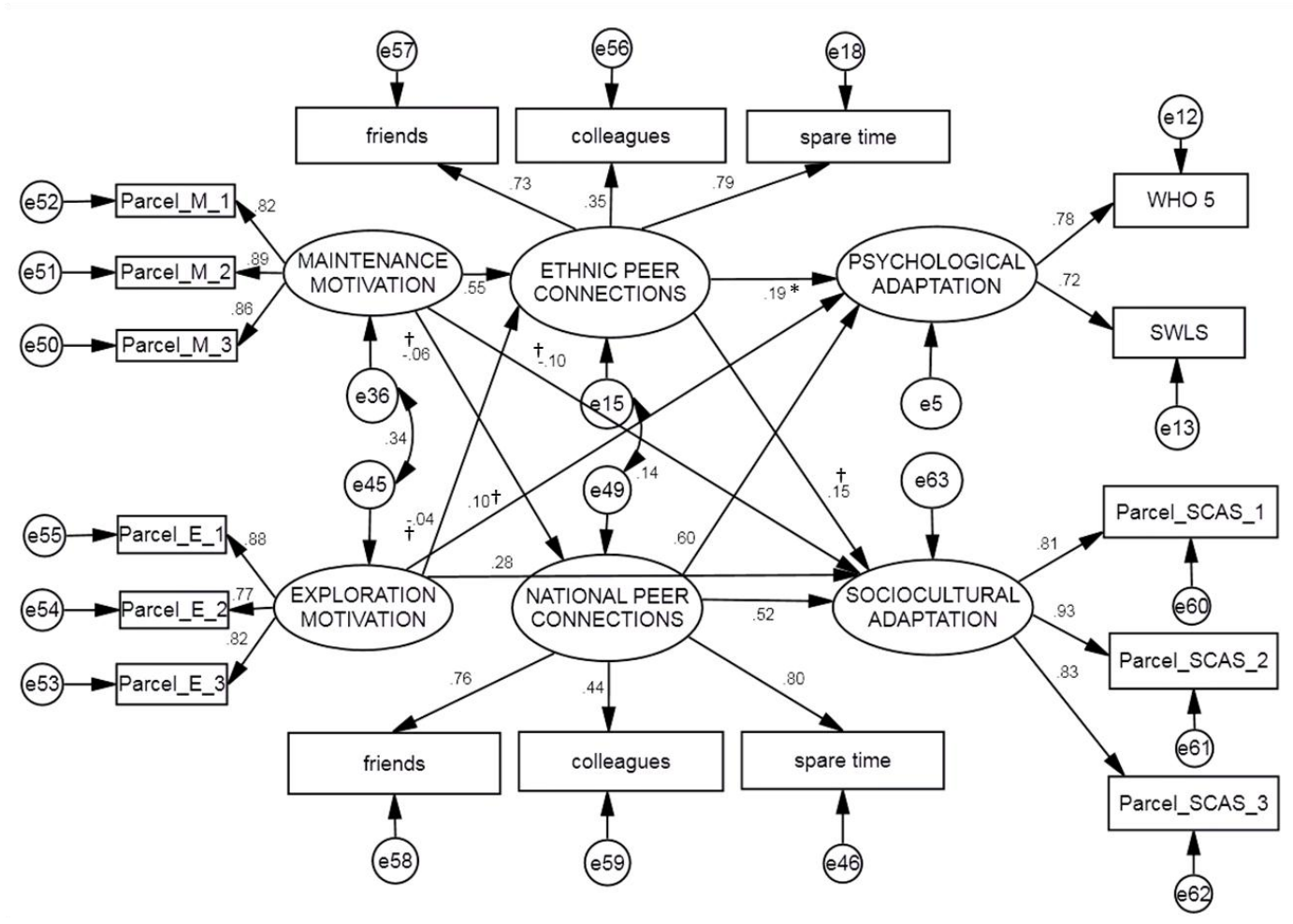

$\dagger$ non-significant; $* \mathrm{p}<.05$; all other paths significant at .001 level

Note: $n=280$. Standardised regression coefficients (betas) are presented to indicate the strength of relationships. 
A Dual-Process Motivational Model of Cross-Cultural Adaptation

Appendix L

Effect Sizes for the Impact of Ethnic Peer Support on Adaptation

\begin{tabular}{llll}
\hline Study & \multicolumn{1}{c}{$\begin{array}{c}\text { Operationalisation of } \\
\text { Ethnic peer contact }\end{array}$} & $\begin{array}{c}\text { Operationalisation } \\
\text { of Adaptation }\end{array}$ & Effect size \\
\hline $\begin{array}{l}\text { Jasikskaja-Lathi } \\
\text { et al. (2006) }\end{array}$ & $\begin{array}{l}\text { Use of ethnic networks for social } \\
\text { support }\end{array}$ & $\begin{array}{l}\text { Psychological well- } \\
\text { being }\end{array}$ & $\beta=.01, \mathrm{p} \geq .05$ \\
& $\begin{array}{l}\text { Availability of ethnic networks } \\
\text { for social support }\end{array}$ & $\beta=-.04, \mathrm{p} \geq .05$ \\
$\begin{array}{l}\text { Searle \& Ward } \\
(1990)\end{array}$ & $\begin{array}{l}\text { Frequency and satisfaction with } \\
\text { contact with co-nationals }\end{array}$ & $\begin{array}{l}\text { Psychological } \\
\text { adaptation }\end{array}$ & $r=-.25, p<.05$ \\
$\begin{array}{l}\text { Vedder et al. } \\
(2006)\end{array}$ & $\begin{array}{l}\text { Latent variable consisting of } \\
\text { national orientation, ethnic } \\
\text { orientation, ethnic behaviours }\end{array}$ & $\begin{array}{l}\text { Psychological } \\
\text { adaptation }\end{array}$ & $\beta=.11 ; p<.05$ \\
$\begin{array}{l}\text { Ward \& Kennedy } \\
(1993 b)\end{array}$ & $\begin{array}{l}\text { Satisfaction with co-national } \\
\text { relations }\end{array}$ & Mood disturbance & $\beta=.-.23 ; p=.003$ \\
$\begin{array}{l}\text { Ward \& Searle } \\
(1991)\end{array}$ & $\begin{array}{l}\text { Time spent in social interactions } \\
\text { with co-nationals }\end{array}$ & Mood disturbance & $r=.24, p=$ sign. ${ }^{\text {a }}$ \\
\hline a exact p-value not reported in study & &
\end{tabular}

